\author{
By \\ Yasaman Naghavi-Anaraki \\ M.Sc., Azad University, Tehran, Iran, 2013
}

\author{
A thesis \\ presented to Ryerson University \\ in partial fulfillment of the \\ requirements for the degree of \\ Master of Applied Science \\ in the program of \\ Chemical Engineering
}

Toronto, Ontario, Canada, 2018

(C) Yasaman Naghavi-Anaraki, 2018 


\section{Author's Declaration}

I hereby declare that I am the sole author of this thesis. This is a true copy of the thesis, including any required final revisions, as accepted by my examiners.

I authorize Ryerson University to lend this thesis to other institutions or individuals for the purpose of scholarly research.

I further authorize Ryerson University to produce this thesis by photocopying or by other means, in total or in part, at the request of other institutions or individuals for the purpose of scholarly research.

I understand that my thesis may be made electronically available to the public. 


\title{
Abstract \\ USING ELECTRICAL RESISTANCE TOMOGRAPHY TO MEASURE THE YIELD STRESS OF PRETREATED WHEAT STRAW AND WHEAT STRAW SLURRIES
}

\author{
Yasaman Naghavi-Anaraki \\ Master of Applied Science \\ Chemical Engineering, 2018 \\ Ryerson University
}

Wheat straw is a low-cost feedstock for production of biofuels as a viable alternative to fossil based fuels. Pretreatment process is an important stage in producing biofuels. Pretreated wheat straw slurries (PWS) are non-Newtonian fluids with yield stress. In mixing operations, the presence of yield stress creates a region of active motion (cavern) around the impeller and stagnant zones elsewhere which causes difficulties in the production of biofuels. In this study, for the first time electrical resistance tomography (ERT) was utilized to measure the cavern dimensions as a function of the impeller type (A200, A100, and A315), impeller speed (20 to $110 \mathrm{rpm}$ ), fiber size ( $\leq 2$ and $\leq 6 \mathrm{~mm})$, and PWS concentration $(6,8$, and $10 \mathrm{wt} \%)$. The cavern sizes were used to measure the yield stress of PWS slurries as a function of fiber size and fiber concentration. The average yield stresses of 6,8 , and $10 \mathrm{wt} \%$ PWS slurries with the fiber sizes of $\leq 2 \mathrm{~mm}$ were 2.00 , 5.43, and 8.51 Pa, respectively, and 4.26, 9.30, and 13.84 $\mathrm{Pa}$ for the fiber sizes of $\leq 6 \mathrm{~mm}$. 


\section{Acknowledgments}

I would first like to express my deep gratitude and appreciation to my supervisors Dr. Farhad EinMozaffari and Dr. Ginette Turcotte for their precious advice, guidance and support throughout my research study.

I acknowledge the assistance of administrative staffs and technologists in the Department of Chemical Engineering at Ryerson University.

I also would like to extend my sincere thanks to all my colleagues in the Fluid Mixing Technology Laboratory at Ryerson University for their helpful advice and suggestions. 
Dedication

To Amir

For his love and support 


\section{Table of Contents}

Author's Declaration............................................................................................................ ii

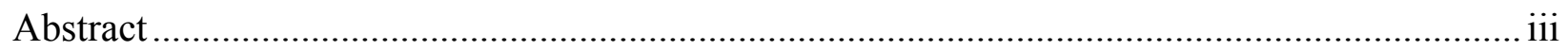

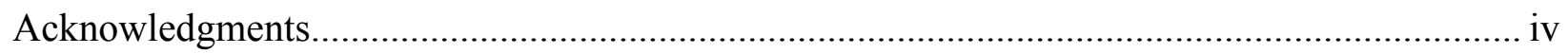

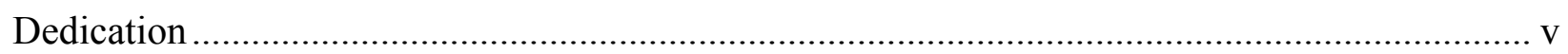

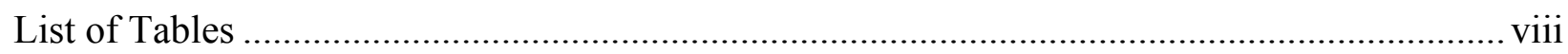

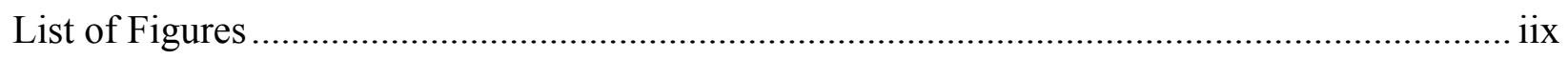

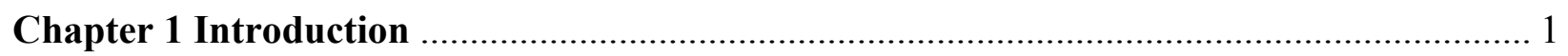

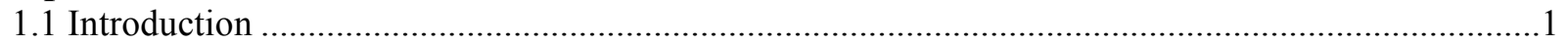

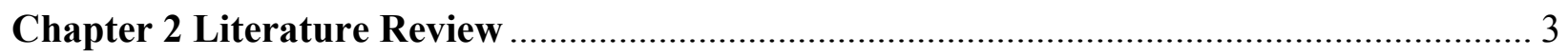

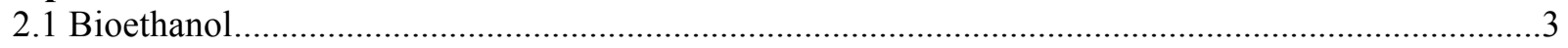

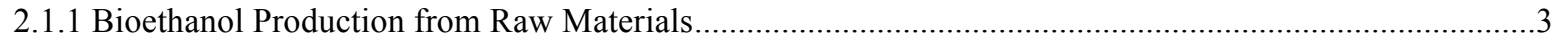

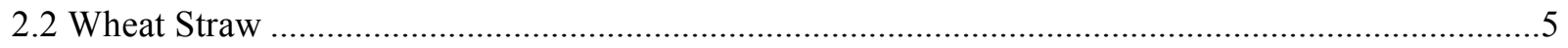

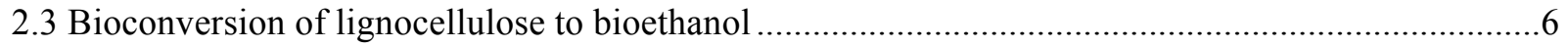

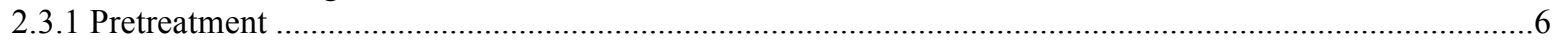

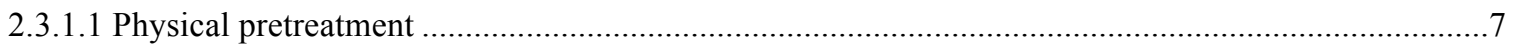

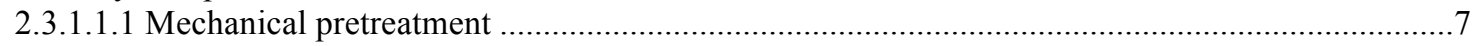

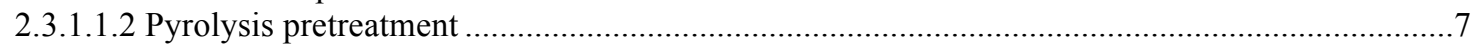

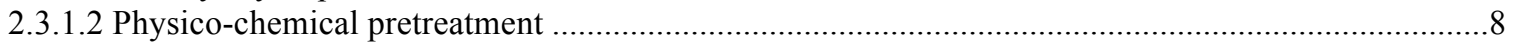

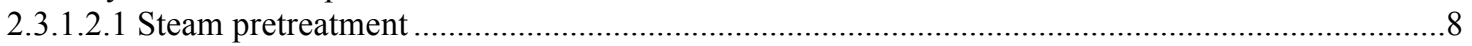

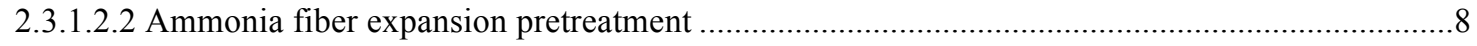

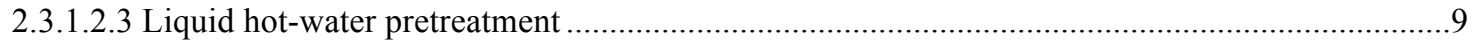

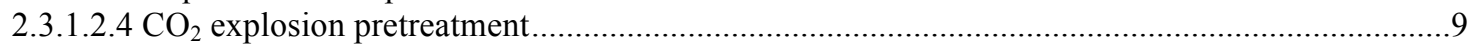

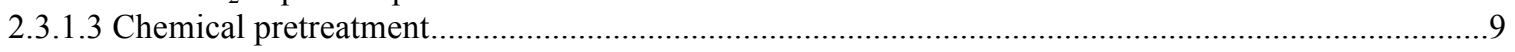

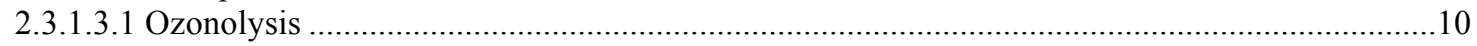

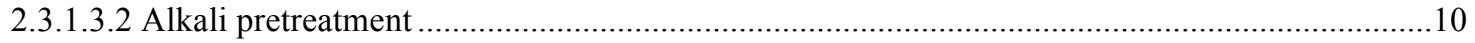

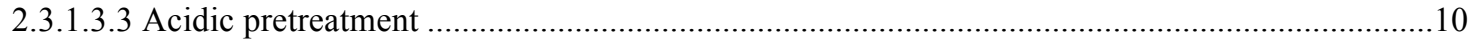

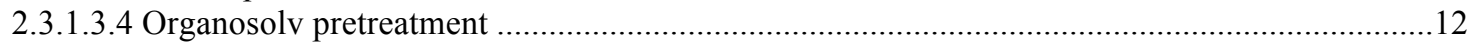

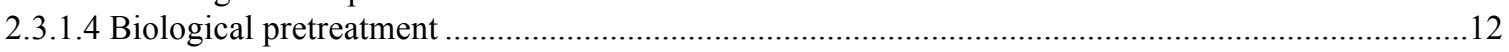

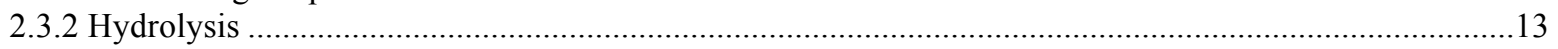

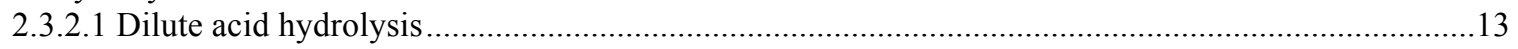

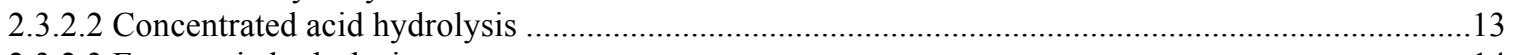

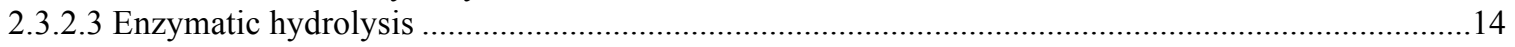

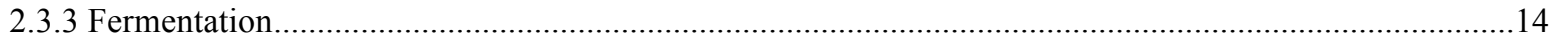

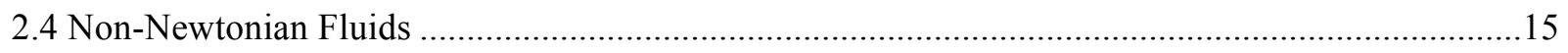

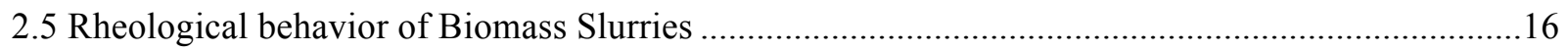

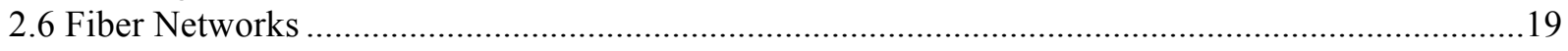

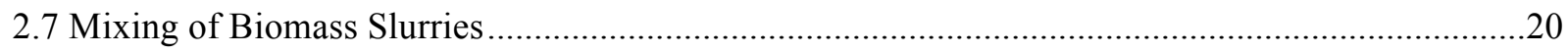

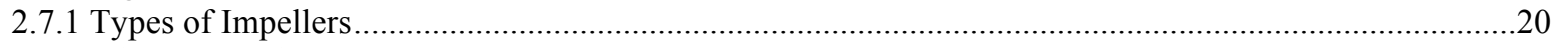

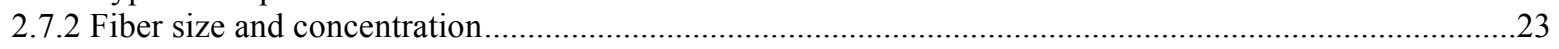

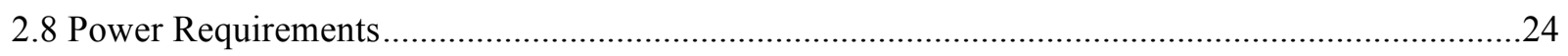

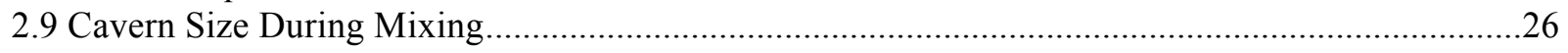

2.9.1 Experimental methods for measuring cavern size.............................................................................

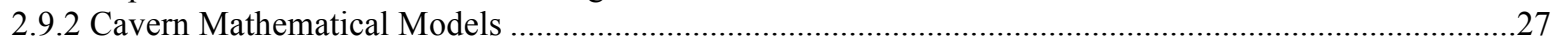




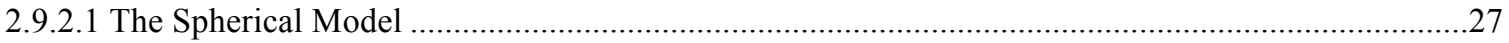

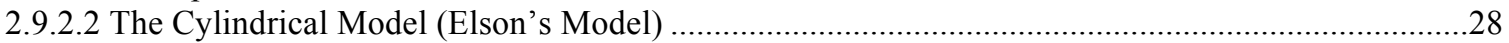

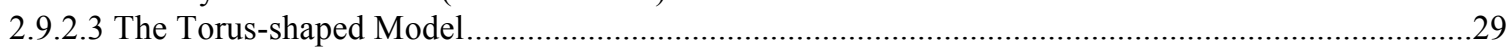

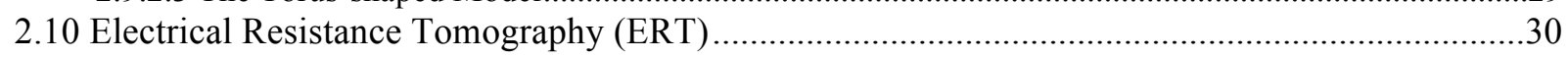

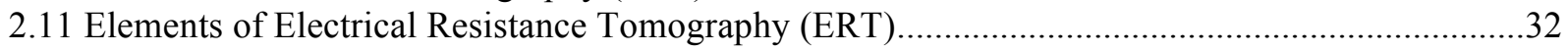

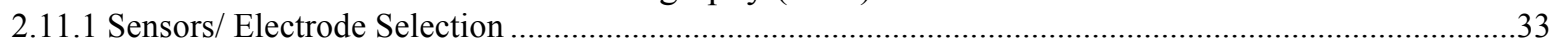

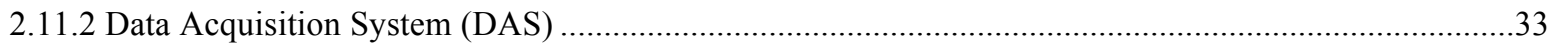

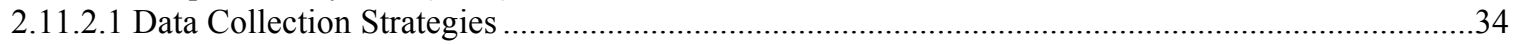

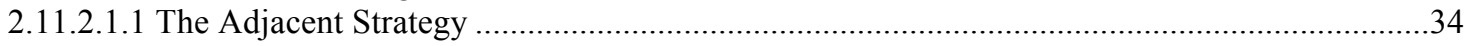

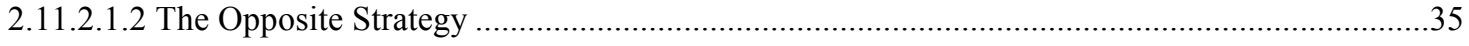

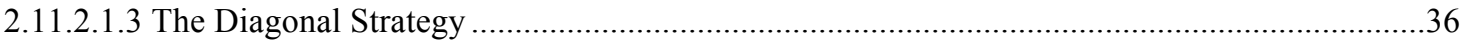

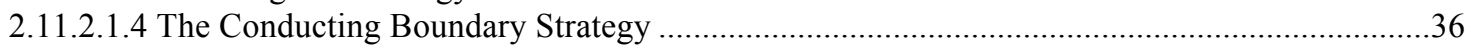

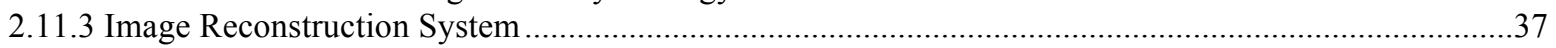

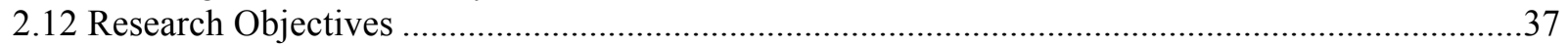

Chapter 3 Experimental Setup and Procedures ………................................................... 39

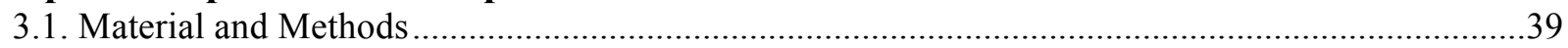

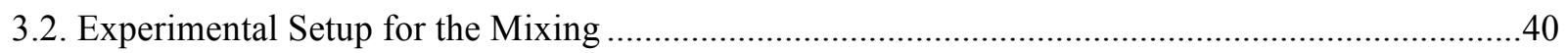

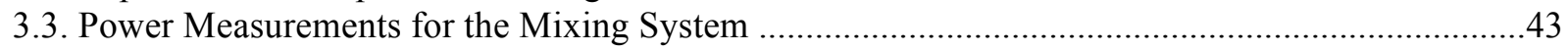

3.4. Procedure for Measuring the Cavern Size Using ERT ..............................................................4

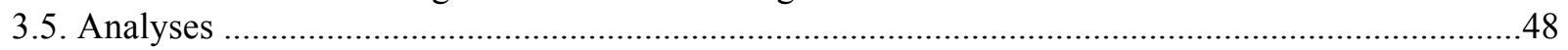

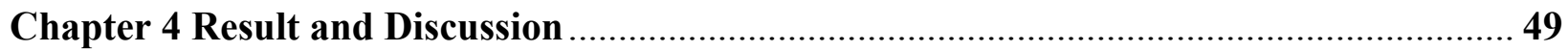

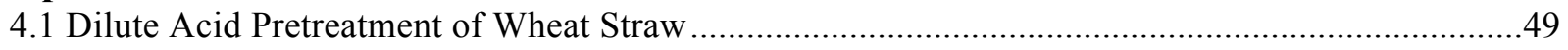

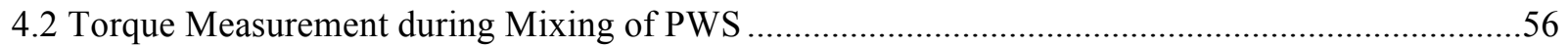

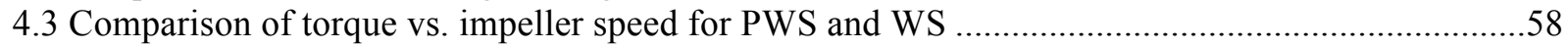

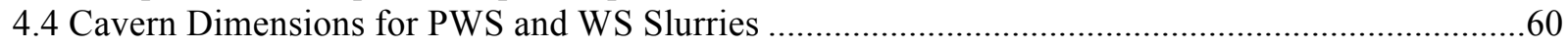

4.4.1 Effect of PWS Concentration on the Cavern Dimensions .....................................................................6

4.4.2 Effect of Impeller Speed on the Cavern Diameter of PWS...............................................................64

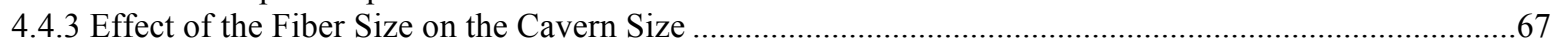

4.4.4 Cavern Sizes Measured for PWS and WS Slurries .............................................................................69

4.4.5 Impact of impeller type on torque and the cavern size .....................................................................75

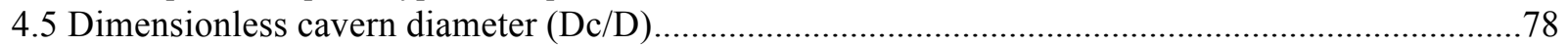

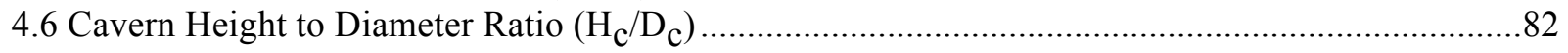

4.7 Yield Stress of Pretreated Wheat Straw Slurries and Wheat Straw Slurries Using Tomography Data

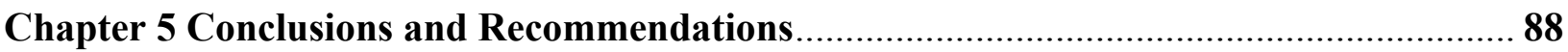

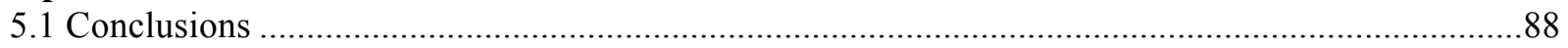

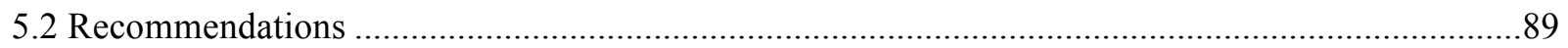

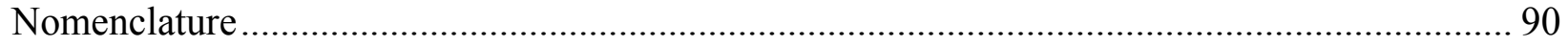

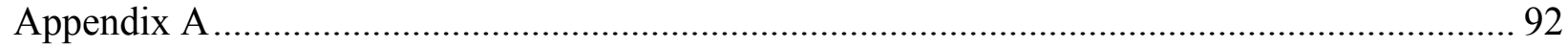

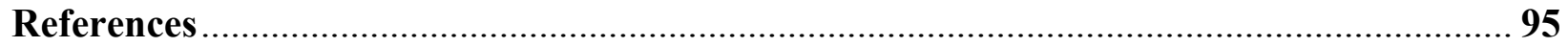




\section{List of Tables}

Table 2.1. Worldwide bioethanol production from agricultural wastes. .................................. 4

Table 2.2. Quantities of wheat straw for bioethanol production (million tonnes)...................... 5

Table 2.3. Literature review on the ERT technique for mixing application (Madhavi et al., 2016).

Table 4.1. $\mathrm{pH}$ of filtrates of pretreated wheat straw after mild acid pretreatment at $\left(\mathrm{T}: 123 \mp 2{ }^{\circ} \mathrm{C}\right.$, $\left.\mathrm{H}_{2} \mathrm{SO}_{4} 0.75 \% \mathrm{v} / \mathrm{v}, \mathrm{t}: 30 \mathrm{~min}\right)$ for three sets of experiments................................................ 49

Table 4.2. Average yield stress of the pretreated wheat straw and wheat straw slurries for fiber size of $\mathrm{x} \leq 2 \mathrm{~mm}$ calculated from the Elson model......................................................... 86 Table 4. 3. Yield stress of the pretreated wheat straw and wheat straw slurries for the fiber size of $\leq 6 \mathrm{~mm}$ calculated from cavern diameter and height................................................... 86 


\section{List of Figures}

Figure 2.1. Generic diagram of bioethanol production from lignocellulose materials (Volynets et al., 2017).

Figure 2.2. Flow curve of non-Newtonian fluids (Chhabra and Richardson, 1999). 16

Figure 2.3. The structure of an electrical resistance tomography system (Babaei et al., 2015)... 32

Figure 2.4. Data collection strategy; adjacent measurement strategy (Madhav et al., 2016)...... 34

Figure 2.5. Data collection strategy; opposite measurement strategy (Pakzad, 2007)............... 35

Figure 2.6. Data collection strategy; Conducting boundary strategy (Ridzuan, 2007)............... 36

Figure 3.1. Schematic diagram of the mixing system in this study ...................................... 42

Figure 3.2. (a) A100, (b) A200, and (c) A315 Impellers used in this study............................. 43

Figure 3.3. Cavern formation in $10 \mathrm{wt} \%$ pretreated wheat straw slurry $(\leq 2 \mathrm{~mm})$ agitated by A315 impeller at $80 \mathrm{rpm} . \mathrm{P}_{1}$ to $\mathrm{P}_{4}$ are the tomography planes......................................... 45

Figure 3.4. Cavern height for $10 \mathrm{wt} \%$ pretreated wheat straw slurry $(\mathrm{x} \leq 2 \mathrm{~mm})$ agitated by the

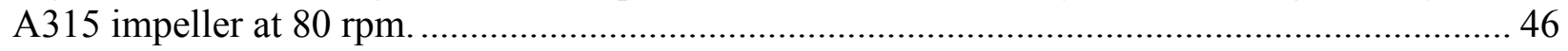

Figure 4.1. Colour of the filtrates after each step of washing pretreated wheat straw with the fiber of size of $\leq 2 \mathrm{~mm}$.

Figure 4.2. The Size distribution of $\leq 2 \mathrm{~mm}$ fibers of dried pretreated wheat straw and the wheat straw.

Figure 4.3. The size distribution of $\leq 6 \mathrm{~mm}$ fibers of dried pretreated wheat straw and wheat straw.

Figure 4.4. SEM micrographs of ( $\mathrm{x} \leq 2 \mathrm{~mm}$ ) WS and PWS (a)size distribution; and (b) surface of one fiber.

Figure 4.5. SEM micrographs of ( $x \leq 6 \mathrm{~mm})$ WS and PWS (a)size distribution; and (b) surface of one fiber.

Figure 4.6. Torque versus impeller speed for 6, 8, and $10 \mathrm{wt} \%$ pretreated wheat straw slurries (fiber size $\leq 2 \mathrm{~mm}$ ) agitated by the A315 impeller; error bars were evaluated at $95 \%$ confidence.

Figure 4.7. Torque versus impeller speed for pretreated wheat straw and wheat straw slurries at two concentrations (fiber size $\leq 2 \mathrm{~mm}$ ) agitated by the A100 impeller. 58

Figure 4.8. Torque versus impeller speed for 6 and $8 \mathrm{wt} \%$ pretreated wheat straw and wheat straw slurries (fiber size $\leq 6 \mathrm{~mm}$ ) agitated by the A100 impeller. 
Figure 4.9. Effect of the pretreated wheat straw mass concentration on the diameter (blue) and height (orange) of the cavern formed around the A315 impeller in the agitation of pretreated wheat straw slurries with the fiber size of $\leq 2 \mathrm{~mm}$ at $70 \mathrm{rpm}$.

Figure 4.10. Effect of the pretreated wheat straw mass concentration on the diameter (blue) and height (orange) of the cavern formed around the A200 impeller in the agitation of pretreated wheat straw slurries with the fiber size of $\leq 2 \mathrm{~mm}$ at $70 \mathrm{rpm}$.

Figure 4.11. Effect of the pretreated wheat straw mass concentration on the diameter (blue) and height (orange) of the cavern formed around the A100 impeller in the agitation of pretreated wheat straw slurries with the fiber size of $\leq 2 \mathrm{~mm}$ at $70 \mathrm{rpm}$.

Figure 4.12. Effect of the impeller speed on the diameter (blue)and (b) height (orange) of the cavern formed around the A100 impeller in the agitation of $8 \mathrm{wt} \%$ pretreated wheat straw slurry with the fiber size of $\leq 6 \mathrm{~mm}$.

Figure 4.13. Effect of the impeller speed on the diameter (blue)and (b) height (orange) of the cavern formed around the A315 impeller in the agitation of $8 \mathrm{wt} \%$ pretreated wheat straw slurry with the fiber size of $\leq 6 \mathrm{~mm}$.

Figure 4.14. Effect of the impeller speed on the diameter (blue)and (b) height (orange) of the cavern formed around the A200 impeller in the agitation of $8 \mathrm{wt} \%$ pretreated wheat straw slurry with the fiber size of $\leq 6 \mathrm{~mm}$.

Figure 4.15. Effect of the fiber size on the diameter of the cavern created around the A100 impeller in the mixing of $10 \mathrm{wt} \%$ pretreated wheat straw slurry with fiber sizes of $\leq 2 \mathrm{~mm}$ and $\leq$ $6 \mathrm{~mm}$ at $60 \mathrm{rpm}$.

Figure 4.16. Effect of the fiber size on the diameter of the cavern created around the A200 impeller in the mixing of $10 \mathrm{wt} \%$ pretreated wheat straw slurry with fiber sizes of $\leq 2 \mathrm{~mm}$ and $\leq$ $6 \mathrm{~mm}$ at $60 \mathrm{rpm}$.

Figure 4.17. Effect of the fiber size on the diameter of the cavern created around the A315 impeller in the mixing of $10 \mathrm{wt} \%$ pretreated wheat straw slurry with fiber sizes of $\leq 2 \mathrm{~mm}$ and $\leq$ $6 \mathrm{~mm}$ at $60 \mathrm{rpm}$.

Figure 4.18. Cavern diameter and height formed around the A315 impeller in the agitation of PWS a WS with the fiber sizes of $\leq 6 \mathrm{~mm}$ at $60 \mathrm{rpm}$ with $6 \mathrm{wt} \%$ concentration.

Figure 4.19. Cavern diameter and height formed around the A315 impeller in the agitation of PWS and WS with the fiber sizes of $\leq 2 \mathrm{~mm}$ at $60 \mathrm{rpm}$ with $6 \mathrm{wt} \%$ concentration.

Figure 4.20. Cavern diameter and height formed around the A100 impeller in the agitation of PWS and WS with the fiber sizes of $\leq 2 \mathrm{~mm}$ at $20 \mathrm{rpm}$ with $6 \mathrm{wt} \%$ concentration......

Figure 4.21. Cavern diameter and height formed around the A200 impeller in the agitation of PWS and WS with the fiber sizes of $\leq 2 \mathrm{~mm}$ at $20 \mathrm{rpm}$ with $6 \mathrm{wt} \%$ concentration.

Figure 4.22. Cavern diameter and height formed around the A315 impeller in the agitation of PWS and WS with the fiber sizes of $\leq 2 \mathrm{~mm}$ at $20 \mathrm{rpm}$ with $6 \mathrm{wt} \%$ concentration.

Figure 4.23. Torque versus impeller speed for $8 \mathrm{wt} \%$ pretreated wheat straw $(\leq 2 \mathrm{~mm})$ agitated by A315, A100 and A200 impellers 
Figure 4.24. Torque versus impeller speed for $8 \mathrm{wt} \%$ pretreated wheat straw $(\leq 6 \mathrm{~mm})$ agitated by A315, A100 and A200 impellers.

Figure 4.25. Effect of the impeller type on the diameter of the cavern created around the impeller in the mixing of $8 \mathrm{wt} \%$ pretreated wheat straw slurry with fibre size $2 \mathrm{~mm}$ at $80 \mathrm{rpm} \ldots \ldots \ldots \ldots \ldots . . . . . .77$

Figure 4.26. Effect of the impeller type on the diameter of the cavern created around the impeller in the mixing of $8 \mathrm{wt} \%$ pretreated wheat straw slurry with fiber size $6 \mathrm{~mm}$ at $80 \mathrm{rpm}$. 77

Figure 4.27. Dimensionless cavern diameter versus dimensionless stress $\left(\mathrm{P}_{\mathrm{o}} \mathrm{Re}_{\mathrm{y}}\right)$ for 6,8 , and 10 wt $\%$ pretreated wheat straw slurries with fiber size $\leq 2 \mathrm{~mm}$ and $\leq 6 \mathrm{~mm}$ agitated by (a) A200 impeller, (b) A315, and (c) A100 impeller. 81

Figure $4.28 . \mathrm{H}_{\mathrm{c}} / \mathrm{D}_{\mathrm{c}}$ versus the impeller speed at 6,8 and $10 \mathrm{wt} \%$ pretreated wheat straw slurries ( $\leq 2 \mathrm{~mm}$ and $\leq 6 \mathrm{~mm}$ ) agitated by (a) A200 impeller, (b) A315, and (c) A100 impeller. 83 Figure 4.29. Yield stress versus rpm for $6 \mathrm{wt} \%$ PWS for fiber size $\leq 2 \mathrm{~mm}$ 85 


\section{Chapter 1 Introduction}

\subsection{Introduction}

Decreasing fossil fuel resources have caused a demand for alternative energy resources such as biofuels. Producing biofuels from lignocellulosic biomass offer a feasible choice for enhancing energy saving and decreasing greenhouse gas emissions. Since lignocellulosic biomass is abundant in agricultural debris (corn stover, wheat straw, sugarcane bagasse), forestry products (sawdust, wood chips) and dedicated crops (switchgrass), it is recognized to be one of the major sources of producing biofuels (Volynets and Dahman, 2011). These materials are considered as the main components, for producing biofuels.

Cellulose, hemicellulose and lignin are the main components of lignocellulosic biomasses such as wheat straw. The cellulose micofibrils are tightly packed and covered with hemicellulose which is wrapped in lignin (Talebnia et al., 2010). The cellulose and hemicellulose must hydrolyze into their identical monomers for the reformation of lignocellulosic biomass to biofuel (Al Jibouri, 2013). The conversion of lignocellulosic biomasses such as wheat straw to biofuels includes these phases: 1) pretreatment, 2) enzymatic hydrolysis, 3) fermentation, and 4) distillation.

The pretreatment process enhances the accessibility of cellulose to enzymes since this process has the ability to break down the lignin structure, which is a barrier for enzymatic hydrolysis. Furthermore, the pretreatment process will decrease the crystallinity structure of the cellulose, solubilize hemicellulose and produce large amounts of fermentable sugars (Patel et al., 2009 and Taherzadeh and Karimi., 2008). The pretreatment process contains three methods: 1) physical, 2) chemical, and 3) biological.

Dilute acid pretreatment is considered a favored procedure that is applicable in industrial processes. A variety of lignocellulosic biomass like rice straw, wheat straw and corn stover has been examined with dilute acid pretreatment. Concentrated acid is not considered as a favorable method for producing ethanol since there are some significant obstacles such as equipment corrosion and acid recovery as reported by Alvira et al., (2010). 
Dilute acid pretreatment is effective method that has the ability to solubilize hemicellulose and remove lignin partially. (Talebnia et al., 2010 and Kumar et al, 2007).

Pretreated biomass slurries are complex fluids due to their fibrous nature, and they are categorized as non-Newtonian fluids with yield stress (Wiman et al., 2011). Mixing of non-Newtonian fluids with a yield stress creates many challenging problems such as creating a well-mixed zone around the impeller (called cavern) and stagnant zones in the rest of the tank according to the complex rheology of non-Newtonian fluids (Wichterle and Wein, 1975). The stagnant zones in the mixing tank cause ineffective heat and mass transfers. It is crucial to eliminate the stagnant zones in the mixing tank in order to boost the effectiveness of mixing in a tank (Amanullah et al., 1998 and Movafagh et al., 2016).

Experimental techniques such as laser Doppler anemometry (LDA), hotwired anemometry (HWA), positron emission particle tracking (PEPT), ultrasonic Doppler velocimetry (UDV), Xray technique and electrical resistance tomography (ERT), and the numerical technique called computational fluid dynamics (CFD) have been applied to examine the formation of cavern generated in the mixing of yield stress fluids.

Previous studies showed that there is limited information about the rheological behavior of pretreated biomass slurries, especially that of wheat straw slurries. For instance, Movafagh et al., (2016) calculated the yields stress of non-pretreated wheat straw slurries. Hou et al., (2016, a) measured the $n$ (power law index) and $k_{p}$ (consistency coefficient) for pretreated wheat straw, and didn't measure the yield stress of the slurry. Furthermore, in the literature, there seems to be no study on the cavern evaluation of pretreated wheat straw suspensions by the tomography method.

In this research, electrical resistance tomography (ERT) is used to estimate the yield stress of pretreated wheat straw and wheat straw slurries. The ERT images are applied to measure the cavern dimensions formed around the impeller as a function of the impeller type and speed, fiber size, and pretreated/non-pretreated biomass concentration. Then, the data will be used to measure the yield stress of the pretreated wheat straw and wheat straw slurries. 


\section{Chapter 2 Literature Review}

\subsection{Bioethanol}

For several reasons, researchers have been increasingly focusing on the potential alternative fuel sources to generate more sustainable energy for motor vehicles all around the world. These reasons include steep increases in the gasoline cost, the unsustainably of fossil fuels, adverse environmental impacts- for instance, health and safety problems and greenhouse gas (GHG) emissions. These new energy resources contain bioethanol, biodiesel, methanol, hydrogen and boron. These alternatives should be technically viable, economically reasonable, environmentally friendly, and obtainable (Meher et al., 2006).

Biofuels are recyclable and sustainable biomass-based, and they have many advantages compared to petroleum-based fuels: biomass sources are readily available, and they are beneficial to the environment and the economy. Biofuels contain bioethanol, biomethanol, biodiesel, biogas, biosynthetic gas (bio-syngas), bio-oil, bio-char, vegetable oils, Fischer-Tropsch liquids, and biohydrogen. Chemical procedures like pyrolysis, supercritical fluid extraction, gasification, liquefaction, supercritical water liquefaction and biochemical lead to the production of biofuels. For transportation purposes, bioethanol between all types of biofuels is considered as the best option. During past decades, bioethanol and bioethanol/gasoline mixtures have been recognized as sustainable fuels (Balat, 2011). The USA increased the production of bioethanol from 10,000 to 15,000 million gallons from 2008 to 2016. Furthermore, The US Department of Energy has decided to replace $30 \%$ of the gasoline demand with bioethanol- at least until 2030 (Renewable Fuels Association, 2016).

\subsubsection{Bioethanol Production from Raw Materials}

The raw materials used for producing bioethanol are categorized in three agricultural groups: 1) starch materials (e.g. corn, wheat, rice, potatoes, cassava, milo, sweet potatoes and barley), 2) sucrose-containing feedstock (e.g. sugar beets, sweet sorghum, sugar cane, and fruits), and 3) 
lignocellulosic materials (Balat, 2011). Lignocellulose is available in the form of many different renewable feedstocks like agricultural residues (wheat straw, corn stover, sugarcane bagasse), dedicated energy crops (poplar trees, switch grass), and forestry residues (sawdust,wood chips). General worldwide ability to produce lignocellulosic biomass is between 10 and $50 \times 10^{9}$ tons per year (Schmidt et al., 1998). The most controversial concept in producing bioethanol is the accessibility of resources. The accessibility of feedstock for bioethanol depends on the season and geographic locations. Moreover, the price of the materials can greatly hit the production expenses of the bioethanol. In general, however, producing bioethanol from rice straw, wheat straw, corn straw and sugarcane bagasse are nowadays significant (Table 2.1).

Table 2.1. Worldwide bioethanol production from agricultural wastes.

\begin{tabular}{|c|c|c|}
\hline Agricultural residue & $\begin{array}{c}\text { Annual bioethanol production } \\
\text { (globally) (giga liter) }\end{array}$ & Reference \\
\hline Rice straw & 205 & Saini et al., 2015 \\
\hline Wheat straw & 104 & Saini et al., 2015 \\
\hline Corn straw & 58.6 & Sarkar et al., 2012 \\
\hline Sugarcane bagasse & 51.3 & \\
\hline
\end{tabular}

Lignocelluloses contain three ingredients: cellulose, hemicellulose and lignin. Ninety percentage of lignocelluloses has been built up of these components, and the other $10 \%$ is made up ash and extractives (Dehkhoda, 2008). Cellulose is shielded with hemicellulose, which is covered by lignin. Cellulose and hemicellulose are polysaccharides. These two can be hydrolyzed to sugar and then fermented into bioethanol. Cellulose and hemicellulose in the feedstock have a chief impact on the bioethanol yield from biomass. Cellulose is a linear mono- polymer chain containing Dglucose units attached to each other through $\beta-1 \rightarrow 4-$ glycosidic bonds. Hemicellulose consists of long chains of xylose molecules attached to each other with cross-linked hydrogen bonds. Hemicellulose plays a connection role between lignin and cellulose chains. Dilute acid or base can hydrolyze the hemicellulose structure. Lignin is an amorphous polymer that contains 
phenylpropane parts, and it has three aromatic alcohols (monolignols) precursors of p-coumaryl, coniferyl and sinapyl alcohols (Buranov and Mezza, 2008).

The phenylpropanic structure of lignin causes the lignocellulosic-biomass cell walls to be firm and unbreakable. The presence of lignin decreases the cellulose enzymatic hydrolysis by creating a physical barrier that prevents enzymes from accessing the cellulose (Pan et al., 2005). To remove lignin from the cell wall and some parts of hemicellulos, adding a pretreatment process before enzymatic hydrolysis of lignocellulosic biomass is necessary.

\subsection{Wheat Straw}

Wheat (Triticum aestivum L.) is one of the most common international grown crop and cultivated in over 115 nations. The straw produced after cultivation might be left on the field, burned or even removed from the land. A large amount of $\mathrm{CO}$ and $\mathrm{NO}_{2}$ will generate in the case of burning wheat straw. Producing ethanol from wheat straw is an approach to generate energy from waste biomass and simultaneously reduce the reliance on fossil-based fuels (Talebnia et al., 2010).

Wheat straw is a low-cost feedstock to provide fuel alcohol due to its excess, renewability and low lignin content (Buranov and Mezza, 2008). Quantities of wheat straw for bioethanol production are reported in Table 2.2 (Sarkar et al., 2012).

Table 2.2. Quantities of wheat straw for bioethanol production (million tonnes).

\begin{tabular}{|l|l|l|l|l|}
\hline Africa & Asia & Europe & America & Oceania \\
\hline 5.34 & 145.20 & 132.59 & 62.64 & 8.57 \\
\hline
\end{tabular}

Wheat straw contains 33-40 wt\% cellulose, 20-25 wt \% hemicelluloses, and 15-20 wt \% lignin (Volynets and Dahman, 2011). Based on the wheat species, soil, and climate conditions, the total chemical ingredients of wheat straws can vary slightly. As mentioned before, wheat straw needs to be pretreated to make cellulose reachable for effective enzymatic hydrolysis. 


\subsection{Bioconversion of lignocellulose to bioethanol}

Bioconversion of lignocellulose to bioethanol contains three steps: (1) pretreatment for breaking down the structures of lignocellulose; (2) hydrolysis for hydrolyzing polysaccharides (cellulose, hemicellulose) into fermentable sugars; and (3) fermentation for converting sugars into bioethanol (Hahn-Hagerdal et al., 2006). Figure 2.1. shows a generic diagram of bioethanol production from lignocellulose materials (Volynets et al., 2017).

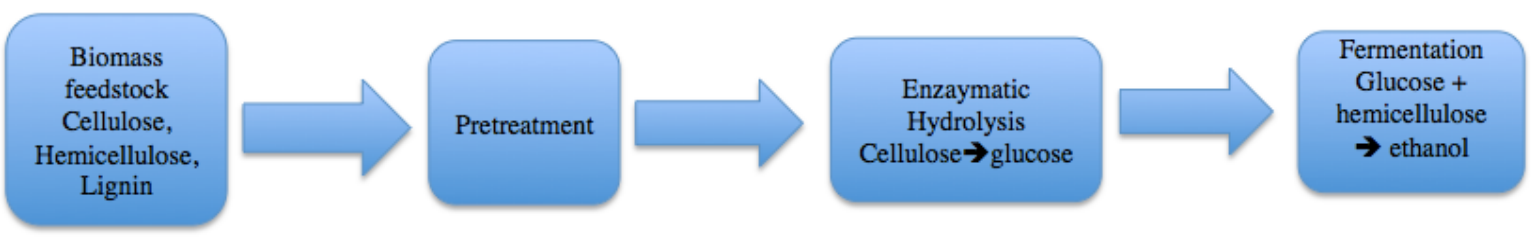

Figure 2.1. Generic diagram of bioethanol production from lignocellulose materials (Volynets et al., 2017).

\subsubsection{Pretreatment}

Pretreatment of biomass is the most important procedure in producing biofuels. This process causes the residual solid biomass to be more reachable to further chemical or biological treatment (Sakar et al., 2012).

The pretreatment is performed to decrease the crystallinity of the cellulose, to break down the lignin structure, to solubilize the hemicellulose and to produce large amounts of fermentable sugars (Patel et al., 2009 and Taherzadeh and Karimi, 2008). An ideal lignocellulose pretreatment should have several characteristics such as (1) preventing any damage to cellulose, (2) producing reactive cellulosic fibers for enzymatic attack, (3) decreasing energy demand, (4) avoiding the creation of possible inhibitors for hydrolytic enzymes and fermenting microorganisms, (5) minimizing the expense of reducing size of feedstocks, (6) decreasing the expense of materials used to construct the pretreatment reactors, and (7) consuming few or no chemicals and using cheap chemicals (Taherzadeh and Karimi, 2008). Pretreatment techniques of lignocellulosic materials are classified in four groups: physical, chemical, physico-chemical, and biological. 


\subsubsection{Physical pretreatment}

There are two types of physical pretreatment: Mechanical comminution and Pyrolysis.

\subsection{Mechanical pretreatment}

Chipping, milling and grinding are the main types of mechanical comminution. These treatments are capable of reducing the degree of polymerization (DP) and crystallinity of cellulose. The specific surface area and the accessibility of the biomass to chemical and biological catalysts will increase due to these pretreatment methods. The biomass size reduces to $10-30 \mathrm{~mm}$ by Chipping, On the other hand, grinding and milling can decrease the particle size to $0.2-2 \mathrm{~mm}$. For cellulose crystallinity reduction of spruce and aspen, vibratory ball milling was found to be more effective compared to ordinary ball milling. A hammer mill or ball mill generally can be used for hardwood while a cutter mill can be used for softwood. Ball milling (BM) and wet disk milling (WDM) are other methods that can be applied for physical pretreatment. In general, mechanical pretreatment techniques have disadvantages such as being energy intensive, time-consuming, and expensive to process (Balat, 2011). Mechanical pretreatment cannot be considered as an efficient pretreatment method by itself since it high energy to operate. It is usually considered as an additional step before physico-chemical pretreatment (Volynets et al., 2017).

\subsection{Pyrolysis pretreatment}

Pyrolysis is an endothermic process and needs less energy to operate compared to the mechanical method. In this process, cellulose breakdown to generate gaseous products such as $\mathrm{H}_{2}$ and $\mathrm{CO}$ and residual char where ingredients are treated at a temperature higher than $300{ }^{\circ} \mathrm{C}$. Then, leaching with water or with mild acid will be used to treat the residual char. The water leachate comprises sufficient carbon to assist microbial growth for bioethanol production. Glucose is the chief element of water leachate (Sarkar et al., 2012). 


\subsubsection{Physico-chemical pretreatment}

Physico-chemical pretreatments are combinations of physical and chemical pretreatments. They include steam pretreatment (or steam explosion), ammonia fiber expansion (AFEX), liquid hot water pretreatment, and $\mathrm{CO}_{2}$ explosion.

\subsection{Steam pretreatment}

Steam explosion is an appropriate pretreatment method because it makes cellulose more accessible to enzyme attacks. In steam explosion, high-pressure saturated steam goes through the chipped biomass. For a period of time, the biomass/steam mixture is held to increase hemicellulose hydrolysis. Then pressure is reduced which causes an explosive decompression of the materials (Balat, 2011). Steam explosion is an effective method that requires no catalyst; however, $\mathrm{SO}_{2}$ and $\mathrm{H}_{2} \mathrm{SO}_{4}$ as catalysts can enhance hemicellulose dissolution (Volynets et al., 2017). However, the main drawback with this method is the generation of inhibitors. The chief inhibitors are furan derivatives, weak acids and phenolic compounds (Alvira et al., 2010).

\subsection{Ammonia fiber expansion pretreatment}

In an ammonia fiber expansion process, material is exposed to liquid ammonia at a temperature between 60 and $100{ }^{0} \mathrm{C}$, high pressure and a fast decompression. Then, physical disruption of biomass fibers and the fractional decrystallization of cellulose will happen when the pressure is released. In general, during this pretreatment method, low amounts of hemicellulose and lignin will be removed. As a result, AFEX is not suitable for a biomass with high lignin content (Alvira et al., 2010). However, after AFEX pretreatment, the digestibility of the biomass is increased which causes greater yields after enzymatic hydrolysis (Galbe and Zacchi, 2007).

The most important parameters that influence the AFEX process are ammonia loading, temperature, water loading, high pressure, residence time, and number of treatments (Taherzadeh and Karimi, 2008). The principal benefit of this process is its short process time and zero formation 
of inhibitors for the downstream biological processes (Alvira et al., 2010).

\subsection{Liquid hot-water pretreatment}

Liquid hot-water pretreatment is a hydrothermal pretreatment method that releases hemicellulose in the form of oligomers, makes the cellulose more available and avoids the creation of inhibitors. However, lignin is moderately solubilized throughout hot water pretreatment, and complete delignification is not plausible (Alvira et al., 2010).

The treatment usually happens at temperatures of $170-230{ }^{0} \mathrm{C}$ (Sarkar et al., 2012). In liquid hotwater pretreatment, the biomass is subjected to hot water in a liquid state at high pressure throughout a fixed period of time. Liquid hot-water pretreatment method is economical and environmentally-friendly because it can be done in the absence of acid or chemical components. However, water demands required in the process and energy requirements are high. Therefore, this method has not been utilized on a commercial scale (Alvira et al., 2010).

\subsubsection{4 $\mathrm{CO}_{2}$ explosion pretreatment}

The method employs $\mathrm{CO}_{2}$ as a supercritical fluid. Supercritical flow means a fluid that is in a gaseous form but is compressed at temperatures above its critical point. This method is able to remove lignin fragments (Alvira et al., 2010). This method is not resulted in the creation of inhibitors as the steam explosion method does. Also, this procedure is cheaper than ammonia expansion to operate (Kumar et al., 2009).

\subsubsection{Chemical pretreatment}

Chemical pretreatment is categorized in several groups: Ozonolysis, alkaline pretreatment, acidic pretreatment, biological pretreatment, and organosolv pretreatment. 


\subsection{Ozonolysis}

Generally, ozonolysis is taken a place at normal pressure and room temperature. This method is capable of delignification without any inhibitory formation (Alvira et al., 2010). Also, the rate of enzymatic hydrolysis can be amplified by ozonolysis. García-Cubero et al. (2009) examined the pretreatment of the wheat and rye straws with ozone in order to enhance the enzymatic hydrolysis and produce fermentable sugars. Results illustrated that enzymatic hydrolysis yields of wheat straw increased from $29 \%$ to $88.6 \%$ in the presence of ozonolysis compared to non-ozonated ones. Also, enzymatic hydrolysis yields of rye straw increased from $16 \%$ to $57 \%$ in the presence of ozonolysis compared to non-ozonated ones as well. A significant disadvantage associated with this method is the cost of ozone because a large quantity of ozone is needed and that causes this process to be expensive (Kumar et al., 2009).

\subsection{Alkali pretreatment}

Alkali pretreatment like $\mathrm{NaOH}, \mathrm{KOH}, \mathrm{Ca}(\mathrm{OH})_{2}$, hydrazine, and anhydrous ammonia can decompose the lignin, increase the accessible surface of the biomass, and decrease the crystallinity of cellulose. Of these, $\mathrm{NaOH}$ is the most common one (Kumar et al., 2009). Comparing to other pretreatment methods, this pretreatment applies lower temperatures and pressures. However, Alkali pretreatment may need longer time to be carried out comparing to acid pretreatment (Balat, 2011).

\subsection{Acidic pretreatment}

Acid pretreatments with sulfuric, nitric, or hydrochloric acids eliminate hemicellulose components, alter lignin structure and facilitate the enzymatic hydrolysis of cellulose (Taherzadeh and Karimi, 2008). The acid medium attacks the polysaccharides, especially hemicellulose because it is more accessible to hydrolyze than cellulose. Furthermore, the chief goal of the acidic pretreatment is to enhance the accessible surface area of the biomass for the enzymatic attack. However, acid pretreatment produces some inhibitors like acetic acid and furfural, which are 
drawbacks (Sarkar et al., 2012).

Acid pretreatment has been categorized in two groups: dilute acid pretreatment and concentrated acid pretreatment (Taherzadeh and Karimi, 2008). Concentrated acid is not suitable for producing ethanol due to equipment corrosion and acid recovery. These constitute significant obstacles in the use of concentrated acid pretreatments. (Alvira et al., 2010).

Diluted acid pretreatment seems to be an applicable method for industrial process and has been used for pretreating a variety of lignocellulosic biomass. Percolation, plug flow, shrinking-bed, batch and counter- current reactors are different types of reactors that have been used for pretreatment of lignocellulosic materials (Taherzadeh and Karimi., 2007). The procedure can be completed at a high temperature (e.g. $\left.180{ }^{\circ} \mathrm{C}\right)$ throughout a short period of time; or at a lower temperature (e.g. $120^{\circ} \mathrm{C}$ ) for longer retention time $(30-90 \mathrm{~min})$ (Alvira et al., 2010). This pretreatment produces lower degradation products like furfural and aromatic degradation compounds as compared to concentrated acid pretreatments (Alvira et al., 2010).

Dilute acid effectively removes the hemicellulose as dissolved sugar. By almost complete removing of hemicellulose during hemicellulose hydrolysis, the glucose yields from cellulose enhance (Kumar et al., 2009). Dilute acid pretreatment is suitable for agricultural feedstocks, such as corn stover, rice straw, and wheat straw. Among all acids, dilute sulfuric acid is more applicable for the treatment of lignocellulosic biomass, hemicellulose hydrolysis, and pretreatment for the enzymatic hydrolysis of cellulose.

Literature reveals that sulfuric acid at lower concentration than $4 \mathrm{wt} \%$ is best for pretreatment since it is cheap and effecient. For instance, Lu et al. (2007) examined the pretreatment of corn stover with sulfuric acid concentrations of $2 \mathrm{wt} \%, 4 \mathrm{wt} \%$, and $6 \mathrm{wt} \%$ at different temperatures. $\mathrm{H}_{2} \mathrm{SO}_{4}$ concentration of $2 \mathrm{wt} \%$ and a reaction time of $43 \mathrm{~min}$ at $120{ }^{\circ} \mathrm{C}$ were reported the optimum conditions for corn stover pretreatment. When wheat straw when subjected to $0.75(\mathrm{v} / \mathrm{v}) \%$ of $\mathrm{H}_{2} \mathrm{SO} 4$ at $121{ }^{0} \mathrm{C}$ for 1 hour a saccharification yield of $74 \%$ was observed by Saha et al. (2005) Shekiro et al. (2014) optimized the dilute acid pretreatment of corn stover at a low acidic loading $(0.15-0.3 \mathrm{wt} \%)$ in a horizontal pretreatment reactor. The pretreatment of algal biomass in the presence of $2 \mathrm{wt} \% \mathrm{H}_{2} \mathrm{SO}_{4}$ for 15 minutes was examined by Dong et al. (2017). Ranjan and Moholkar (2013) examined different pretreatment methods for rice straw and found that acidic 
pretreatment ( $1 \mathrm{wt} \% \mathrm{H}_{2} \mathrm{SO}_{4}$ ) liberated the highest amount of glucose (nearly $38 \%$ ). Kim et al., (2012) examined the saccharification of pretreated rice straw, followed by fermentation of glucose. The optimal dilute acid concentration for this experiment was $1.2 \mathrm{wt} \% \mathrm{H}_{2} \mathrm{SO} 4$. Moreover, Hsu et al. (2010) revealed a sugar yield of $83 \%$ was reached, when the rice straw was pretreated with 1 $\mathrm{wt} \%$ sulfuric acid with a reaction time of $1-5 \mathrm{~min}$ at $160{ }^{\circ} \mathrm{C}$ or $180{ }^{\circ} \mathrm{C}$, after the enzymatic hydrolysis. Cara et al., (2008) reported $76.5 \%$ of hydrolysis yields for Olive tree biomass, when it was pretreated with $1.4 \mathrm{wt} \% \mathrm{H}_{2} \mathrm{SO}_{4}$ at $210{ }^{\circ} \mathrm{C}$. Saha et al. (2005) examined both concentrated and dilute-sulfuric acid pretreatments on wheat straw. Concentrated and diluted acid treatments yielded $49 \%$ and $63 \%$ of the whole amount of sugars. The optimal acid dose for the maximum yield of carbohydrates in dilute acid treatment was 0.75 (v/v) \%. It seems that dilute $\mathrm{H}_{2} \mathrm{SO}_{4}$ is the most practical chemical pretreatment method for different kinds of materials such as wheat straw, corn stover, and rice straw.

\subsection{Organosolv pretreatment}

Organic solvent has been considered as delignification agent in organosolv pretreatment. Lignin is precipitated as a solid material in this pretreatment process. The degree of crystallinity of cellulose and solubilization of hemicellulose will decrease as a result of this pretreatment method (Volynets et al., 2017).

\subsubsection{Biological pretreatment}

Biological pretreatment includes the use of microorganisms like brown, white and soft-rot fungi. White and soft-rot fungi are capable of delignifying biomass by producing lignin-degrading enzymes, whereas brown rot fungi can degrade cellulose structure. White-rot fungi are known to be the most useful biological pre-treatment. Biological pretreatments don't need so much energy to perform and can be stabilized in mild environmental conditions and these are the merits of biological pretreatment. However, in most biological pretreatment process, the rate of hydrolysis is very low, which makes this method unsuitable for industry, and hence this method needs a long residence time and large biological reactors (Sarkar et al., 2002). 
In general, pretreated biomass slurries are complex fluids due to their fibrous nature, and are classified as non-Newtonian fluids with yield stress (Wiman et al., 2011).

\subsubsection{Hydrolysis}

Hydrolysis is a procedure that converts the carbohydrate polymers in lignocellulosic materials to simple sugars before fermentation. Hydrolysis is categorized in three methods: dilute acid hydrolysis, concentrated acid hydrolysis and enzymatic hydrolysis (Taherzadeh and Karimi., 2007).

\subsubsection{Dilute acid hydrolysis}

Dilute acid hydrolysis is a way to breakdown bonds between hemicellulose and lignin complexes. Dilute acid hydrolysis happens in two stages. The first stage is happened at low temperatures to raise the yield from the hemicellulose, and the second one is performed at higher temperatures to enhance the hydrolysis of the cellulose parts of the feedstock (Balat, 2011). Dilute acid (0.75\% $\mathrm{H}_{2} \mathrm{SO}_{4}$ ) at $120-180{ }^{0} \mathrm{C}$ can solubilize hemicellulose and alter solubilized hemicellulose to fermentable sugars (Saha et al., 2005).

\subsubsection{Concentrated acid hydrolysis}

Concentrated acid hydrolysis includes an acid (dilute or concentrated) pretreatment to liberate the hemicellulose. The following process needs the biomass to be dried before adding concentrated sulfuric acid for the hydrolysis. A complete and fast change of cellulose to glucose and hemicelluloses to five-carbon sugars with minimum degradation will happen due to this process. However, reaction time for this process is much longer compared to the dilute acid process (Balat, 2011). 


\subsubsection{Enzymatic hydrolysis}

Enzymatic hydrolysis needs lower energy and mild environmental conditions comparing to acid hydrolysis. Other merits of enzymatic hydrolysis comparing to acidic hydrolysis are: low utility cost, low toxicity, low corrosion (Taherzadeh and Karimi, 2007), and no creation of inhibitory byproduct.

Cellulase enzymes involve endo and exoglucanases and $\beta$-glucosidases. The small crystallinity areas of the cellulose fiber are cut by endoglucanase (1,4-D- glucanhydrolase or E.C. 3.2.1.4). The cellobiose units from the free chain ends are removed by exoglucanase $(1,4-\beta$-D glucan cellobiohydrolase or E.C. 3.2.1.91). In the last step, these cellobiose units are hydrolyzed to glucose by $\beta$-glucosidase (E.C. 3.2.1.21) (Taherzadeh and Karimi, 2007).

Hemicellulolytic enzymes are composite that made up a combination of at least eight enzymes like endo-1,4- $\beta$-D-xylanases, exo-1,4- $\beta$-D xylocuronidases, etc. (Sarkar N. et al, 2012). Cellulose is hydrolyzed to glucose while hemicellulose increases some pentoses and hexoses.

\subsubsection{Fermentation}

Ethanol fermentation is classified as a biological process. In this procedure, sugars such as glucose, xylose, and sucrose are changed into cellular energy and provide ethanol and carbon dioxide as metabolic waste products (Hahn et al., 2007).

Saccharomyces cerevisiae and Zymomonas mobilis are the microorganisms that are used for bioethanol fermentation because they have the ability to ferment glucose into bioethanol. Furthermore, the microorganisms should be able to ferment pentoses and hexsoses released during the pretreatment process. In general, S. cerevisiae is used in the industrial process to ferment lignocellulosic hydrolysates since offers a high ethanol yield (90-97\%) (Talebnia et al, 2010).

In general, there are two strategies that are used in the fermentation of lignocellulosic hydrolysate: simultaneous saccharification and fermentation (SSF), and separate hydrolysis and fermentation (SHF). The SHF process is more common than SSF- however, SSF is better for producing ethanol because this method increases ethanol yields by eliminating end product inhibition and removing 
separate reactors (Sarkar et al, 2012).

As explained before, pretreated biomass slurries (wheat straw slurries) are non-Newtonian fluids with yield stress due to the fibre/fibre interactions in these fibrous slurries. This group of nonNewtonian fluids exhibits the shear-thinning behavior with yield stress. The shear-thinning fluids have low apparent viscosities at higher shear rates and inversely high apparent viscosities at the lower shear rates. In Section 2.4, the terms of non-Newtonian, shear-thinning, and yield stress have been explained.

\subsection{Non-Newtonian Fluids}

The shear stress versus shear rate plot (flow curve) in Non-Newtonian fluids is non-linear. Time independent fluids are an important class of Non-Newtonian fluids. For this type of nonNewtonian fluid, the rate of shear at any point is described only by the shear stress at that point and relies on nothing else. Shear-thinning or pseudoplastic, viscoplastic, and shear-thickening or dilatant are categorized under time independent fluids (Chhabra and Richardson, 1999).

A viscoplastic flow curve doesn't pass through the origin of the shear stress-shear rate plot compared to pseudoplastic or dilatant, and the flow curve can be linear or non-linear. Yield stress is the characteristic of this kind of fluid. That means minimum stress is required to break down the fluid structure sufficiently before the fluid flows. As a result, in the case of viscoplastic, cavernwhich is a well-mixed region- is created around the impeller, while relatively stagnant regions are observed elsewhere in the mixing tank. There are two kinds of viscoplastic fluids: Bingham plastic and yield-pseudoplastic. Figure 2.2. illustrates the flow of these non-Newtonian fluids (Chhabra and Richardson, 1999). 


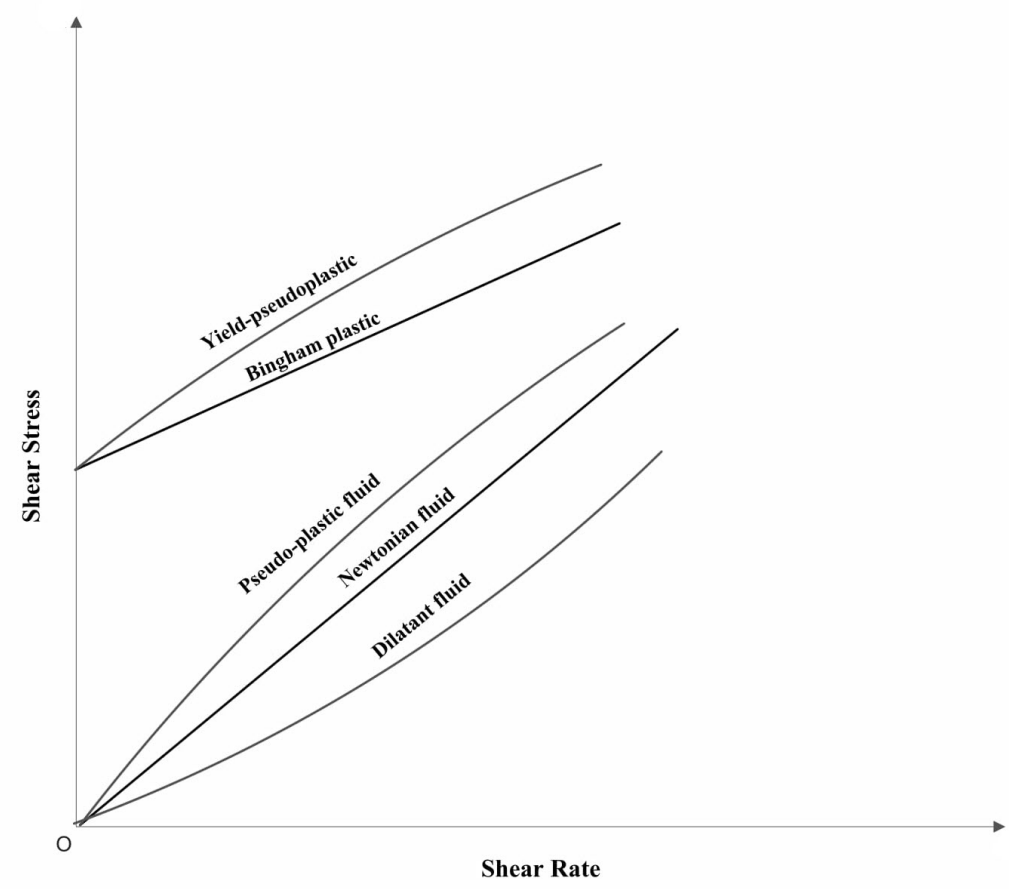

Figure 2.2. Flow curve of non-Newtonian fluids (Chhabra and Richardson, 1999).

Bingham plastic fluid shows a linear flow curve described by a constant plastic viscosity and yield stress. The constant plastic viscosity is defined by the slope of the shear stress versus the shear rate curve (Solomon et al., 1981).

A yield-pseudoplastic fluid shows yield stress and a non-linear flow curve. Pretreated biomass slurries are an example of yield-pseudoplastic fluid (Wiman et al., 2011). Moreover, these materials illustrate shear-thinning behavior (Solomon et al., 1981). Shear-thinning is a phenomenon that causes the reduction in the viscosity of the non-Newtonian fluids with increasing shear rate (Morrison, 2001).

\subsection{Rheological behavior of Biomass Slurries}

Rheology means the study of deformation and flow of matter, especially in soft solids and liquids with a complex flow behavior. The rate at which the fluid deforms depends on the magnitude of the applied force (shear stress) and the fluid viscosity. Viscosity is the property of a liquid to resist 
flow or a change in shape through internal forces and molecular attraction.

Studies on rheology of the lignocellulosic biomass for the production of biofuels are mostly about dilute acid pretreated corn stover and spruce with a biomass concentration varying from 4 to 40 $\mathrm{wt} \%$. It has been reported that untreated/pretreated biomass slurries are shear-thinning fluids with yield stress (Primenova et al., 2004; Stickel et al., 2009; Wiman et al., 2011).

For instance, Primenova et al. (2004) reported that the yield stress of the slurry increased with the fiber mass concentration of corn stover. The yield stress increased from $0.26 \mathrm{~Pa}$ for $5 \mathrm{wt} \%$ to 12.7 $\mathrm{Pa}$ for $15 \mathrm{wt} \%$ corn stover. For describing corn stover suspension viscosity, the Power Law could be used to with correlation coefficients above 0.99 for all four concentrations $(5 \%, 10 \%, 20 \%$, and $30 \mathrm{wt} \%)$ tested.

Movafagh et al. (2016) revealed that increasing the fiber concentration and fiber size caused, the yield stress of untreated wheat straw slurries increased because the number of fiber/fiber interactions raised. They further demonstrated that the cavern diameter decreased by increasing the yield stress, and also the formation of stagnant regions outside the cavern increased. Wiman et al. (2011) measured the yield stress of dilute acid pretreated spruce softwood at 6-12 wt\% concentration. They reported that increasing the concentration and the volume fraction occupied by the fibers caused an increase in the yield stress from 0 to $28 \mathrm{~Pa}$.

Dasari and Berson (2007) revealed that the rheology of sawdust slurries was affected by the fiber size. They reported that the lower viscosities were measured for slurries of smaller particle sizes at the equivalent initial solids concentration. They found that the viscosity of $10 \mathrm{wt} \%$ sawdust slurries reduced from $3000 \mathrm{cP}$ for the particle size range of $150 \mu \mathrm{m}<x \leq 180 \mu \mathrm{m}$ to $61.4 \mathrm{cP}$ for the particle size range of $33 \mu \mathrm{m}<x \leq 75 \mu \mathrm{m}$. Reduction of particle size can be considered as a reason for viscosity reduction of the biomass slurries and operational costs, or cause an increase in solids loading.

Viamajala et al. (2009) examined the rheology of acid hydrolyzed corn stover at concentrations between 10-40 wt $\%$ and particle sizes of $0.177 \mathrm{~mm}$ and $0.841 \mathrm{~mm}$. These slurries behaved like non-Newtonian fluids with yield stress. The yield stress decreased, with increasing hydrolysis temperature and decreasing particle size. They believed that with solids concentration up to 20 
$\mathrm{wt} \%$, yield stresses increased and then became independent of concentration at the higher concentrations. The cause of this plateau at high concentrations is unclear. Furthermore, they explained that dilute acid pretreatment led to lower viscosities and yield stresses at equivalent solids concentrations compared to untreated corn stover. The same is true of smaller particle size. Stickel et al. (2009) examined the rheological characteristics of acidic pretreated corn stover up to $30 \%$ insoluble solids, and revealed that the slurry was strongly shear-thinning, and the yield stress relied on the slurry concentration. Ehrhardt et al. (2010) examined the rheological characteristics of acid hydrolyzed corn stover at high solids concentration (20-35 wt \%). They used the Bingham model to represent rheological properties and reported that yield stress and plastic viscosities increased with increasing solid concentrations, and decreased by increasing the pretreatment reaction temperature and increasing the dilute acid concentration.

Rosgaard et al. (2007) studied the influence of solids content and enzymatic hydrolysis on the apparent viscosity of steam pretreated barley straw biomass slurries. They observed that with increasing solid mass fraction from 5 to $15 \mathrm{wt} \%$, the apparent viscosity increased. They also found that the apparent viscosity decreased over time during the enzymatic hydrolysis. The results obtained from Viamajala et al. (2009), Ehrhardt et al. (2010), and Rosgaard et al. (2007) are in agreement: increasing the concentration of biomass slurries increased the yield stress.

Bashir (2008) measured the rheological properties of untreated wheat straw suspensions at concentrations between 5-20 wt\% with four fiber sizes (0.42, 0.841, 1.68 and $2.38 \mathrm{~mm})$. He found out that the slurry yield stress increased with the degree of concentration and the size of wheat straw fibers.

The apparent viscosities of the raw and pretreated corn stover and wheat straw slurries were measured by Hou et al. (2016a). They noticed that the apparent viscosity of the corn stover slurry (both the raw and the pretreated) was somewhat larger than that of the wheat straw slurry. Furthermore, they reported that the apparent viscosities of the pretreated corn stover were almost three times larger than those of the raw corn stover at a fixed agitation rate due to the smaller particle sizes. These results are in contrast with those reported by Viamajala et al. (2009), who observed a lower viscosity for the pretreated corn stover slurry compared to that for the untreated corn stover slurry. 
Wiman et al. (2011) stated the pretreated spruce during the enzymatic hydrolysis showed a lower yield stress and viscosity in comparison with the non-hydrolyzed spruce. Moreover, they measured a higher yield stress and viscosity for the smaller fiber sizes, a finding inconsistent with the results attained by Dasari and Rajesh (2007) and Movafagh et al. (2016).

In another study, Samaniuk et al. (2012) reported that the addition of water-soluble polymers (WSPs) increased the corn stover biomass plastic viscosity and decreased the yield stress of the slurry from $55 \mathrm{kPa}$ to $18 \mathrm{kPa}$ by adding $2 \mathrm{wt} \%$ WSPs. Hui et al. (2009) revealed that pulp fiber suspensions with concentrations between $1.0 \mathrm{wt} \%$ to $5.0 \mathrm{wt} \%$ suspensions exhibited a nonNewtonian rheological behavior with yield stress.

In general, rheological studies on the slurries of pretreated corn stover and various pulp fibers have shown that the yield stress is a function of fiber mass concentration, $C_{m}$, through a power-law relationship as shown below (Lavenson et al., 2011):

$$
\tau_{y}=a C_{m}^{b}
$$

where $\tau_{y}$ is the yield stress, $C_{m}$ is the fiber mass concentration $a$ and $b$ are empirical constants.

The yield stress of synthetic fiber suspensions (nylon fibers) was measured by Bennington et al. (1990) using equation (2.2), which included the fiber aspect ratio and Young's modulus:

$$
\frac{\tau_{y}}{E}=a A^{2} C_{v}^{3}
$$

where $A$ is the fiber aspect ratio, $E$ is the fiber's Young's modulus, $a$ is a constant and $C_{v}$ is the volume concentration of the fiber suspension.

\subsection{Fiber Networks}

Samaniuk et al. (2011) reported that cellulose fibers in water create networks that cause an increase in apparent yield stress, mainly in the case of high solids contents. Every fiber must have an interaction with at least three other fibers to form flocs or coherent fiber networks. This contact 
regime has been defined by a crowding number $(\mathrm{N})$. A crowding number is defined as the average number of fibers swept out in a spherical volume of a diameter equal to the length of the single fiber (Kerekes et al., 1985).

\subsection{Mixing of Biomass Slurries}

The alternation of a non-uniform system to a uniform one is described as a mixing process. Mixing of fluids is a general operation process in chemical, pharmaceutical, polymer, biochemical, biofuels, and wastewater treatment plants. A common type of the non-Newtonian fluids is yieldpseudoplastic fluids (Skelland, 1967). For instance, pretreated biomass slurries are yieldpseudoplastic fluids, and the quality of mixing has a significant impact on the rate of enzymatic hydrolysis of pretreated biomass slurries (Wiman et al., 2011).

Designing mixing systems for non-Newtonian fluids such as yield-pseudoplastic (pretreated biomass slurries) is more complex than those for Newtonian fluids due to the complex rheology exhibited by non-Newtonian fluids. Mixing of yield-pseudoplastic causes a well-mixed zone around the impeller, which is called cavern, with stagnant regions in the rest of the tank (Wichterle and Wein, 1975). The stagnant regions in the mixing tank cause ineffective heat and mass transfers (Amanullah et al., 1998). Eliminating stagnant zones in the mixing of non-Newtonian fluids with yield stress increases the mixing effectiveness.

Many design parameters such as the type of impeller, impeller clearance, impeller diameter, wall baffles, fiber concentration and fiber size must be taken into account to optimize the fiber suspension mixing process.

\subsubsection{Types of Impellers}

Using a proper impeller is a critical design parameter for mixing processes utilized in chemical industries. Classification of impellers depends on the viscosity of fluids. Turbines are used for low to medium viscosity fluids, while close-clearance impellers are utilized for high viscosity fluids. Impellers can also be classified into two main types regarding flow patterns: axial-flow and radial- 
flow impellers. The appropriate type of impeller should be utilized based on the type of fluid and mixing requirements. For a high aspect ratio $(Z / T>1.5)$, more than one impeller should be used in tanks (Paul et al., 2004), where $Z$ is the height of the liquid in the tank and $T$ is the diameter of the tank.

Marine propellers, hydrofoil impellers, propellers, and pitched blade turbines are the examples of axial-flow impellers. These impellers discharge flow along the axis of the impeller. These types of impellers are effective for, solids suspension, solids incorporation, liquid blending or draw down, heat transfer and gas inducement. For non-Newtonian fluids, the axial flow impeller saves energy compared to the radial flow impeller since this impeller can create the highest cavern volume per unit power. However, when the cavern grows and reaches the tank walls, the impeller type (axial versus radial flow type) does not have a significant influence on the growth of the cavern volume (Elson, 1986). The Lightning A315 impeller is a hydrofoil impeller that has been used in this study. In general, hydrofoil impellers are suitable for mixing purposes that axial flow and low shear are needed. The A315 impeller has four twisted blades that are inflected with rounded leading edges. The blade angle at the hub is thicker than at the tip. This impeller causes uniform velocity through the whole discharge area. This characteristic causes this impeller to be efficient for gas dispersion in viscous systems, liquid blending and solids suspension.

The oldest axial flow impeller is the marine propeller (A100). This impeller is a three rounded and twisted blade impeller with a $45^{\circ}$ blade angle that has been used in this study as well. As mentioned, the A100 impeller produces an axial flow directed to the bottom of the vessel and has a high discharge capacity with a low head.

A pitched blade turbine (A200) contains of a hub with four blades with a $45^{\circ}$ angled blade attached to it, and has been used in this study. Regarding of weight at the equal diameter, this impeller is much lighter than a propeller impeller. A pitched blade impeller makes the flow discharge to axial flow in low to medium viscosity liquids (Paul et al., 2004).

The A100, A200, and A310 impellers were applied in the mixing of wheat straw by Movafagh et al. (2016). They found that these impellers are suitable for mixing untreated wheat straw slurries with different concentrations $(5,7$ and $10 \mathrm{wt} \%)$. They reported that the highest torque and largest 
cavern size the were gained by theA100 impeller. Compared to other impellers, A100 impeller was more effective in order to break the fiber network and generate a well-mixed region at a fixed rotational speed. Palmqvist et al. (2011) reported that, in a stirred tank reactor, the impeller speed of the pitched blade had a significant influence on enzymatic conversion of steam-pretreated spruce. The conversion was higher after 48 hours at $500 \mathrm{rpm}$ comparing with $25 \mathrm{rpm}$. This difference remained during the 96 hours of hydrolysis. This procedure produced a quick breakdown of the fibers- and that increased accessibility for enzymes.

Hollow blade turbines (Scaba), flat-blade impellers, and disk turbines (Rushton) are examples of radial-flow impellers. Radial-flow impellers discharge flow radially to the tank's walls. These impellers produce a high shear rate with lower pumping. This type of impeller usually is used for gas-liquid dispersion, liquid-liquid, and mixing of immiscible fluids. Radial flow impellers generally have six blades (Paul et al., 2004).

Anchors, helical ribbons, and helical screws are examples of close-clearance impellers. These impellers are used in high viscosity applications (Chhabra and Richardson, 2008). These impellers cause an effective top-to- bottom mixing since they have the ability to create satisfying homogenization system. For mixing non-Newtonian fluids, a low speed helical ribbons rotating can be applied. For instance, a helical ribbon impeller is appropriate for dilute acid pretreatment, enzymatic hydrolysis and fermentation in bioreactors. In order to increase the mixing of corn stover-water mixture at high solid loadings (up to $50 \mathrm{wt} \%$ ) with a dilute acid solution in the pretreatment reactors, Zhang et al. (2014) used a helical ribbon impeller. In another study, for increasing the rate of corn stover with dry dilute acid and steam in pretreatment reactors, He et al. (2014) utilized a helical ribbon impeller as well. The results showed that- with this impeller- the pretreatment effectiveness was notably enhanced compared to the pretreatment without mixing.

In another study, Rushton and helical impellers were used for the simultaneous saccharification and fermentation process (SSF) with a high solid loading of pretreated corn stover. The pretreated corn stover contained approximately $40.0 \%$ dry solids matter. The results showed that the feeding time of pretreated corn straw using the helical impeller was shorter than that of using the Rushton impeller. As a result, the shorter feeding time showed that the mixing with helical impeller was better than using the Rushton impeller (Zhang et al., 2010). 
Wu et al. (2012) compared six impellers (three counterflow (CF-2) impellers, two modified high solidity (MHS 3/398) impellers, one helical ribbon impeller, one anchor impeller, one curtain-type impeller, and two pitched blade turbine impellers) for mixing of high-solids anaerobic digestion systems. They reported that the helical ribbon impeller was the best available choice for the mixing.

\subsubsection{Fiber size and concentration}

The size and concentration of fibers greatly influence the mixing performance of biomass slurries. Samaniuk et al. (2011) stated by decreasing the fiber length of corn stover biomass, the yield stress decreased. They explained that adding water-soluble polymers (WSPs) such as $2 \mathrm{wt} \% \mathrm{CMC}$ caused a reduction in fiber length of corn stover that decreased the yield stress from 55 to $18 \mathrm{kPa}$. Primenova et al. (2004) revealed that by increasing the fiber mass concentration from 5 to $30 \mathrm{wt} \%$, the yield stress of biomass slurry increased. The yield stress increased from $0.26 \mathrm{~Pa}$ for $5 \mathrm{wt} \%$ to 12.7 Pa for $15 \mathrm{wt} \%$ corn stover. They used fibers with an average length of $120 \mu \mathrm{m}$. Bashir (2008) measured the rheological properties of untreated wheat straw slurry at different concentrations $(5$, $10,15$ and $20 \mathrm{wt} \%)$ and with four fiber sizes $(0.42,0.841,1.68$ and $2.38 \mathrm{~mm})$. He stated that the yield stress of slurry increased with the fiber concentration and size. For instance, the yield stress of $10 \mathrm{wt} \%$ untreated wheat straw slurry increased from $153 \mathrm{~Pa}$ for $0.42 \mathrm{~mm}$ fiber size to $195 \mathrm{~Pa}$ for $0.841 \mathrm{~mm}$ fiber size. Also, yield stress increased from $171 \mathrm{~Pa}$ for $5 \mathrm{wt} \%$ concentration to 195 Pa for $10 \mathrm{wt} \%$ concentration at a fiber size of $0.841 \mathrm{~mm}$. Movafagh et al. (2016) investigated the rheological behavior of untreated wheat slurries with the fiber size of $x \leq 2 \mathrm{~mm}$ and $8 \mathrm{~mm}$ at 5, 7 and $10 \mathrm{wt} \%$ concentration. They explained that there was a direct relationship between the yield stress, fiber size and concentration of wheat straw slurries. By increasing the fiber concentration and size, the yield stress increased. This was due to an increase in the strength of the fiber network and the number of fiber/fiber interactions. For instance, the yield stress increased from $1.3 \mathrm{~Pa}$ for $5 \mathrm{wt} \%$ wheat straw slurry to $14.8 \mathrm{~Pa}$ for $10 \mathrm{wt} \%$ wheat straw slurry for the fiber size of $x \leq 2 \mathrm{~mm}$. Furthermore, the yield stress increased from 4.2 $\mathrm{Pa}$ for the fiber size of $x \leq 2 \mathrm{~mm}$ to $6.8 \mathrm{~Pa}$ for the fiber size of $8 \mathrm{~mm}$ at $7 \mathrm{wt} \%$ concentration. Moreover, the rheological behavior of pretreated spruce chips between the range of 2 to $10 \mathrm{~mm}$ was investigated by Wiman et al. (2011). They reported a 
higher yield stress for the smaller fiber size. These results were inconsistent with previous findings reported by Samaniuk et al. (2011), Primenova et al. (2004), and Movafagh et al. (2016).

\subsection{Power Requirements}

Power consumption is an important parameter for a mixing system. The energy transferred from an impeller to a fluid per unit time is called power consumption. The geometry of impeller and tank, density and viscosity of the fluid, impeller speed and gravity influence the impeller power in a homogeneous liquid, as shown in Equation (2.3):

$$
P=f(\mu, \rho, N, D, T, g)
$$

where $P, \mu, \rho, N, D, T$, and $\mathrm{g}$ are power, fluid Newtonian viscosity, fluid density, impeller speed, impeller diameter, tank diameter, and gravitational acceleration, respectively. Applying dimensional analysis, Equation (2.4) is obtained (Skelland, 1967):

$$
\frac{P}{\rho N^{3} D^{5}}=f\left(\frac{\rho N D^{2}}{\mu}, \frac{N^{2} D}{g}\right)=f(R e, F r)
$$

This equation shows that the dimensionless power coefficient $P / \rho N^{3} D^{5}$ depends on both Reynolds number, $R_{e}$, and Froude number, $F r$, for a Newtonian fluid. The dimensionless groups are as follows:

$$
\begin{aligned}
& P_{O}=\frac{P}{\rho N^{3} D^{5}} \\
& F r=\frac{D N^{2}}{g} \\
& R e=\frac{\rho N D^{2}}{\mu}
\end{aligned}
$$

For Newtonian fluids, the shear stress is proportional to the shear rate as shown by Equation (2.8): 


$$
\tau=\mu \dot{\gamma}
$$

For non-Newtonian fluids such as lignocellulosic materials, the Reynolds number is defined as Equation (1.8):

$$
R e=\frac{\rho N D^{2}}{\mu_{a p p}}
$$

Contrariwise Newtonian fluids, non-Newtonian fluids don't have an exclusive value for viscosity over a large range of shear rates. Shear rate decreases with the distance from the impeller, and it may fall to zero in stagnant zones (Gabelle et al., 2011).

Power Law, Herschel Bulky and Bingham models were projected for non-Newtonian fluids. The power law is discribed by Equation (2.10):

$$
\tau=k \dot{\gamma}^{n}
$$

where $\tau$ is shear stress $(\mathrm{Pa}), \gamma^{\circ}$ is shear rate $(1 / \mathrm{s}), \mathrm{k}$ is flow consistency coefficient $\left(\mathrm{Pa} \cdot \mathrm{s}^{\mathrm{n}}\right)$, and $n$ is power-law index (dimensionless).

Moreover, equation 2.11 shows apparent viscosity as a function of shear rate that is normally used for a power law fluid (Equation 2.11):

$$
\mu_{a p p}=k \dot{\gamma}^{n-1}
$$

where $\mu_{a p p}$ is the apparent viscosity (Pa.s) as a function of shear rate (1/s).

The Herschel Bulkley model is defined as follows:

$$
\tau=\tau_{y}+k \dot{\gamma}^{n}
$$

$\tau_{y}$ is the yield stress $(\mathrm{Pa})$ which means no flow occurs until the absolute value of the shear stress exceeds the value of the yield stress, and the apparent viscosity is expressed by Equation (2.13): 


$$
\mu_{a p p}=\frac{\tau_{y}}{\dot{\gamma}}+k \dot{\gamma}^{n-1}
$$

The Bingham model can be defined by Equation (1.14):

$$
\mu_{a p p}=\mu_{0}+\frac{\tau_{y}}{\dot{\gamma}}
$$

where $\mu_{0}$ is the viscosity of the fluid at high shear rates.

Metzner and Otto (1957) stated that the fluid movements nearby the impeller could be described by an averaged shear rate in the mixing vessel, linearly associated to the rotational speed of the impeller as follows:

$$
\dot{\gamma}=k_{s} N
$$

Metzner and Otto (1957) obtained a value of 13 for $k_{\mathrm{S}}$ for a disk flat-blade turbine. Skelland (1967) reported that the values of $k_{S}$ for the impellers such as turbines, propellers, paddles, and anchors were in the range of 10-13 in the mixing of pseudoplastic fluids. However, the values of this parameter for the anchor and helical ribbon were in the range of 25-30.

\subsection{Cavern Size During Mixing}

Mixing of viscous fluids with yield stress in stirred tanks results in formation of cavern. At the cavern boundary, the shear stress is identical to the yield stress and unmixed regions appear outside of the cavern boundary. Non-Newtonian fluids such as viscoplastic fluids with yield stress have a relatively high apparent viscosity at low shear rates. Hence, the region around an impeller has intensive motion while elsewhere in the mixing tank there is basically stagnancy. The formation of cavern around the impeller is observed in mixing pulp suspensions, food, biochemical, biopolymers, and ceramic pastes. (Wichterle and Wein, 1975). Therefore, it is important to determine the cavern size and its shape in mixing processes to eliminate these stagnant regions. 
Some parameters such as an impeller's speed and fluid rheology have significant impact on the cavern size.

\subsubsection{Experimental methods for measuring cavern size}

Several techniques have been used and reported in the literature for the assessment of cavern size and shape. A suitable technique should be applicable in a nontransparent medium and vessel. Moreover, it should have high temporal and spatial resolution, and it should be cheap. On the other hand, it should not disturb the flow domain (Pakzad, 2007). The most important experimental techniques are laser Doppler anemometry (LDA) (Yeh and Cummins (1964)), hot-wire anemometry (HWA) (Mavros, 2001), positron emission particle tracking (PEPT) (Chiti et al.,2011), ultrasonic Doppler velocimetry (UDV) (Williams, 1986 and Hui et al., 2009), X-ray technique Elson et al., (1986) and electrical resistance tomography (ERT) (William and Beck, 1995).

\subsubsection{Cavern Mathematical Models}

Different mathematical models have been proposed in the literature to calculate the size of cavern as a function of mixing conditions and fluid properties for different cavern shapes like spherical (Solomon et al., 1981), cylindrical (Elson et al., 1986), and toroidal (Amanullah et al., 1998).

\subsubsection{The Spherical Model}

A spherical cavern was assumed by Solomon et al. (1981) with the torque induced by an impeller performing tangentially at the cavern boundary. This model assumes that the tangential motion dominates within the cavern. The foundation of this model is that the shear stress is equal to the fluid yield stress at the cavern boundary. The following equation was proposed for the cavern diameter, $D_{c}$ :

$$
\left(\frac{D_{c}}{D}\right)^{3}=\left(\frac{4 P_{0}}{\pi^{3}}\right)\left(\frac{N^{2} D^{2} \rho}{\tau_{y}}\right)
$$


when $D \leq D_{C} \leq T$. In this equation, $\mathrm{D}_{\mathrm{C}}$ is the cavern diameter, $D$ is the impeller diameter, $\mathrm{P}_{0}$ is the power number $\left(P_{0}=P / \rho N^{3} D^{5}\right), N$ is the impeller speed, $\rho$ is fluid density and $\tau_{y}$ is fluid yield stress. The term $N^{2} D^{2} \rho / \tau_{y}$ on the right hand side of the equation (2.16) is called the yield stress Reynolds number, and it is usually shown as $R e_{y}$.

\subsubsection{The Cylindrical Model (Elson's Model)}

The X-ray heavy-metal tracer method was used by Elson et al. (1986) to discover cavern formation in the xanthan gum solution (a yield-pseudoplastic fluid). In this research, the cavern was defined by a cylinder of height $H_{c}$ and diameter $D_{c}$ with the ratio of $H_{\mathcal{C}} / D_{c}$ ranging from 0.35 to 0.45 for the Rushton impeller. The value of 0.4 for $H_{c} / D_{c}$ is a good estimate until the cavern boundary reaches the baffles stated by Volynets et al. (2016).

In this model, the cubed cavern diameter ratio $\left(D_{C} / D\right)^{3}$ is proportional to the product of the power number and the "yield Reynolds number" as shown by equation (2.17):

$$
\left(\frac{D_{c}}{D}\right)^{3}=\left[\frac{1}{\left(\frac{H_{C}}{D_{c}}+\frac{1}{3}\right) \pi^{2}}\right]\left(\frac{N^{2} D^{2} \rho}{\tau_{y}}\right) P_{0}
$$

In this equation, $D_{C}$ is the cavern diameter, $D$ is the impeller diameter, $\mathrm{P}_{0}$ is the power number $\left(P_{0}=P / \rho N^{3} D^{5}\right), N$ is the impeller speed, $\rho$ is fluid density and $\tau_{y}$ is fluid yield stress. The term $N^{2} D^{2} \rho / \tau$ on right hand side of the equation (2.17) is called the yield stress Reynolds number, and it is usually shown as $R e_{y}$.

The measured cavern diameter of the xanthan gum solution compared with those predicted using Elson's cylindrical model by Patel et al. (2014). They explained that before the cavern touches the vessel wall, this model can be applied to evaluate the diameter of the cavern. They measured the 
dimensionless diameter $\left(D_{c} / D\right)$ versus dimensionless $P_{o} R e_{y}$ on a $\log$ - log scale for the radial flow impeller (RT) and two axial-flow impellers (A310 and 3AM). By increasing the impeller speed, the diameter of the cavern was initiated to increase and continued to grow till the cavern reached the vessel wall. A log-log plot of the $D_{C} / D$ versus $P_{O} R e_{y}$ should give a straight line with a slope of 1/3, according to Elson's cylindrical model. Both spherical and cylindrical models predicted the cavern diameter identically acceptable; however, the cylindrical model represented the cavern shape better (Amanullah et al., 1998 and Patel et al., 2014). The impeller type had not great impact on vertical expansion of fluid, once the cavern reached the wall (Amanullah et al., 1998).

Movafagh et al. (2016) examined the Elson model to calculate the cavern size for the wheat straw slurries agitated with axial-flow impellers. They reported that increasing the impeller speed increased the cavern size. Consequently, the volume of the stagnant region was reduced when the impeller speed increased. They reported a slope of 0.33 for the $\log -\log$ plot of the $D_{C} / D$ versus $P_{o} R e_{y}$, which showed that Elson's model can be used to predict the cavern sizes created in the mixing of biomass slurries.

\subsubsection{The Torus-shaped Model}

A model was developed by Amanullah et al. (1998) for a torus-shaped cavern. This model grants the total momentum imparted by the impeller. by the pumping action of the impeller, the total momentum which is the sum of tangential and axial shear components, transported to the cavern boundary:

$$
\left(\frac{D_{c}}{D}\right)^{2}=\frac{1}{\pi}\left(\frac{N^{2} D^{2} \rho}{\tau_{y}}\right) \sqrt{N_{f}^{2}+\left(\frac{4 P_{0}}{3 \pi}\right)^{2}}
$$

where $N_{f}=F_{a} / P N^{2} D^{4}$ is the dimensionless axial force number, and $F_{a}$ is the axial force imparted by the impeller. This model can also be used for caverns created by radial flow impellers if $N_{f}=$ 0, as follows (Bhole and Bennington, 2010): 


$$
\left(\frac{D_{c}}{D}\right)^{2}=\left(\frac{1}{3 \pi}\right)\left(\frac{4 P_{0}}{\pi}\right)\left(\frac{N^{2} D^{2} \rho}{\tau_{y}}\right)
$$

In the literature, there seems to be not even one study on the cavern evaluation of pretreated wheat straw suspensions. The new and fast developing of non-intrusive ERT appears to provide an efficient tool for the analysis and control of mixing processes, especially in the case of nonNewtonian fluids (either opaque or transparent). Electrical resistance tomography (ERT), which is an emerging technology, can be the best alternative to measure the cavern size (diameter and height). The cavern dimensions $\left(D_{c}, H_{c}\right)$ obtained from ERT will be substituted into the Elson's model to analyze the yield stress.

\subsection{Electrical Resistance Tomography (ERT)}

As explained before, different techniques have been suggested as ways to measure the cavern size. Working with opaque fluids has limitations that restrict the efficacy of most of these techniques. Electrical resistance tomography (ERT), a non-intrusive method, however, is compatible with opaque fluids. This method has several advantages: non-intrusive, with quick data acquisition, high accuracy, applicability in transparent and opaque fluids, simplicity, low cost and guarantees the sensitivity of the object of the interest and high temporal resolution of images. Also, this method has the ability to do continuous measurements over a large range of scales (Sardeshpande et al., 2016, Sharifi et al., 2013).

Tomography is originated from the Greek word. "Tomos" means "to slice" and "graph" means "image". It is an imaging technique that describes the contents of the vessel without having to physically look inside it. (Madhavi et al., 2016).

ERT is a non-invasive imaging technique that measures the distribution of conductivity within a area of interest (Ridzuan et al., 2014 and Mann et al., 1997). In this method, electrodes are placed around the process vessel while they are in contact with process fluid. ERT can determine the conductivity distribution within the vessel based on the measurement of currents or voltages through the mentioned electrodes- without interrupting the flow (Hashemi et al., 2016). 
Furthermore, utilizing ERT offers the chance to measure mixing time and observe the mixing dynamics of non-Newtonian fluids. In addition, ERT is a measurement technique offering a variety of applications listed in Table 2.3.

Table 2.3. Literature review on the ERT technique for mixing application (Madhavi et al., 2016).

\begin{tabular}{|c|c|}
\hline Reference & Objective of the study \\
\hline Dickin and Wang, (1996) & Monitoring multiphase processes like liquid-liquid \\
\hline Tan et al., (2007) & Evaluation of gas-liquid flow pattern in pipe flow \\
\hline Zhao et al., (2008) & $\begin{array}{l}\text { Measuring mixing time in an agitated multi- lamp } \\
\text { cylindrical photo-reactor }\end{array}$ \\
\hline Pakzad et al., (2008) & Cavern formation in the mixing of pseudoplastic fluids \\
\hline $\begin{array}{l}\text { Pakzad and Ein-Mozaffari, } \\
(2008)\end{array}$ & $\begin{array}{l}\text { Measuring the mixing time in the agitation of non- } \\
\text { Newtonian fluids }\end{array}$ \\
\hline Yenjaichon et al., (2011) & Evaluating mixing quality in an industrial pulp mixer \\
\hline Hosseini et al., (2010) & $\begin{array}{l}\text { Investigating solid liquid mixing in an agitated tank } \\
\text { using an axial-flow impeller }\end{array}$ \\
\hline Harrison et al., (2012) & $\begin{array}{l}\text { Evaluating solids concentration homogeneity in } \\
\text { slurry reactors }\end{array}$ \\
\hline Carletti et al., (2014) & $\begin{array}{l}\text { Measuring axial solid concentration distribution } \\
\text { mixing index }\end{array}$ \\
\hline Babaei et al., (2015) & Measuring the mixing time for gas-liquid systems \\
\hline Movafagh et al., (2016) & Measuring the yield stress of wheat straw \\
\hline Kazemzadeh et al., (2016) & $\begin{array}{l}\text { Evaluating the mixing quality of an industrial pulp } \\
\text { mixer }\end{array}$ \\
\hline Kazemzadeh et al., (2016) & $\begin{array}{l}\text { Investigation of hydrodynamic performances of } \\
\text { coaxial mixers in agitation of yield-pseudoplastic } \\
\text { fluids }\end{array}$ \\
\hline Hashemi and Ein-Mozaffari, & Measuring the mixing time for viscous Newtonian \\
\hline
\end{tabular}




\begin{tabular}{|l|l|}
\hline (2016) & fluids \\
\hline $\begin{array}{l}\text { Sher et al., (2016) } \\
\text { Hosseini et al., (2010) }\end{array}$ & Monitoring multiphase processes like gas-liquid \\
\hline Prakash et al., (2017) & $\begin{array}{l}\text { Assessing the local solid concentration in a slurry } \\
\text { reactor equipped with a maxblend impeller for solid- } \\
\text { liquid mixing }\end{array}$ \\
\hline
\end{tabular}

\subsection{Elements of Electrical Resistance Tomography (ERT)}

The aim of ERT is to measure the conductivity distribution in the domain of interest by injecting the current between electrodes and measuring the voltage. The diagram of ERT system is shown in figure 2.3.

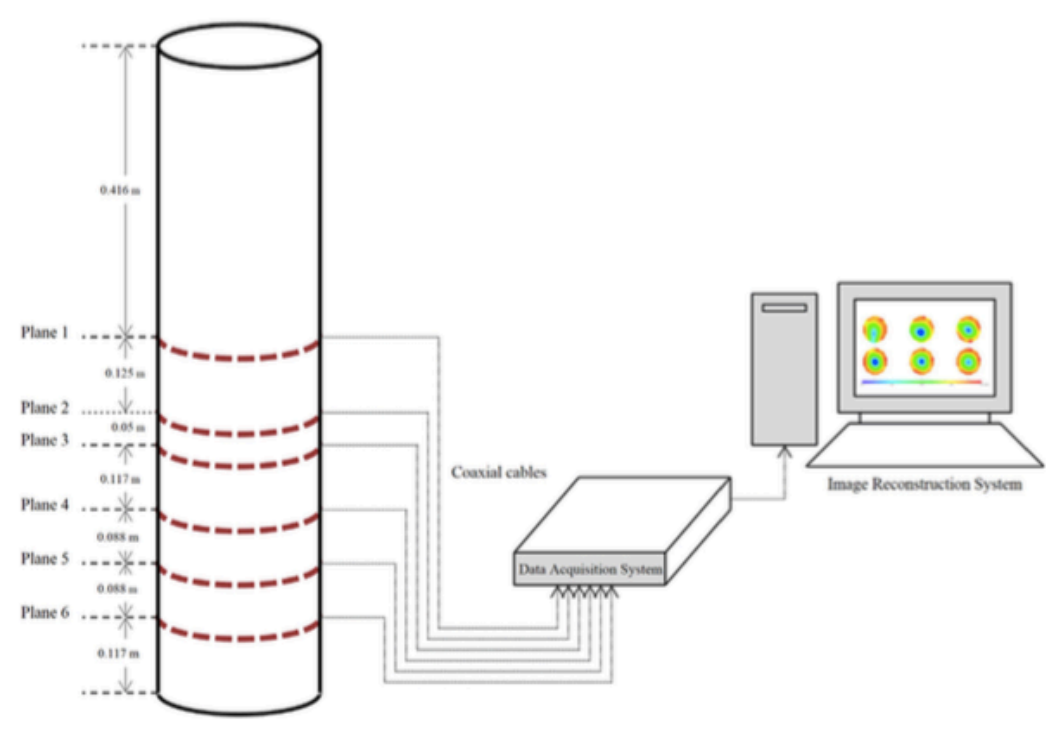

Figure 2.3. The structure of an electrical resistance tomography system (Babaei et al., 2015).

ERT system consists of three principal elements: sensors, a data acquisition system (DAS) and image reconstruction system (host computer). 


\subsubsection{Sensors/ Electrode Selection}

Electrodes play a crucial role in ERT system. They have to be in constant contact with the fluid inside the vessel. Moreover, electrodes should have low cost, be easy to install, have the appropriate conductivity and resistance to corrosion or process operation environment, e.g. temperature and pressure. Electrodes can be made-up from stainless steel, brass, stainless steel, brass, gold, platinum, or silver.

The place, size and number of electrodes are crucial factors that should be closely considered in the design of the system. To maximize the amount of information from inside of the vessel, the location of electrodes is significant because the reconstruction algorithm depends on the electrodes being placed at exactly defined intervals (Kaminoyama et al., 2007). Preferably, they are located at equal distance around the boundary of the vessel at fixed locations. The size of electrodes is also a significant component in measuring the electric field distribution (Ridzuan et al., 2014). Voltagemeasuring electrodes should be small (Paulson et al., 1992). However, current injecting electrodes should have a big surface area to guarantee that sufficient current will be produced within the vessel. Using the same size electrodes for injection and measurement is simpler (Dickin and Wang, 1996). A study recommended that electrodes should cover $60-80 \%$ of the surface of the area of interest to produce a high signal-to-noise ratio (Pinheiro et al., 1998). The time taken to collect data and to reconstruct the image depends on the number of electrodes. More electrodes can increase the 3D resolution of the system due to enhanced number of measurements (Ridzuan et al., 2014).

\subsubsection{Data Acquisition System (DAS)}

DAS is the element that injects current and collects the quantitative information that explains the conductivity distribution inside the vessel (Sharifi and Young, 2013 and Hashemi et al., 2016). It is attached to electrodes and communicates with the host image reconstruction computer. 


\subsubsection{Data Collection Strategies}

if a full set of independent measurements is not collected, misleading images can be rebuilt. Therefore, good data collection strategies are crucial (Ridzuan et al., 2014). Four important strategies can be used to examine conductivity distribution in a tank:

- Adjacent strategy

- Opposite strategy

- Diagonal strategy

- Conducting boundary strategy

\subsection{The Adjacent Strategy}

The adjacent strategy is the most well-known strategy in conventional ERT since it needs minimum hardware requirements and has fast image reconstruction system (Sharifi et al., 2013). A current is applied through a pair of neighboring electrodes and the voltages are measured between other pairs of neighboring electrodes in this strategy. Then, the procedure is repeated for all other possible pairs of neighboring electrodes. For instance, Madhavi et al. (2016) used this strategy for their research. They reported that an electric current was passed between two adjacent electrodes, and the voltages between the other adjacent electrodes were measured. Figure 2.4 illustrates the adjacent measurement strategy that they used in their research.

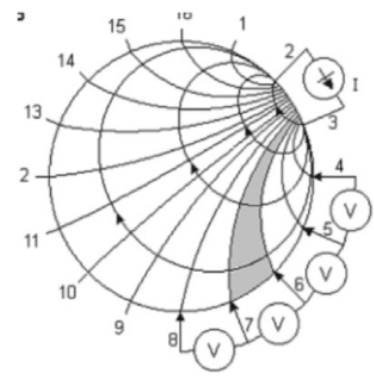

Figure 2.4. Data collection strategy; adjacent measurement strategy (Madhavi et al., 2016). 
In this strategy, the total number of independent measurements $(M)$ is given by:

$$
M=\frac{n(n-3)}{2}
$$

Where $n$ is the number of electrodes. For instance, each tomography plane, which contains 16 electrodes, leads to 104 individual measurements (Sharifi and Young, 2013 and Hashemi et al., 2016).

\subsection{The Opposite Strategy}

In this strategy, current is applied over diametrically opposed electrodes, and voltage reference is the electrode adjacent to the current-injecting electrode. Then, the process is repeated in a clockwise direction. Figure 2.5 demonstrates the opposite measurement strategy. Voltages are measured at all electrodes except the current-injecting ones with respect to the reference voltage.

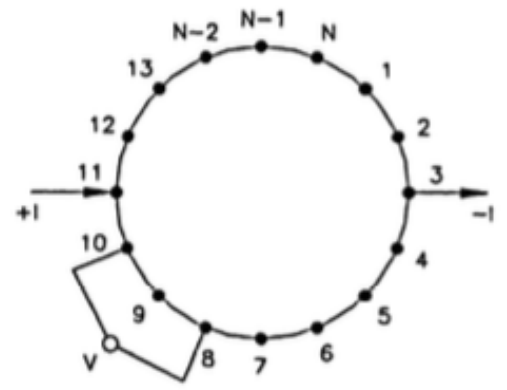

Figure 2.5. Data collection strategy; opposite measurement strategy (Pakzad, 2007).

In this strategy, the total number of independent measurements $(M)$ is given by (Viergever and Todd-Pokropek, 1988):

$$
M=\frac{n}{4}\left(\frac{3 n}{2}-1\right)
$$

There are two disadvantages associated with this strategy. First, it has lower image resolution than the adjacent strategy for the same number of electrodes (Abdullah, 1993). Second, comparing to 
the adjacent strategy, this strategy is less sensitive to conductivity changes near the vessel, because most of the current passes through the central part of the vessel (Hua et al., 1993).

\subsection{The Diagonal Strategy}

In this strategy, a current is applied between electrodes separated by large dimensions. Electrodes 1 and 2 are fixed as the current reference and the voltage reference, respectively. Then, the current is applied to electrodes 3,5, 7, 9, etc., and the voltage is measured from electrodes to the left of electrode number 2. A 16-electrode system yields 104 independent measurements. This strategy has good sensitivity over the whole vessel and provides a good quality image (Hua et al., 1993).

\subsection{The Conducting Boundary Strategy}

In this strategy, both current and voltage are used between two electrodes. The sensitivity of this strategy is similar to the adjacent strategy because the amplitude of the measured voltage is low (Dickin and Wang, 1996). In this system, the influence of electromagnetic noises is reduced by the earth-conducting boundary (Figure 2.6).

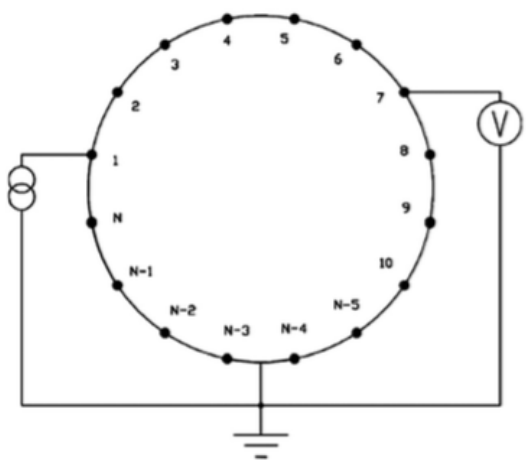

Figure 2.6. Data collection strategy; Conducting boundary strategy (Ridzuan, 2007). 


\subsubsection{Image Reconstruction System}

The adjacent strategy (the most common one) offers 104 individual voltage measurements for each plane with 16 electrodes. A precise and stable DAS is a crucial need for the ERT system. It is responsible for gaining the quantitative data showing the state of the conductivity distribution inside the tank. DAS exchanges data (voltage measurements) with the host image reconstruction computer. The computer processes these data by using a suitable image reconstruction algorithm. An image reconstruction algorithm determines the conductivity distribution within the vessel by processing the data gained from electrodes located on the vessel (Pinheiro et al., 1999; Mann et al., 1996)

There are two types of algorithms: non-iterative and iterative. A non-iterative image reconstruction algorithm (Linear Back Projection (LBP) has low computational demands and an excellent temporal resolution in comparison with the iterative one (Hashemi et al., 2016 and Babaei et al., 2015).

The iterative algorithm has some drawbacks compared to the linear back projection. It is too slow for real-time image reconstruction and has high computational requirements. A non-iterative image reconstruction algorithm, on the other hand, is particularly well adapted to time-dependent multi-phase processes because of appropriate time resolution based on fast electrical measurements (Gigue`re et al., 2008).

The P2000 system (Industrial Tomography Systems-ITS, Manchester, UK) used in this study comes with the adjacent strategy and the non-iterative algorithm (linear back-projection).

\subsection{Research Objectives}

From the literature review, one can see that the information regarding the mixing of pretreated wheat straw slurry is still inadequate. In this study, the ERT technique is employed to study the mixing of pretreated wheat straw and wheat straw slurries with the axial impellers (A200, A100, and A315). The main contributions of this work are:

- To employ Electrical Resistance Tomography (ERT) to measure the dimensions of 
the cavern formed around the impeller at different rotational speeds

- To study the effects of pretreated wheat straw and wheat straw slurry concentration on the cavern size

- To study the effects of pretreated wheat straw fiber size on the cavern size

- To compare the cavern sizes attained for pretreated wheat straw and wheat straw slurries

- To investigate the impact of the pretreatment process on the yield stress of wheat straw slurry

- To investigate the most efficient impeller for the mixing of pretreated wheat straw and wheat straw slurries 


\section{Chapter 3 Experimental Setup and Procedures}

\subsection{Material and Methods}

\section{- Wheat Straw}

Wheat (Triticum sativum Soft White Superior) was from Thos. Leslie farm in Brampton. The baled wheat straw was dry and stored in black plastic bags with various fiber sizes in the lab. A Cutting Mill SM 100 (Master Craft, United States) was used to grind the wheat straw in two different fiber sizes $(\leq 2 \mathrm{~mm}$ and $\leq 6 \mathrm{~mm})$. Milled wheat straw was stored in sealed plastic bags at room temperature until being used for pretreatment process.

\section{- Dilute Acid Pretreatment}

Two Electric Pressure Steam Sterilizers were used for the pretreatment of wheat straw in this study. The ALL-AMERICAN Sterilizer Model 25X consisted of a flat-bottom cylindrical tank with an inside diameter of $32.1 \mathrm{~cm}$, an overall height of $42.5 \mathrm{~cm}$. The dimensions of Model 75X were 38.7 and $48.3 \mathrm{~cm}$, respectively.

The mild acidic procedure reported by Pooja et al. (2015) was utilized in this study. Two hundred grams of wheat straw (WS) $\leq 2 \mathrm{~mm}$ fiber size was placed in $1800 \mathrm{~g}$ aqueous sulfuric acid $(0.75 \% \mathrm{v} / \mathrm{v})$ in a $2000 \mathrm{ml}$ beaker. Five more identical solution were prepared and placed in two sterilizers. The sterilizers were filled up to mark with distilled water, and the beakers were placed in the pan of the sterilizers. The lid of the sterilizers was then secured. The reaction temperature was set at $123{ }^{\circ} \mathrm{C}$. It took about one hour to reach 123 ${ }^{\circ} \mathrm{C}$. The temperature was kept constant for 30 more minutes (called contact time). The power was then set to off and the steam was released using a control valve. After 10 minutes of steam releasing, the $\mathrm{pH}$ of the solution in the beakers was measured. The content of each beaker was divided into 2 portions and each portion was poured and filtered in a vacuum filter system (which contained a filter paper on it) and was washed five times with 
$500 \mathrm{~mL}$ of distilled water to reach transparent colour for the filtrate. The filtrates were separated by filter paper under vacuum. The $\mathrm{pH}$ of re-combine filtrates of two portions was recorded. The solid residue of wheat straw was separated from filter paper as well. The pretreated wheat straw was dried in an oven at $70{ }^{\circ} \mathrm{C}$ for 12 hours. This pretreated wheat straw was labelled as PWS $\leq 2$ fiber size. Similarly, when wheat straw with $\leq 6$ fiber size was used, the obtained pretreated wheat straw was labelled PWS $\leq 6$ fiber size. PWS was stored in $500 \mathrm{~g}$ sealed plastic bags in a refrigerator to decrease the risk of damage.

\subsection{Experimental Setup for the Mixing}

The mixing system was a flat-bottom cylindrical tank with a height of $600 \mathrm{~mm}$ and a diameter of $400 \mathrm{~mm}$ (Figure 3.1). The slurry height in the tank was equal to the tank diameter with a total volume of 50.26 L. The tank contained four equally spaced axial baffles with a width of $40 \mathrm{~mm}$. The mixing tank was equipped with a top-entering impeller driven by a 2-hp motor (Neptune Mier, Model No. JD-7.1, Serial No. 167083, USA). The A100, A200, and A315 impellers with a $180 \mathrm{~cm}$ diameter (D) were used in this study (Figure 3.2 (a,b,c)). Each impeller was installed on the mixer shaft with a clearance of $180 \mathrm{~mm}$ from the bottom of the tank. The impeller rotational speed was varied using a variable frequency drive (Teco FM50, Model No.E177007, Taiwan). The impeller torque $(M)$ and speed $(N)$ were measured using a rotary torque meter (Staiger Mohilo, Model No.010/01MS20RAU, Germany) and a tachometer (Nidec-Shimpo America Crop, Model No. 21 CFR 1040.10, USA), respectively. The power input to the impeller (P) was calculated using the impeller torque and speed, which has explained in the next section. Further, the mixing tank was equipped with ERT (electrical resistance tomography). The ERT system compromises of electrodes, a data acquisition system (DAS), and a host computer with an image reconstruction system. As shown in Figure 3.1, the mixing tank was fitted with four tomography sensor planes. The top plane was numbered P1 and the subsequent lower planes were numbered P2, P3, and P4, respectively. The bottom plane (P4) was located $80 \mathrm{~mm}$ from the bottom of the tank and each impeller located on plane P3.

Each sensor plane was comprised of 16 stainless steel electrodes, which were set at equal interval through the circumference of the tank. The height, width, and thickness of the electrodes were 20 $\mathrm{mm}, 30 \mathrm{~mm}$, and $1 \mathrm{~mm}$, respectively. Each electrode was connected to the data acquisition system 
(Industrial Tomography Systems-ITS, Manchester, UK), which was also connected to a host computer. DAS (data acquisition system) is a portable unit that is responsible for describing the state of the conductivity distribution inside the tank. DAS injects current between two neighboring electrodes, and measures the resultant voltage through all other neighboring electrodes. This data collection strategy is called adjacent strategy (Pakzad et al. 2007). To processing the obtained data from electrodes and determining the conductivity distribution inside the vessel, an image reconstruction algorithm is required. A non-iterative image reconstruction algorithm (linear back projection-LBP) was used to convert the measured voltage data in to $2 \mathrm{D}$ and vertical slice image of planes (Barber and Brown, 1984). 


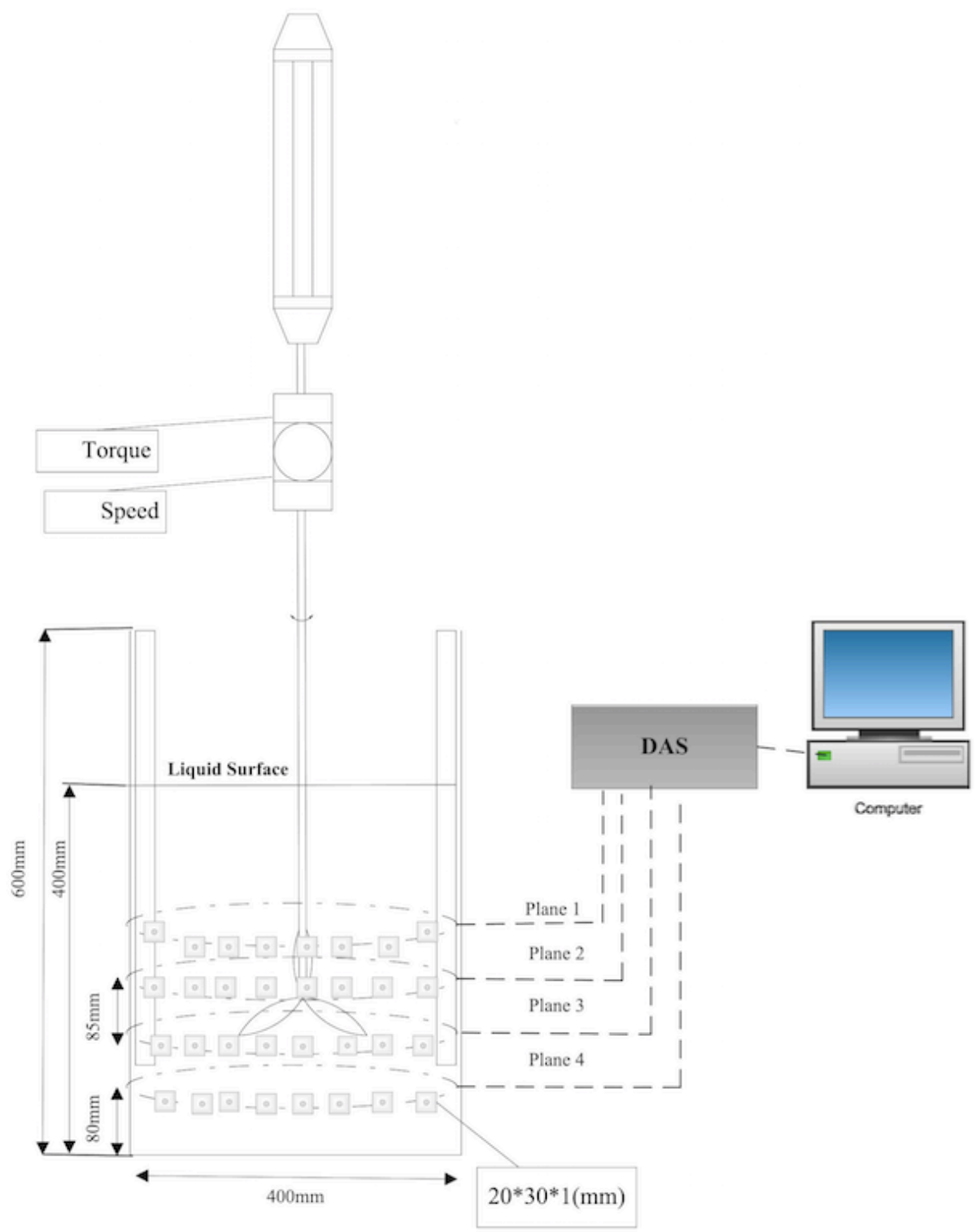

Figure 3.1. Schematic diagram of the mixing system in this study. 


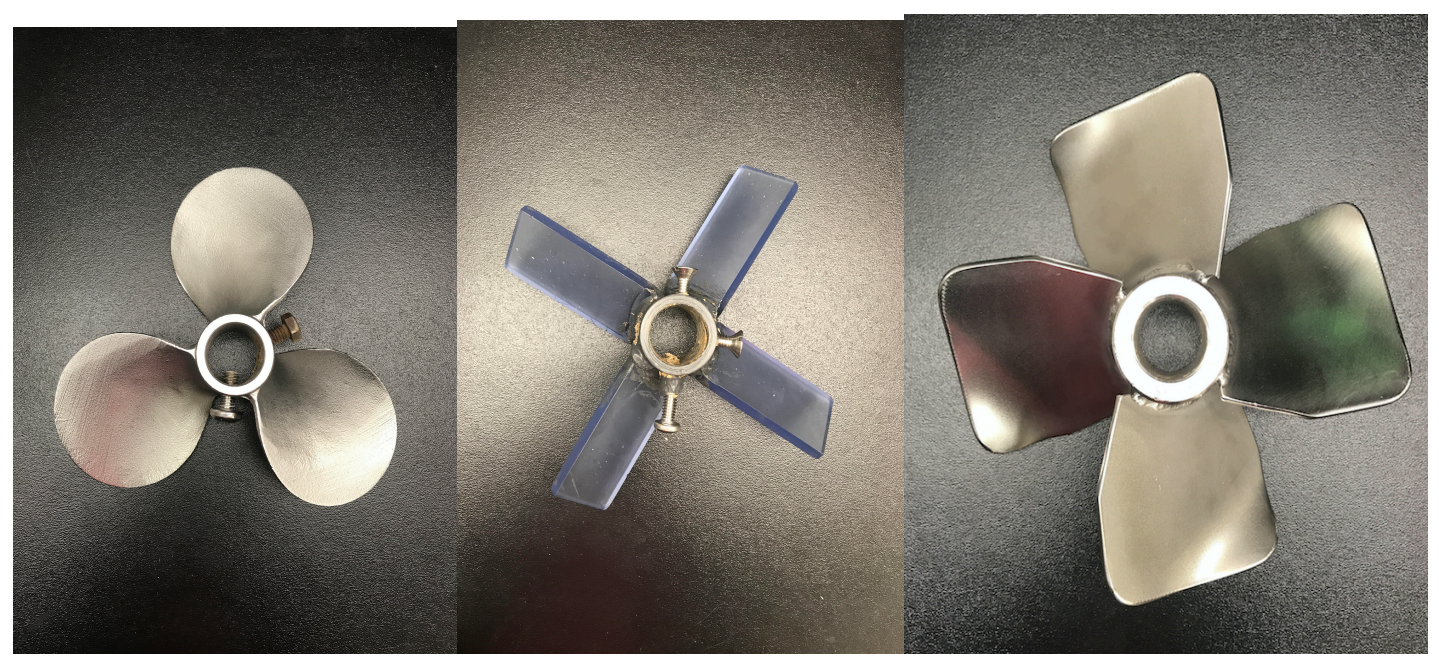

Figure 3.2. (a) A100, (b) A200, and (c) A315 Impellers used in this study.

\subsection{Power Measurements for the Mixing System}

Power is the energy that transferred from the impeller to the fluid per unit time. The input power of the impeller $(P)$ can be calculated from torque $(M)$ and impeller rational speed $(N)$ using the following formula:

$$
P=2 \pi N M
$$

The friction torque was measured by the operation of the empty system. The friction torque was subtracted from all subsequent measured torques.

The impeller power was then used to calculate $P_{0}$ (Power number) by the following equation:

$$
P_{0}=\frac{P}{\rho N^{3} D^{5}}
$$

where $P$ is the impeller power, $\rho$ is the density of the slurry, $N$ is the impeller speed and $D$ is the impeller diameter. 


\subsection{Procedure for Measuring the Cavern Size Using ERT}

To measure the cavern size, electrical resistance tomography (ERT) was utilized in this study. For each experiment, the specific amount of PWS or WS and water were loaded in layers to attain the slurry height of $400 \mathrm{~mm}$ inside the mixing tank without any mixing. Before each experiment run, the conductivity of the continuous phase of PWS or WS slurries was measured using a conductivity meter (PC10 portable meter, Oakton Instruments, USA). The measured conductivity of continuous phase was applied for the DAS setup. The data collection rate was performed at 50 frames per second for $9600 \mathrm{KHz}$ injection frequency with a current injection of $75 \mathrm{~mA}$. After calibrating and checking the ERT for current, electrodes and gain map, a reference frame was recorded to eliminate the effects of stirrer and baffles. To peruse this, 50 frames were taken before each run and the average of these frames was considered as a reference frame.

Then at about 10-12 frames after starting the experiment at a desired rotational speed of the impeller, $20 \mathrm{ml}$ of $10 \%$ saline solution as a tracer was injected into the PWS or WS slurry near the hub of the impeller using a plastic syringe. The tracer injection time was about 2 to 3 seconds for all the experiments. Each run continued for 50 frames and took about 3 minutes. The dimensions of the cavern were measured as the cavern size remained unchanged after the injection (12 frames after the injection).

The cavern boundary was assigned to the location, where the tracer concentration was low (dark blue). In fact, the conductivity of the slurry at the cavern boundary was equal to the conductivity of the slurry before injecting the salt. The range of colors in tomograms (Figure 3.3) indicate the dispersion of the tracer in the mixing tank. The red color displays high conductivity regions (higher tracer concentrations) whereas the dark blue color represents low conductivity regions which demonstrate lower tracer concentration. Each set of tomography test was repeated three times with the same material in the mixing tank.

This figure illustrates the formation of cavern based on using the two-dimensional (2D) tomograms generated after the injection of the saline tracer in the mixing of $10 \mathrm{wt} \%$ of PWS slurry $(\leq 2 \mathrm{~mm})$ with A315 impeller at $80 \mathrm{rpm}$. 


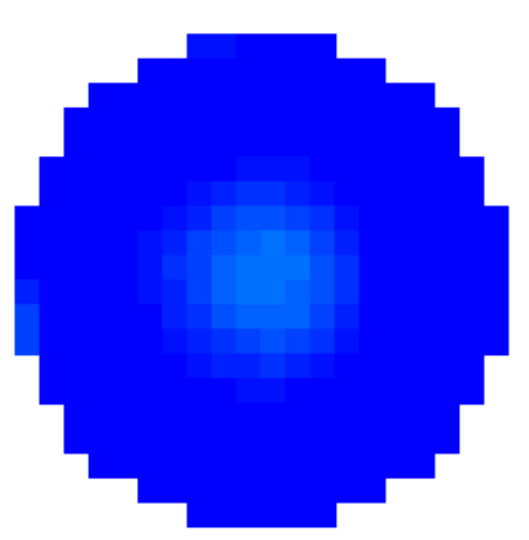

P1

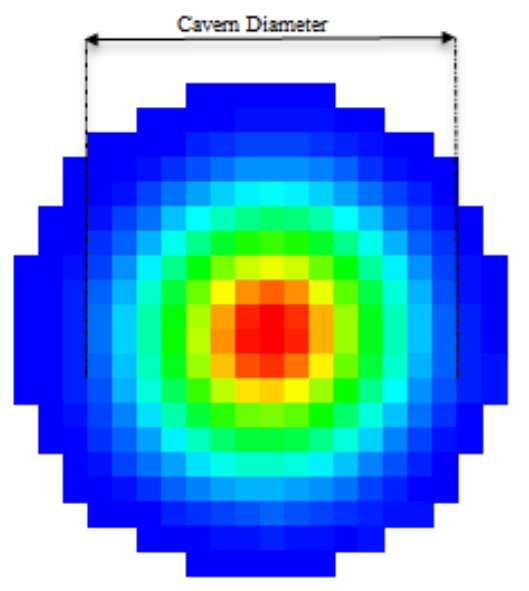

P3

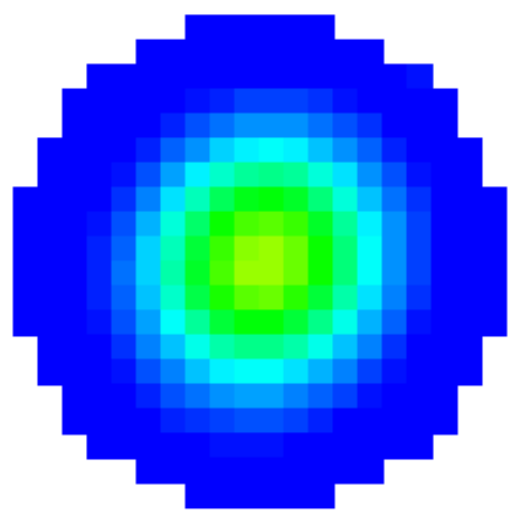

P2

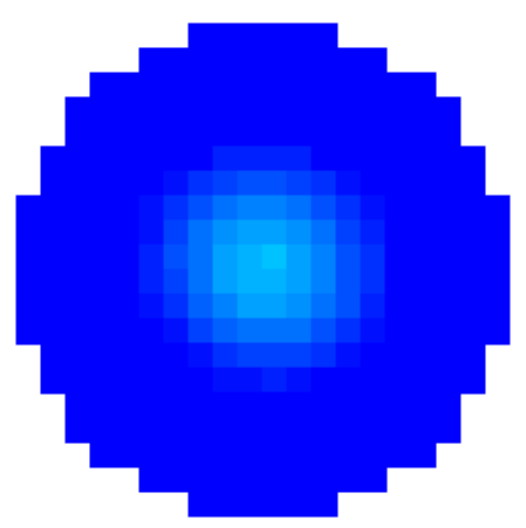

P4

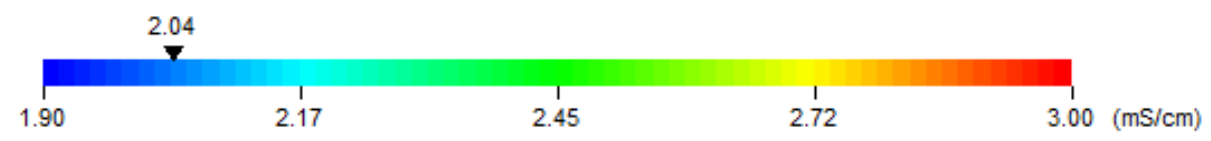

Figure 3.3. Cavern formation in $10 \mathrm{wt} \%$ pretreated wheat straw slurry $(\leq 2 \mathrm{~mm})$ agitated by $A 315$ impeller at $80 \mathrm{rpm} . \mathrm{P}_{1}$ to $P_{4}$ are the tomography planes.

Each plane represents a circular image comprising of 316 square pixels with a width of $3.0 \mathrm{~mm}$. The number of pixels across the image of Plane 3 (impeller plane) on Figure 3.3 consists of 20 pixels. Therefore, the diameter of the circular image of Plane 3 was calculated to be $6 \mathrm{~cm}$ (20 $\times 3.0 \mathrm{~mm}$ ). Considering that the real diameter of the mixing tank is $40 \mathrm{~cm}$ and the diameter of circular image is $6 \mathrm{~cm}$, the ratio between them is 6.6 . Assuming that the conductivity of 2.04 
$\mathrm{mS} / \mathrm{cm}$ represents the boundary of the cavern, one counts 15 pixels from left to right as the diameter of the cavern. As a result, the diameter of the cavern, $D_{c}$, would be $30 \mathrm{~cm}(15.0 \times 0.3 \mathrm{~cm} \times 6.6)$.

The height of the cavern $\left(H_{c}\right)$ was also measured through the vertical slice image (which contains data from all electrodes from all planes) as shown in Figure 3.4. A similar approach adopted to measure the height of the cavern. The height of the cavern, $H_{c}$, was calculated to be $18 \mathrm{~cm}$ $(16 \times 0.3 \mathrm{~cm} \times 3.8)$.

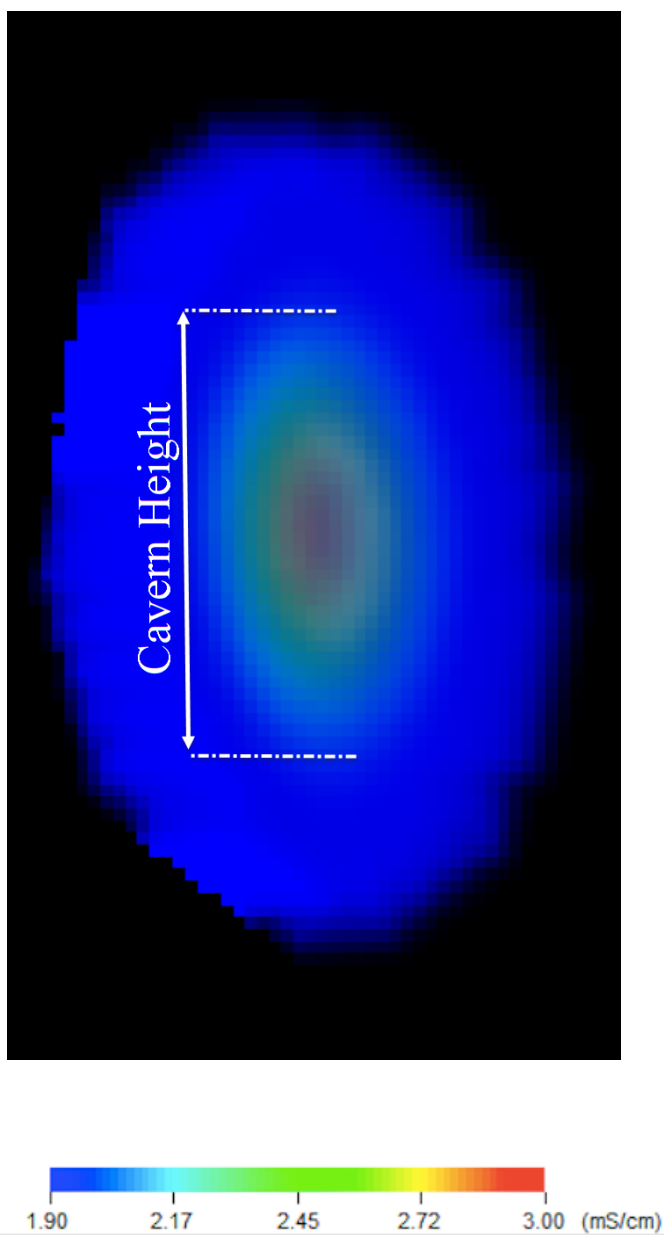

Figure 3.4. Cavern height for $10 \mathrm{wt} \%$ pretreated wheat straw slurry $(\leq 2 \mathrm{~mm})$ agitated by the A315 impeller at $80 \mathrm{rpm}$. 
The cavern dimensions obtained from the tomography measurements were then substituted into the cylindrical model proposed by Elson $\left(\left(\frac{D_{c}}{D}\right)^{3}=\left[\frac{1}{\left(\frac{H_{C}}{D_{C}}+\frac{1}{3}\right) \pi^{2}}\right]\left(\frac{N^{2} D^{2} \rho}{\tau_{Y}}\right) P_{0}\right)$ to calculate the yield stress, $\tau_{Y}$, of the slurries where $D_{c}$ is the cavern diameter, $H_{c}$ is the height of the cavern, $D$ is the impeller diameter, $P_{O}$ is the impeller power number, $N$ is the impeller speed, $\rho$ is fluid density .

In order to check the accuracy of the tomography measurements, the cavern dimensions obtained from the tomography measurements for $10 \mathrm{wt} \% \mathrm{WS}$ with fiber size of $\leq 2 \mathrm{~mm}$ for A200 and A100 impellers were substituted into Elson model. The resulting yield stress calculated from the Elson model of $14.79 \pm 0.04 \mathrm{~Pa}$ for A200, was in good agreement with that reported by Movafagh et al. (2016) of $14.70 \pm 0.08 \mathrm{~Pa}$ for A200 impeller. Furthermore, the resulting yield stress of $14.37 \pm 0.12$ Pa for A100, was in good agreement with that reported by Movafagh et al. (2016) of 15.07 $\pm 0.04 \mathrm{~Pa}$ for A100 impeller. Movafagh et al. (2016) measured the yield stress of the xanthan gum solution as a reference to check the accuracy of the tomography measurements. The yield stress estimated using the tomography images was in good agreement with that measured using a Bohlin CVOR Rheometer 150 (Malvern Instruments, USA) as reported by Pakzad (2007).

The operating conditions for measuring the cavern sizes generated during the mixing of PWS and WS slurries in this study, are summarized in Table 3.1.

Table 3.1. Operating conditions for PWS and WS slurries with $x \leq 2 \mathrm{~mm}$ and $x \leq 6 \mathrm{~mm}$ fiber sizes.

\begin{tabular}{|l|l|l|}
\hline Slurry concentration & Impeller types & Impeller speed (RPM)* \\
\hline $6 \mathrm{wt} \%$ & A200, A315, A100 & $20-70 \mathrm{rpm}$ \\
\hline $8 \mathrm{wt} \%$ & A200, A315, A100 & $40-90 \mathrm{rpm}$ \\
\hline $10 \mathrm{wt} \%$ & A200, A315, A100 & $60-110 \mathrm{rpm}$ \\
\hline
\end{tabular}

*The rpm has increased in 10-rpm increment.

As it shown in Table 3.1, $40 \mathrm{rpm}$ and $60 \mathrm{rpm}$ were the lowest rmp for $8 \mathrm{wt} \%$ and $10 \mathrm{wt} \%$ slurries, respectively for both PWS and WS to measure the cavern size. No cavern was formed for the rotational speeds lower than 40 and $60 \mathrm{rpms}$ for mentioned slurries. 


\subsection{Analyses}

- Fiber size

After finishing the pretreatment process, $150 \mathrm{~g}$ of dried PWS and WS were sieved separately to compare their size distribution. For sieving PWS and WS with $\leq 2 \mathrm{~mm}$ fibers size, four sieves with the mesh sizes of $2.36,1.19,0.481$, and $0.425 \mathrm{~mm}$ were installed on each other from top to bottom, respectively. Also, a plate was set under the bottom sieve and considered as $<0.425 \mathrm{~mm}$. The sieving process was carried out by hand. The sieves were shaken in horizontal direction four times, and then they were rotated 90 degrees clockwise. This procedure was repeated two more times. Then the amount of PWS or WS on the top of each sieves and the plate was weighted separately. Similar procedure was repeated for PWS and WS with the fiber size of $\leq 6 \mathrm{~mm}$. However, this time another sieve with a $4.76 \mathrm{~mm}$ mesh size was added to the top. The sieving process have been done only once without any replicate because of the size distribution of fibers in bags expected to varying since smaller particles migrate to the bottom of the bags.

\section{- SEM (Scanning Electron Microscope) Images}

SEM images were taken to compare the size and structure of fibers of PWS with those of WS. Scanning electron microscope (Model JSM-6380LV from JEOL Company, Tokyo, Japan) was used in order to take SEM images. A black ribbon is under all the SEM images which contains information about the operation condition of the Scanning electron microscope. $20 \mathrm{kV}$ shows the applied voltage into the equipment, which is the same for all the samples. X10, X20, and X1,000 are the magnification of the pictures which is the same for a set of pictures for PWS and WS to make an accurate comparison. $10 \mu \mathrm{m}, 1 \mathrm{~mm}$ and 2 $\mathrm{mm}$ are the scale of the measurements. 


\section{Chapter 4 Result and Discussion}

\subsection{Dilute Acid Pretreatment of Wheat Straw}

The $\mathrm{pH}$ of the dilute acid in contact with the pretreated fibers was considered as "Wash 0" step in Table 4.1. The $\mathrm{pH}$ of filtrates of pretreated wheat straw with the fiber size of $2 \mathrm{~mm}$ and less $(\leq 2$ $\mathrm{mm})$ and $6 \mathrm{~mm}$ and less $(\leq 6 \mathrm{~mm})$ is shown in Table 4.1 after the washing process.

Table 4.1. $p H$ of filtrates of pretreated wheat straw after mild acid pretreatment at $\left(\mathrm{T}: 123 \mp \mathbf{2}^{\circ} \mathrm{C}, \mathrm{H}_{2} \mathrm{SO}_{4}\right.$

$0.75 \% \mathrm{v} / v, t: 30 \mathrm{~min})$ for three sets of experiments.

\begin{tabular}{|c|c|c|}
\hline $\begin{array}{c}\text { Number of } \\
\text { Wash }\end{array}$ & $\begin{array}{c}\mathrm{pH} \text { of Filtrate for } \\
\leq 2 \mathrm{~mm}\end{array}$ & $\begin{array}{c}\mathrm{pH} \text { of Filtrate for } \\
\leq 6 \mathrm{~mm}\end{array}$ \\
\hline Wash 0 & $0.22 \pm 0.02$ & $0.26 \pm 0.03$ \\
\hline Wash 1 & $0.88 \pm 0.04$ & $0.96 \pm 0.03$ \\
\hline Wash 2 & $1.70 \pm 0.05$ & $1.79 \pm 0.02$ \\
\hline Wash 3 & $2.29 \pm 0.03$ & $2.34 \pm 0.02$ \\
\hline Wash 4 & $3.34 \pm 0.04$ & $3.41 \pm 0.05$ \\
\hline Wash 5 & $3.54 \pm 0.04$ & $3.59 \pm 0.03$ \\
\hline
\end{tabular}

After pretreating wheat straw fibers with dilute acid solution at $123 \mp 2^{\circ} \mathrm{C}$ for $30 \mathrm{~min}$, the filtrate showed a dark brown color as Wash 0 in Figure 4.1 for fiber size $\leq 2 \mathrm{~mm}$. 


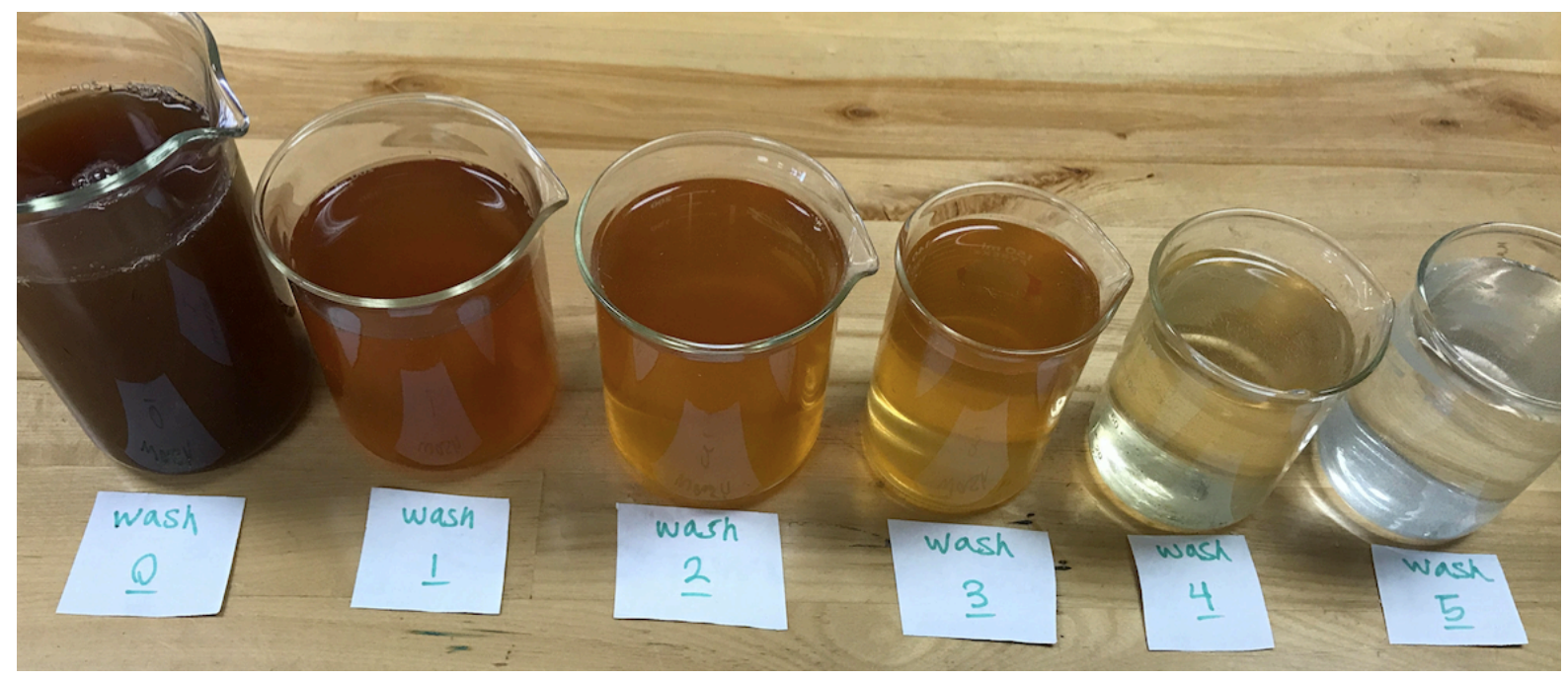

Figure 4.1. Colour of the filtrates after each step of washing pretreated wheat straw with the fiber of size of $\leq 2 \mathrm{~mm}$.

Four subsequent washes of the fibers resulted in a decolorizing of filtrates. The $\mathrm{pH}$ of filtrates resulting from subsequent washing of pretreated wheat straw of size $\leq 2 \mathrm{~mm}$ increased from $0.22 \pm 0.02$, right after the pretreatment to $3.54 \pm 0.04$ after 5 washings of the fibers in the distilled water. Similarly, the $\mathrm{pH}$ of the filtrate increased from $0.26 \pm 0.03$ (wash 0 ) to $3.59 \pm 0.03$ for wash 5 , in the case of fibers of size $\leq 6 \mathrm{~mm}$. For both sizes of fibers, the preteatment released acidic chemicals, as evidenced when comparing the $\mathrm{pH}$ values of Wash 0 with that of the dilute acid used for the pretreatment $(0.84 \pm 0.04)$. The $\mathrm{pH}$ of distilled water and dilute acid solution were $6.57 \pm 0.02$ and $0.84 \pm 0.04$ at 95 percent confidence, respectively.

These acidic chemicals are supported to be carboxylic acid compounds released from the delignification of wheat straw fibers by the action of dilute acid pretreatment. Al Jibouri (2012) reported that during the ozonolysis of wheat straw, some delignification products (lignin fragments) such as carboxylic acids are removed during the washing steps. A small amount of these acidic chemicals remained after Wash 5 since the $\mathrm{pH}$ did not reach the value of $6.57 \pm 0.02$ for distilled water.

The size distributions of dried fibers of pretreated wheat straw and wheat straw are shown in Figure 4.2 for the fiber size of $\leq 2 \mathrm{~mm}$. 


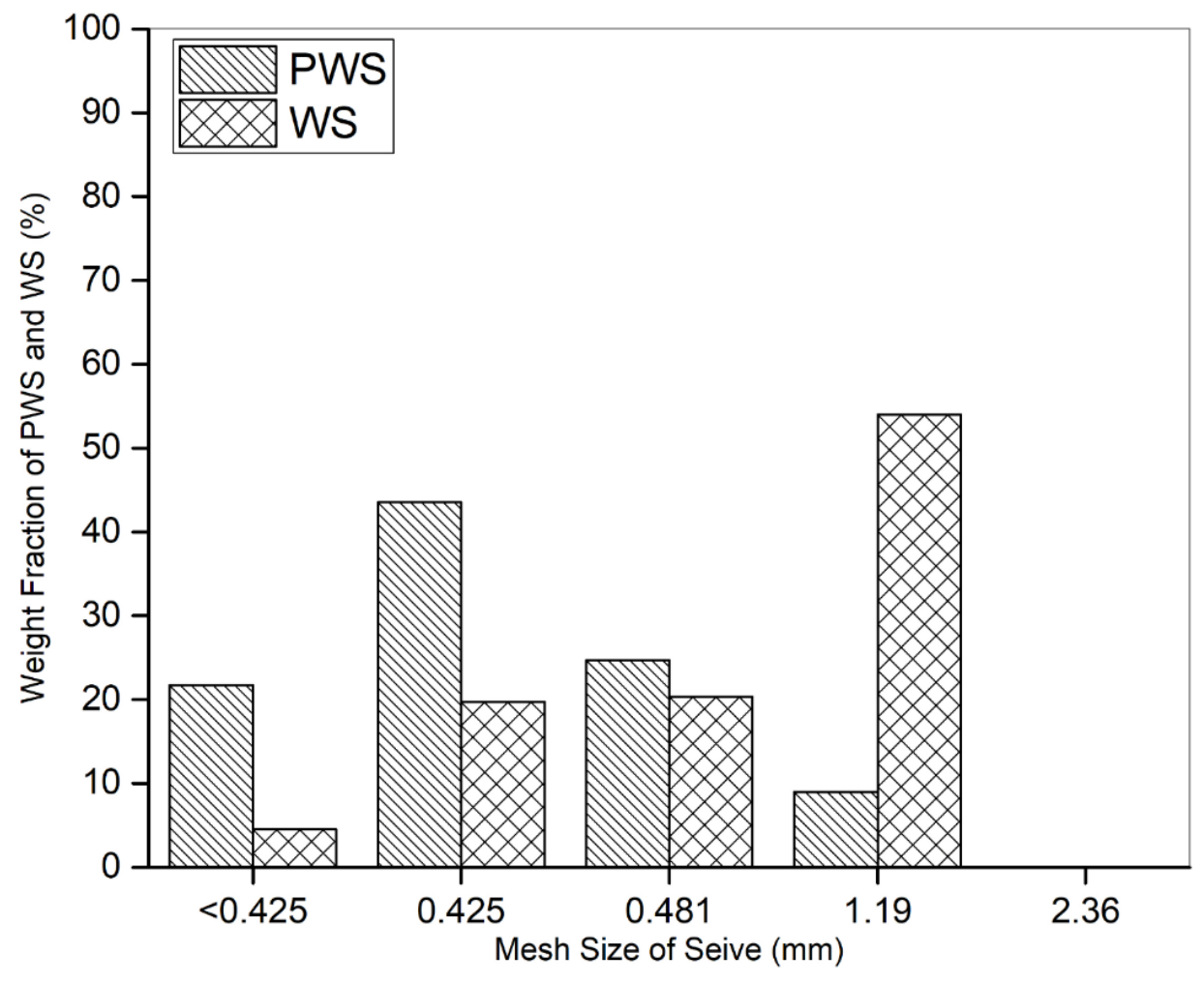

Figure 4.2. The size distribution of $\leq 2 \mathrm{~mm}$ fibers of dried pretreated wheat straw and the wheat straw.

The results show that $54 \%$ of WS remained on the sieve with 1.19 mesh size which is almost six times greater than the amount of PWS on the same sieve. It can also be seen that half of the PWS fibers were collected on smaller sieves. These results are in the agreements with Hou et al. (2016) who stated that higher mass fraction of PWS and pretreated corn stover were obtained for smaller particle size compared to raw wheat straw and raw corn stover. Furthermore, the reduction in fiber size will probably cause a reduction in the yield stress of a slurry made of these fibers.

The size distribution of fibers (dried pretreated wheat straw and wheat straw) is shown in Figure 4.3 for fiber size of $\leq 6 \mathrm{~mm}$. 


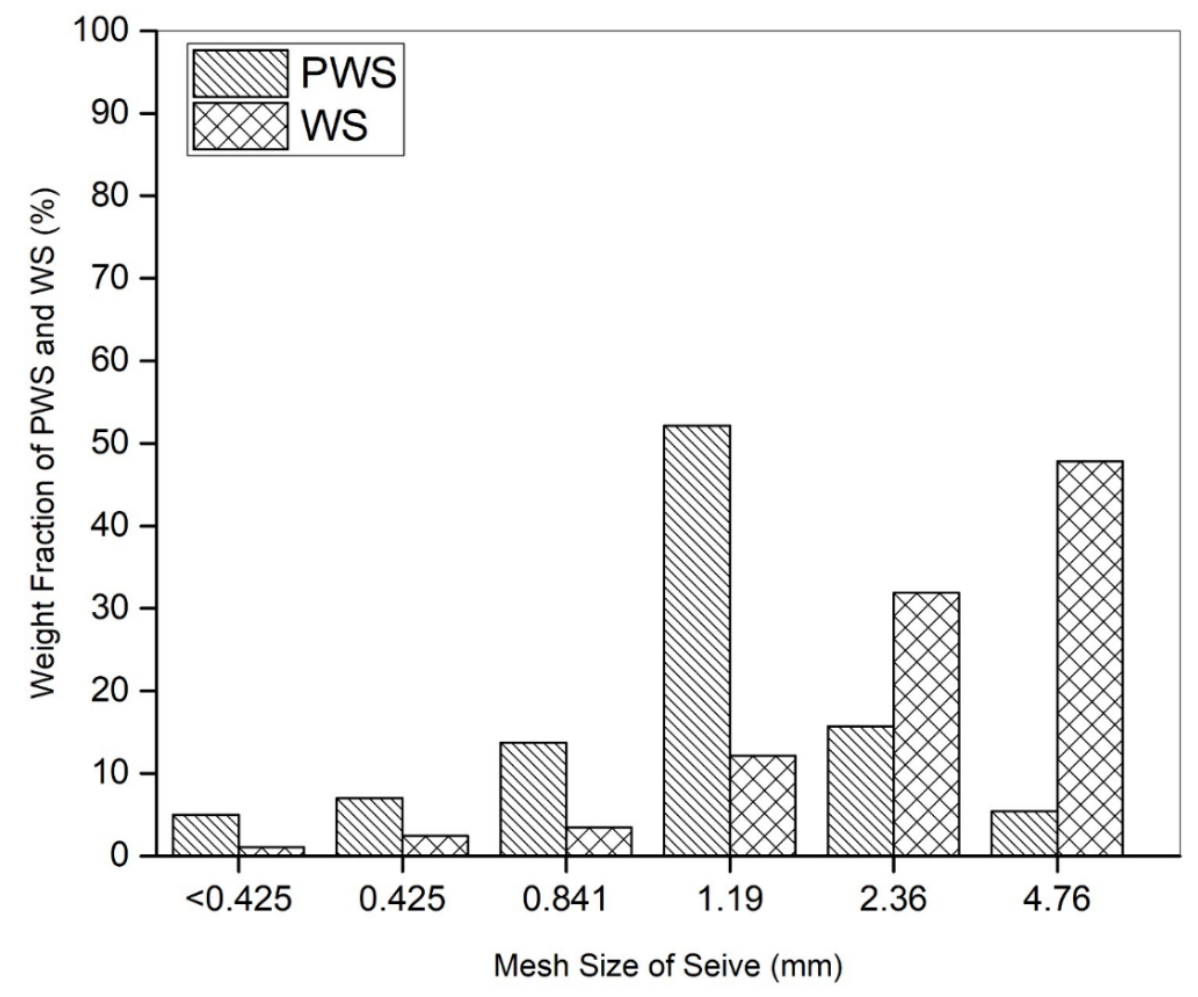

Figure4.3. The size distribution of $\leq 6 \mathrm{~mm}$ fibers of dried pretreated wheat straw and wheat straw.

Most of the weight of PWS was found to have fiber sizes less than $2.36 \mathrm{~mm}$ whereas WS fibers had mostly the sizes greater than $2.36 \mathrm{~mm}$. By comparing the results of Figure 4.2 with those of Figure 4.3, it seems that the weight fraction of WS that accumulated on the sieves has decreased from higher mesh size to the smaller mesh size for both cases. Also, PWS has accumulated on sieves with smaller mesh size compered to WS in both cases. Therefore, the dilute acidic pretreatment significantly reduced the fiber size which has a considerable impact on the yield stress of the slurry. PWS will probably show lower yield stress compared to WS since smaller fibers move more freely during the mixing process.

Scanning Electron Microscope (SEM) results for WS and PWS fibers, Figure 4.4, also supports the data reported for $\leq 2 \mathrm{~mm}$ in Figure 4.2. 


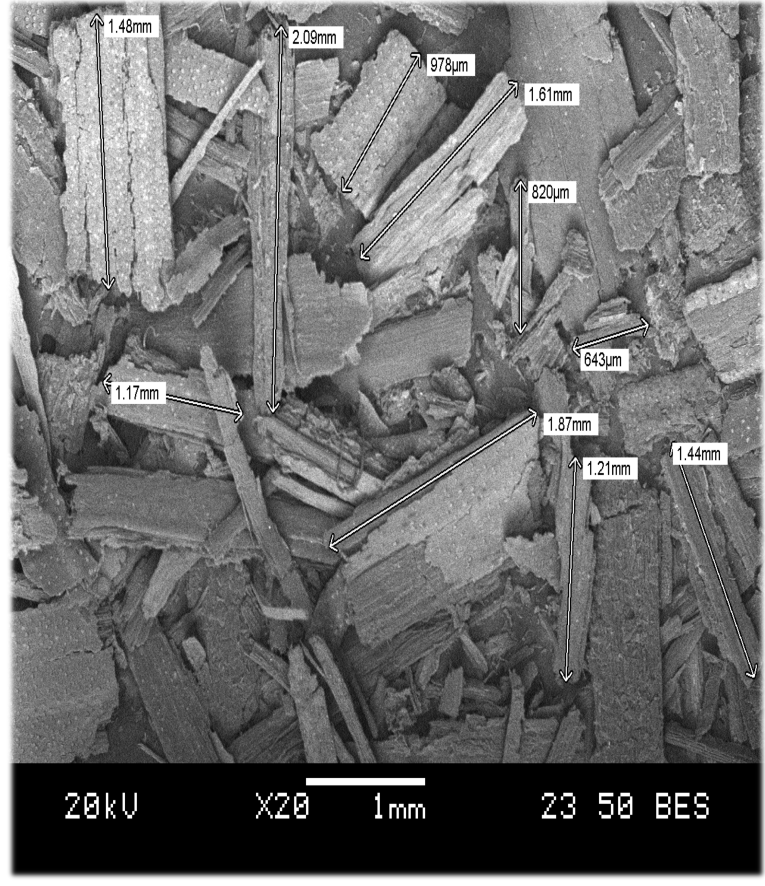

$W S$

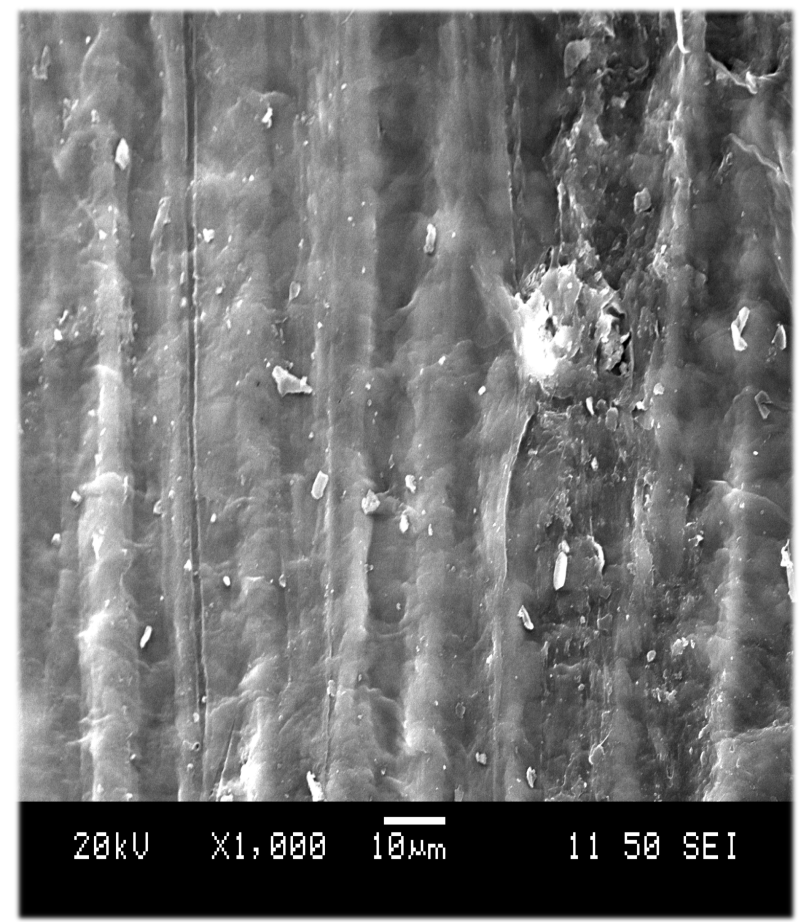

WS

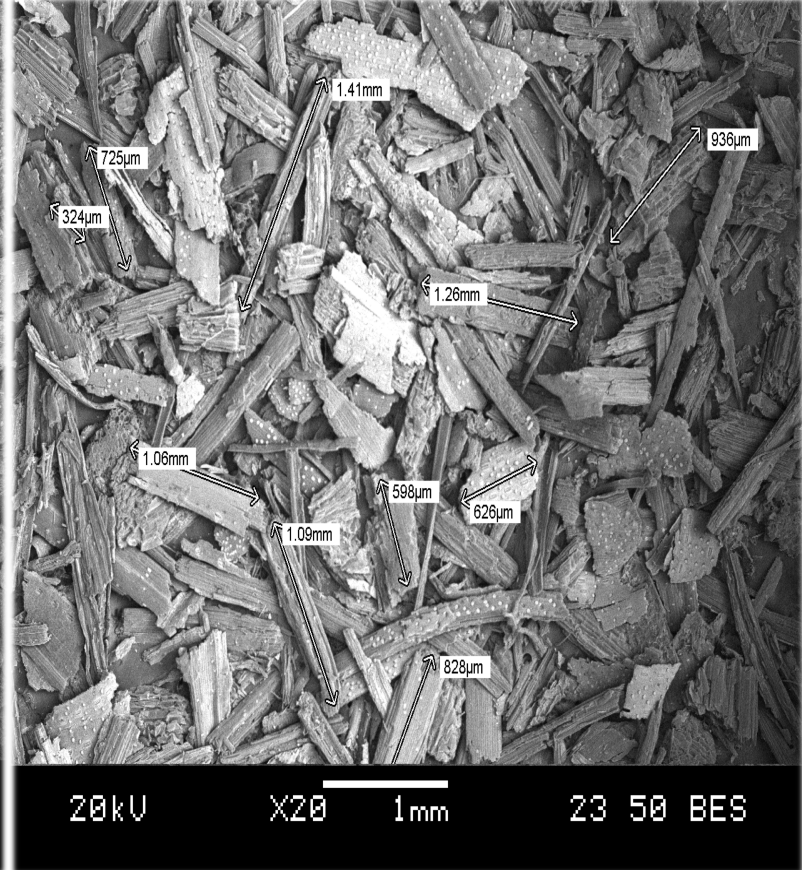

(a)

PWS

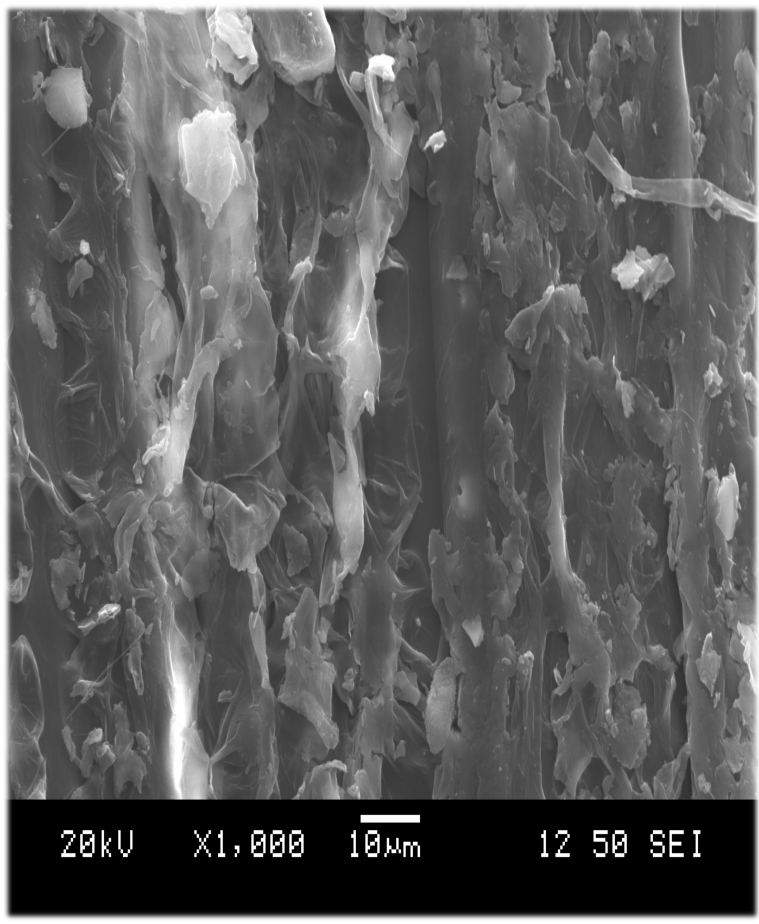

(b)

Figure 4.4. SEM micrographs of ( $\leq 2 \mathrm{~mm})$ WS and PWS (a) size distribution; and (b) surface of one fiber. 
These results show that most of WS fibers were less than $2 \mathrm{~mm}$ long (Figure 4.2 also shows that most of WS fibers were collected on $1.19 \mathrm{~mm}$ mesh size sieve) whereas most of PWS fibers were less than $1 \mathrm{~mm}$ long (Figure 4.2 also demonstrates that most of PWS fibers had the sizes from 0.425 to $1.19 \mathrm{~mm}$ ). Furthermore, the image of the surface of a single fiber (Figure $4.4 \mathrm{~b}$ ) shows that the fiber surface of WS had an orderly structure. However, for PWS the structure exploded by the dilute acid pretreatment and became loosened. In conclusion, dilute acidic preteatment process caused a reduction in fiber size which has a direct influence on yield stress. Since smaller fiber size can move more freely in the tank, the yield stress is expected to decrease. In addition, the preteatment process removed some parts of lignin and hemicellulose from the fibers which caused them to become more fragile. The fragile fibers can break into the smaller fibers during the mixing process resulting in a decrease in the slurry yield stress.

Figure $4.5(a, b)$ shows the surface morphology of wheat straw and pretreated wheat straw with $\leq 6 \mathrm{~mm}$ fiber size before and after pretreatment, respectively.

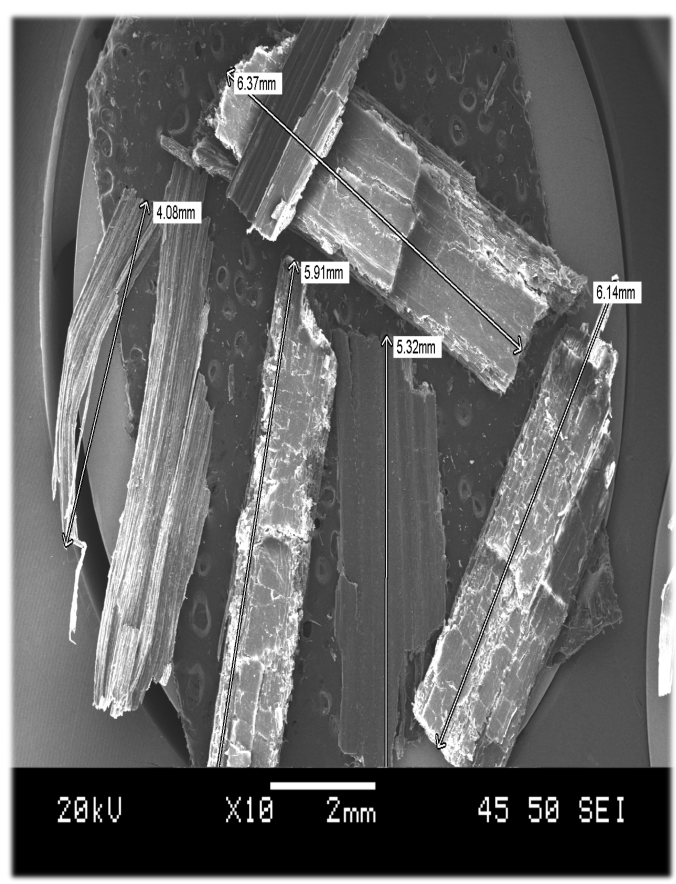

$W S$

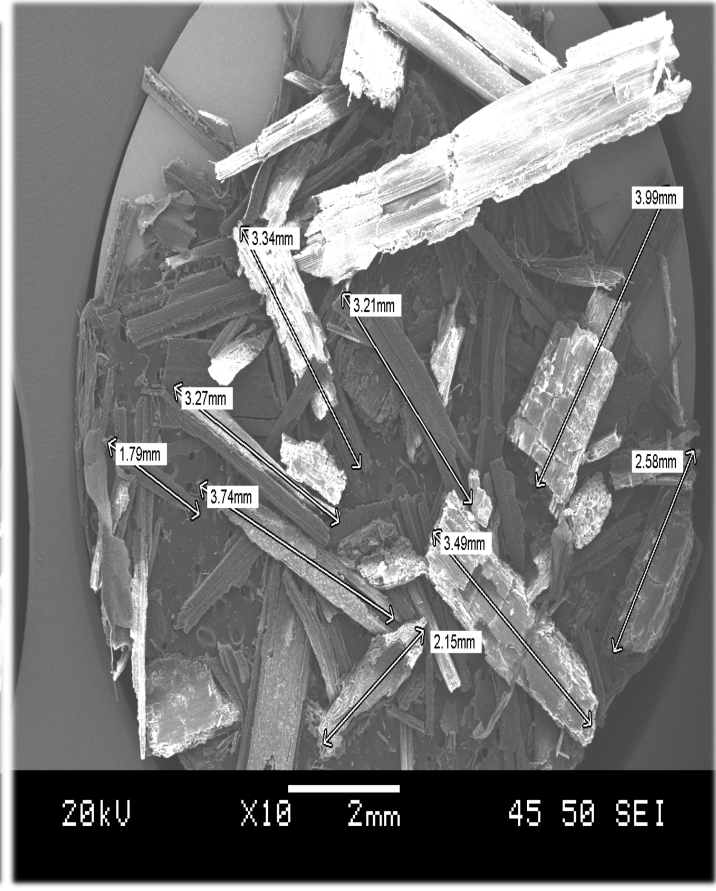

(a)

PWS 


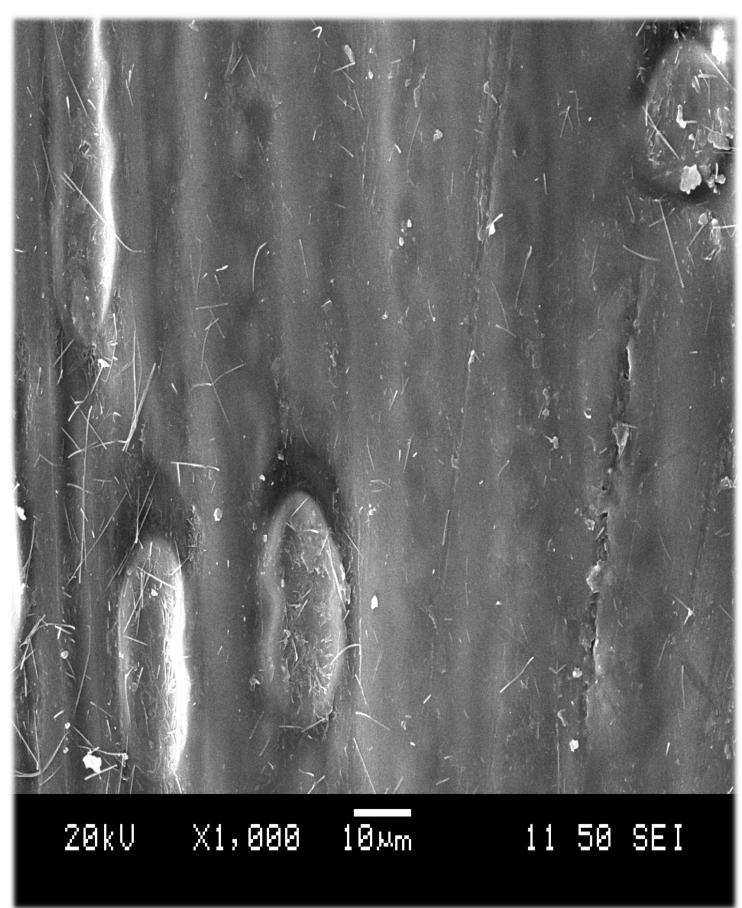

(b)

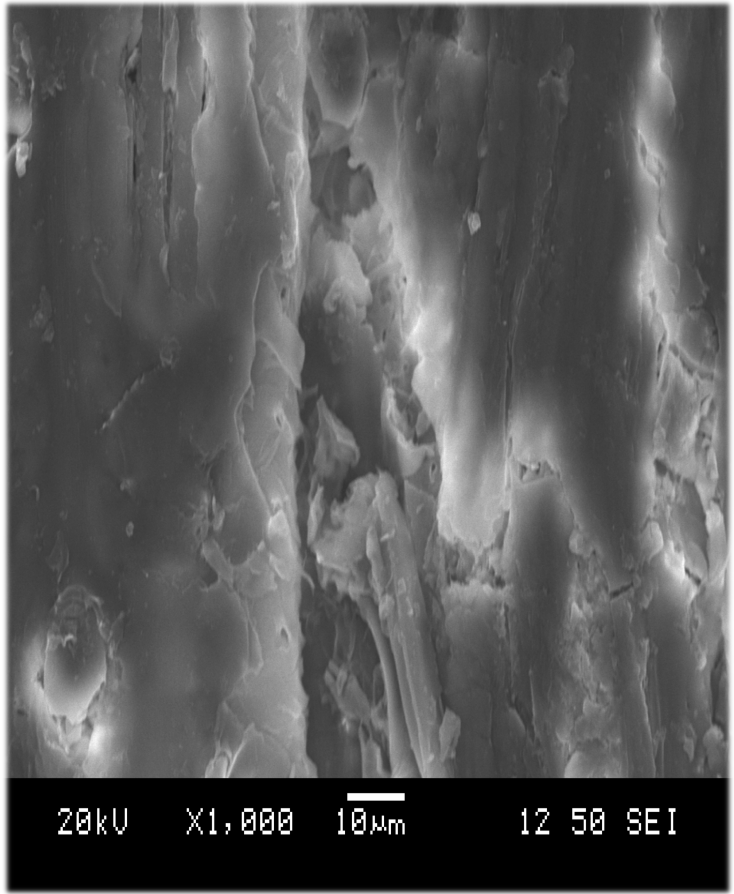

PWS

Figure 4.5. SEM micrographs of ( $\leq 6 \mathrm{~mm})$ WS and PWS (a)size distribution; and (b) surface of one fiber.

Most of fibers are less than $4 \mathrm{~mm}$ for PWS which confirms that the pretreatment decreased the size of PWS compared to that for WS. The surface structure of the wheat straw without pretreatment was tight and orderly, and the texture was relatively hard. In contrast, the surface of the pretreated wheat straw became exploded and loosened. These observations were similar to those described for Figure 4.4. Furthermore, the surface of WS fibers were hard for both fiber sizes. In fact, when WS fibers with $\leq 6 \mathrm{~mm}$ size was placed between index and thumb, they resisted crushing. However, PWS fibers were broken easily between two fingers.

In the next part, the experimental results that are relevant to the impeller torque, yield stress, and cavern formation in the mixing of PWS and WS slurries as a function of the impeller type, impeller speed, slurry concentration, and fiber size are presented and discussed. 


\subsection{Torque Measurement during Mixing of PWS}

A rotary torque meter (Staiger Mohilo, Germany) was used to measure the impeller torque as a function of the operating conditions. Each torque measurement was repeated three times and the standard deviation for the torque measurements was calculated using the equation below:

$$
\sigma=\sqrt{\frac{\sum_{i=1}^{N}\left(M_{i}-\bar{M}\right)^{2}}{K}}
$$

where $M_{i}$ is the torque measurement for sample $i$ and $\bar{M}$ is the mean value of the torque measurements and $K$ is the number of measurements.

Figure 4.6. depicts the torque versus the impeller speed in the mixing of PWS as a function of the slurry concentration for fibers $\leq 2 \mathrm{~mm}$. As it shown in this figure, there was an increase in the impeller torque by increasing the rpm for $6 \mathrm{wt} \%$ slurry. Similar trend was observed for $8 \mathrm{wt} \%$ and $10 \mathrm{wt} \%$. There were no torque measurements beyond $70 \mathrm{rpm}$ for $6 \mathrm{wt} \%$ since the cavern reached the surface of the tank. For $8 \mathrm{wt} \%$ and $10 \mathrm{wt} \%$ slurry concentrations, $40 \mathrm{rpm}$ and $60 \mathrm{rpm}$ were the lowest speed at which a cavern could be detected. The spread of the torque about the mean value was indicated by error bars at 95 percent confidence level. The errors were small $(< \pm 0.01$ N.m). 


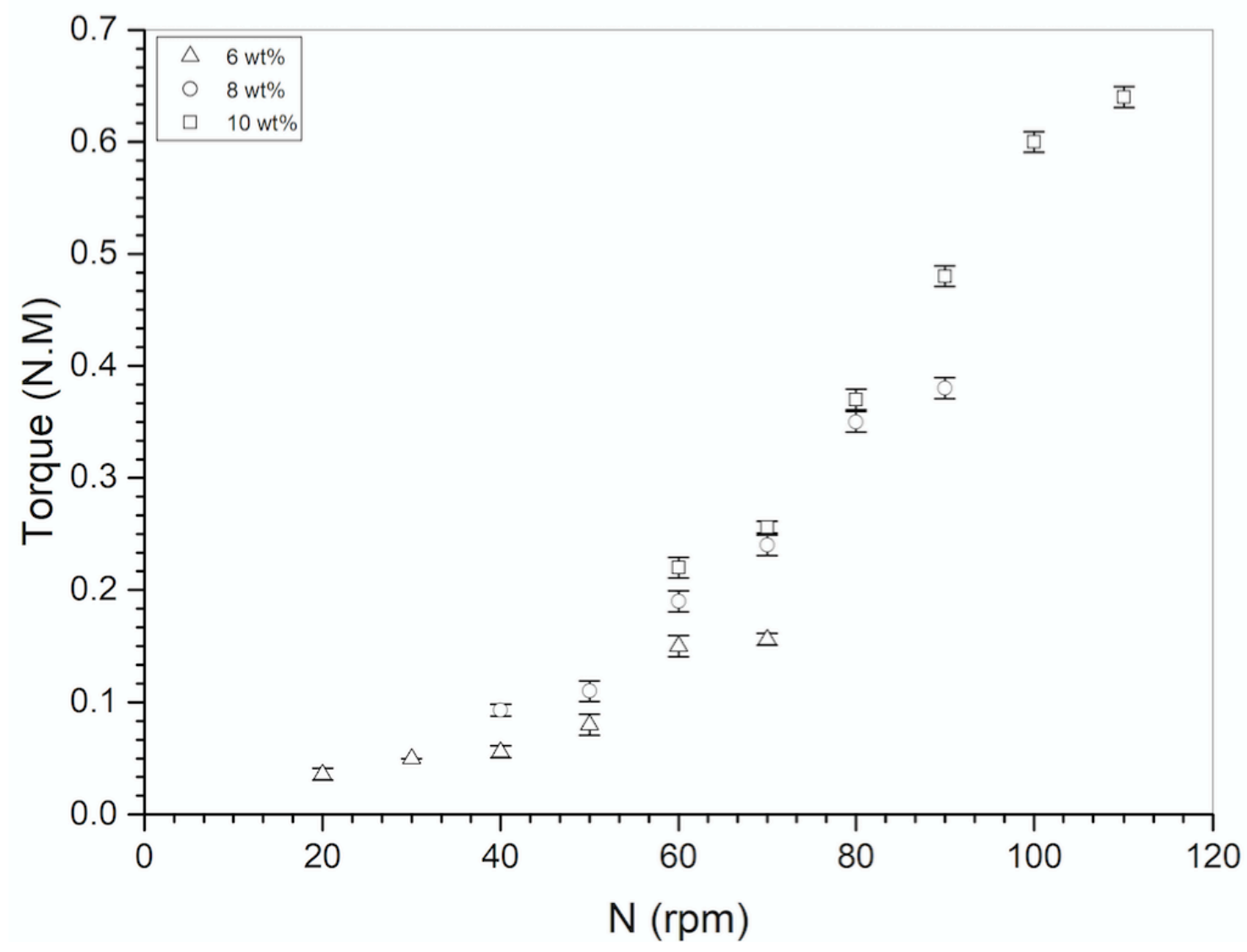

Figure 4.6. Torque versus impeller speed for 6, 8, and $10 \mathrm{wt} \%$ pretreated wheat straw slurries (fiber size $\leq 2 \mathrm{~mm})$ agitated by the A315 impeller; error bars were evaluated at 95\% confidence.

Increasing the slurry concentration for fiber size $\leq 2 \mathrm{~mm}$ resulted in an increase in impeller torque. Similar results were observed for slurry with fiber size $\leq 6 \mathrm{~mm}$. When fiber concentration increased, the strength of the slurry networks increased as well resulting in an increase in the impeller torque. In fact, by increasing the slurry concentration, the slurry yield stress increases due to an increase in fiber-fiber interactions and the strength of the fiber network. This enhances the required power for the agitation of slurries with the higher concentrations. Similar results were obtained for the other two impellers for both fiber sizes. 


\subsection{Comparison of torque vs. impeller speed for PWS and WS}

Figure 4.7 shows the impeller torque versus the impeller speed as a function of slurry concentration for pretreated wheat straw and wheat straw slurries of fibers $\leq 2 \mathrm{~mm}$.

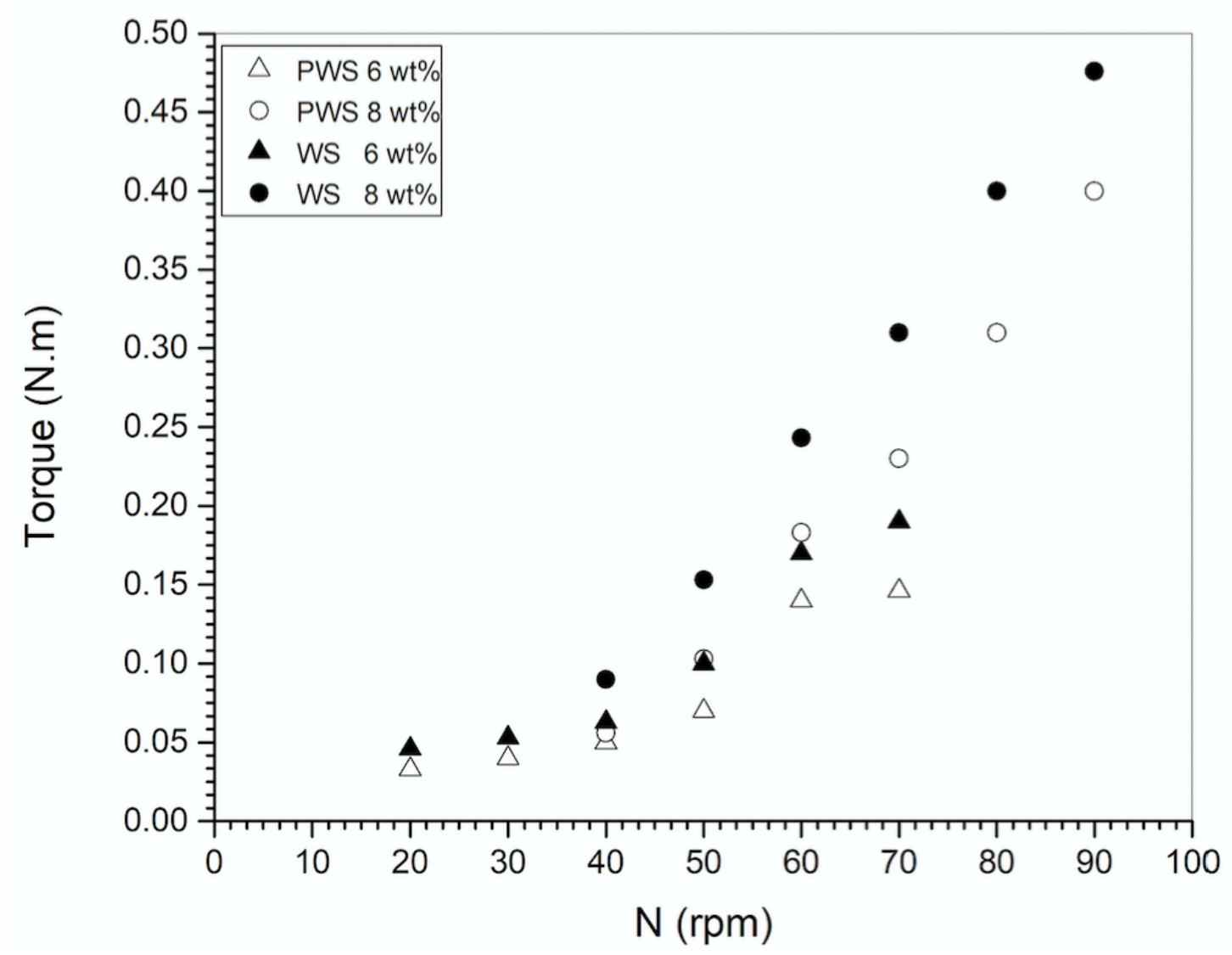

Figure 4.7. Torque versus impeller speed for pretreated wheat straw and wheat straw slurries at two concentrations (fiber size $\leq 2 \mathrm{~mm}$ ) agitated by the A100 impeller with error bar $<$

0.01 at $95 \%$ confidence.

The measured torques for PWS were lower than those for WS at both $6 \mathrm{wt} \%$ and 8 wt $\%$ concentrations. For instance, the measured torque for the agitation of PWS with 6 wt\% concentration at $60 \mathrm{rpm}$ was 0.14 N.m. However, the torque for WS at the same condition was 0.17 N.m. Similar to Figure 4.6, it can be seen that the torque measurements increased by increasing the rpm. In fact, as mentioned earlier, the pretreatment process reduces the fiber size and makes fibers more fragile due to extracting lignin and hemicellulose. Therefore, the mixing of PWS is easier and requires less torque compared to the agitation of WS. 
Figure 4.8. shows the impeller torque versus the impeller speed as a function of slurry concentration for pretreated wheat straw and wheat straw slurries for fibers $\leq 6 \mathrm{~mm}$.

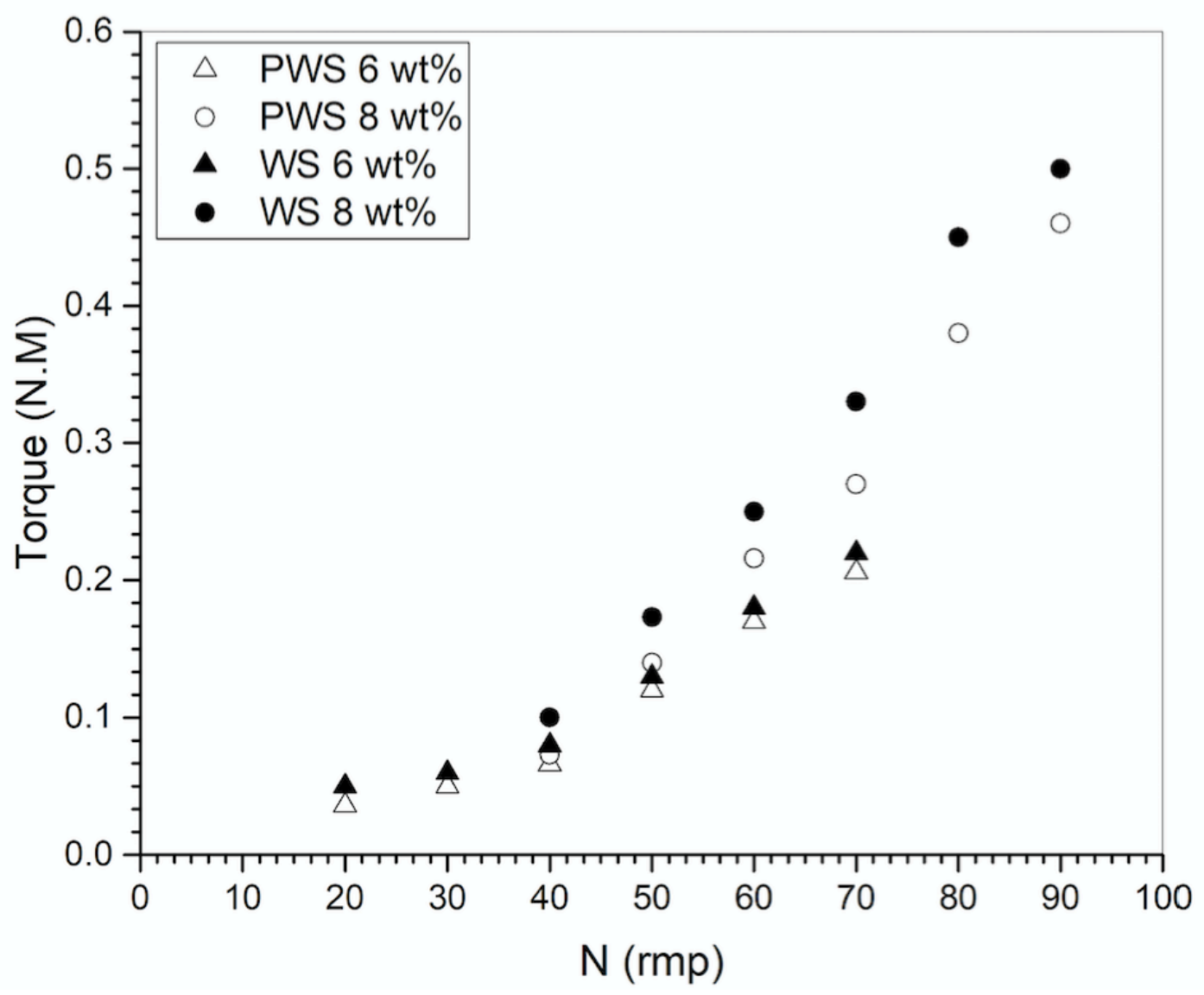

Figure 4.8. Torque versus impeller speed for 6 and $8 w t \%$ pretreated wheat straw and wheat straw slurries (fiber size $\leq 6 \mathrm{~mm}$ ) agitated by the A100 impeller with error bar $<0.02$ at $95 \%$ confidence.

The results presented in Figure 4.8 for the fiber sizes of $\leq 6 \mathrm{~mm}$ were similar to those depicted in Figure 4.7 for the fiber sizes of $\leq 2 \mathrm{~mm}$. For instance, the measured torque was 0.46 N.m for the agitation of PWS with $8 \mathrm{wt} \%$ concentration at $90 \mathrm{rpm}$ with the A100 impeller. However, for WS at the same conditions, the required torque increased to 0.5 N.m. Since the fiber size decreases after the pretreatment, the strength of the slurry network decreases as well due to a decrease in the fiber/fiber interactions. As a result, the yield stress of the slurry will be lower for PWS. By comparing the data depicted in Figures 4.7 and 4.8, it can be seen that the required torques for the mixing of PWS and WS slurries with the fiber sizes of $\leq 2 \mathrm{~mm}$ were lower than those for PWS and WS slurries with the fiber sizes of $\leq 6 \mathrm{~mm}$ for both $6 \mathrm{wt} \%$ and $8 \mathrm{wt} \%$ concentrations at different 
rpms. For example, the measured torque for the mixing of $8 \mathrm{wt} \%$ of PWS slurry with the fiber sizes of $\leq 2 \mathrm{~mm}$ at $50 \mathrm{rpm}$ was 0.10 N.m while the required torque for the agitation of PWS slurry with the fiber sizes of $\leq 6 \mathrm{~mm}$ at the same operating conditions was 0.14 N.m. This result shows that more torque is required for the mixing of slurries with the larger sizes due to an increase in fiber interactions in slurries with the larger fibers. Furthermore, one can see that the torque difference between PWS and WS at the same mixing conditions for the fiber sizes of $\leq 2 \mathrm{~mm}$ was larger than that for the fiber sizes of $\leq 6 \mathrm{~mm}$. This may show that the pretreatment process was more effective for the smaller fiber sizes compared to the larger fiber sizes.

\subsection{Cavern Dimensions for PWS and WS Slurries}

In this section, the effects of the slurry concentration, impeller speed, and fiber size on the cavern dimensions for PWS and WS slurries are presented and discussed.

\subsubsection{Effect of PWS Concentration on the Cavern Dimensions}

Figure 4.9 shows the effect of the slurry concentration on the cavern dimensions when pretreated wheat straw slurries of $\leq 2 \mathrm{~mm}$ fiber size agitated with the A315 impeller at $70 \mathrm{rpm}$. 


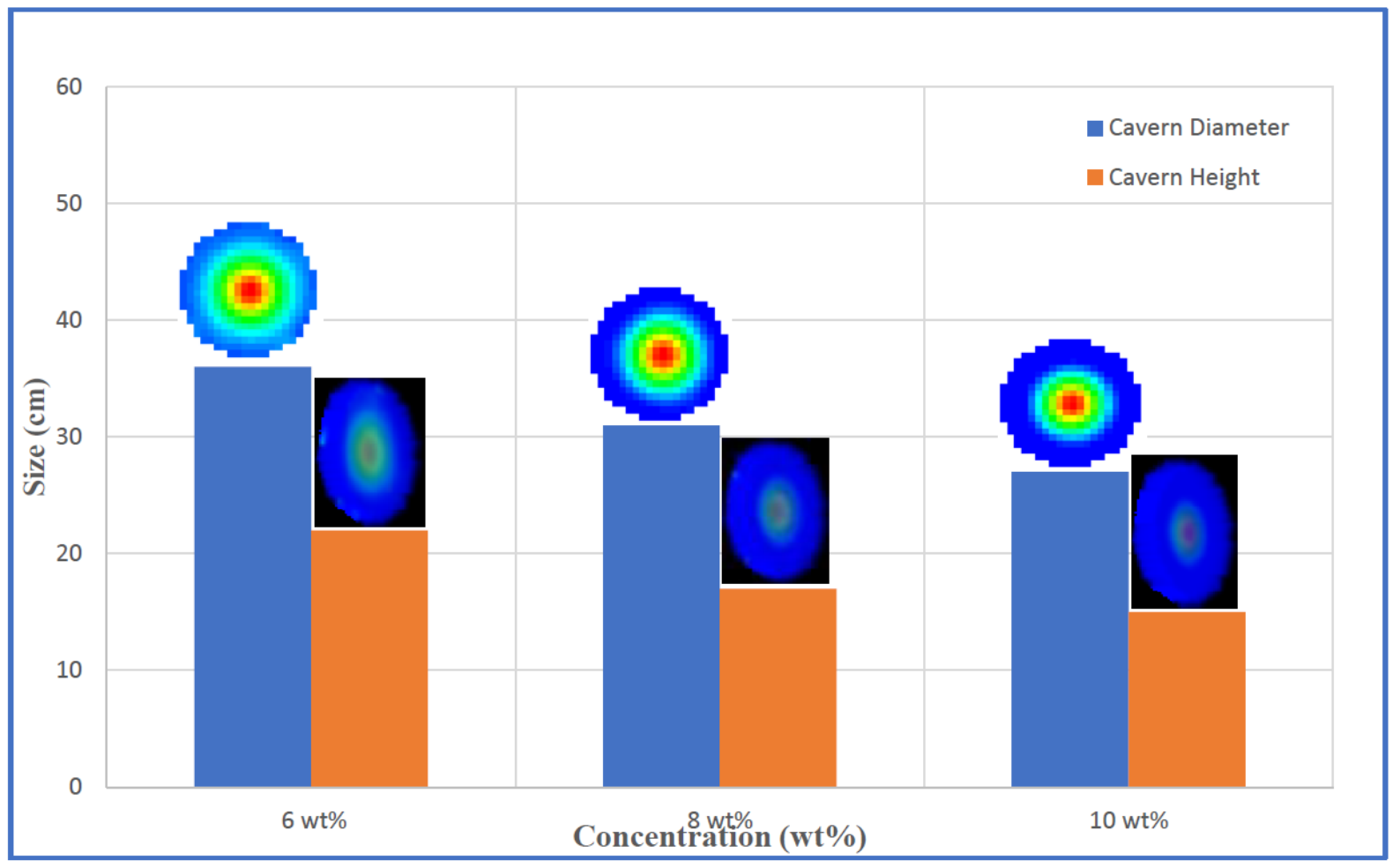

Figure 4.9. Effect of the pretreated wheat straw mass concentration on the diameter (blue) and height (orange) of the cavern formed around the A315 impeller in the agitation of pretreated wheat straw slurries with the fiber size of $\leq 2 \mathrm{~mm}$ at $70 \mathrm{rpm}$.

The cavern diameters of $27 \mathrm{~cm}, 31 \mathrm{~cm}$, and $36 \mathrm{~cm}$ were obtained for slurry concentrations of 10 $\mathrm{wt} \%, 8 \mathrm{wt} \%$, and $6 \mathrm{wt} \%$, respectively. The corresponding cavern heights were found to be $15 \mathrm{~cm}$, $17 \mathrm{~cm}$, and $22 \mathrm{~cm}$.

Similar results were observed for the A200 and A100 impellers at the same condition as shown in Figures 4.10 and 4.11.

Figure 4.10 shows the effect of the slurry concentration on the cavern dimensions when pretreated wheat straw slurries of $\leq 2 \mathrm{~mm}$ fiber size agitated with the A200 impeller at $70 \mathrm{rpm}$. 


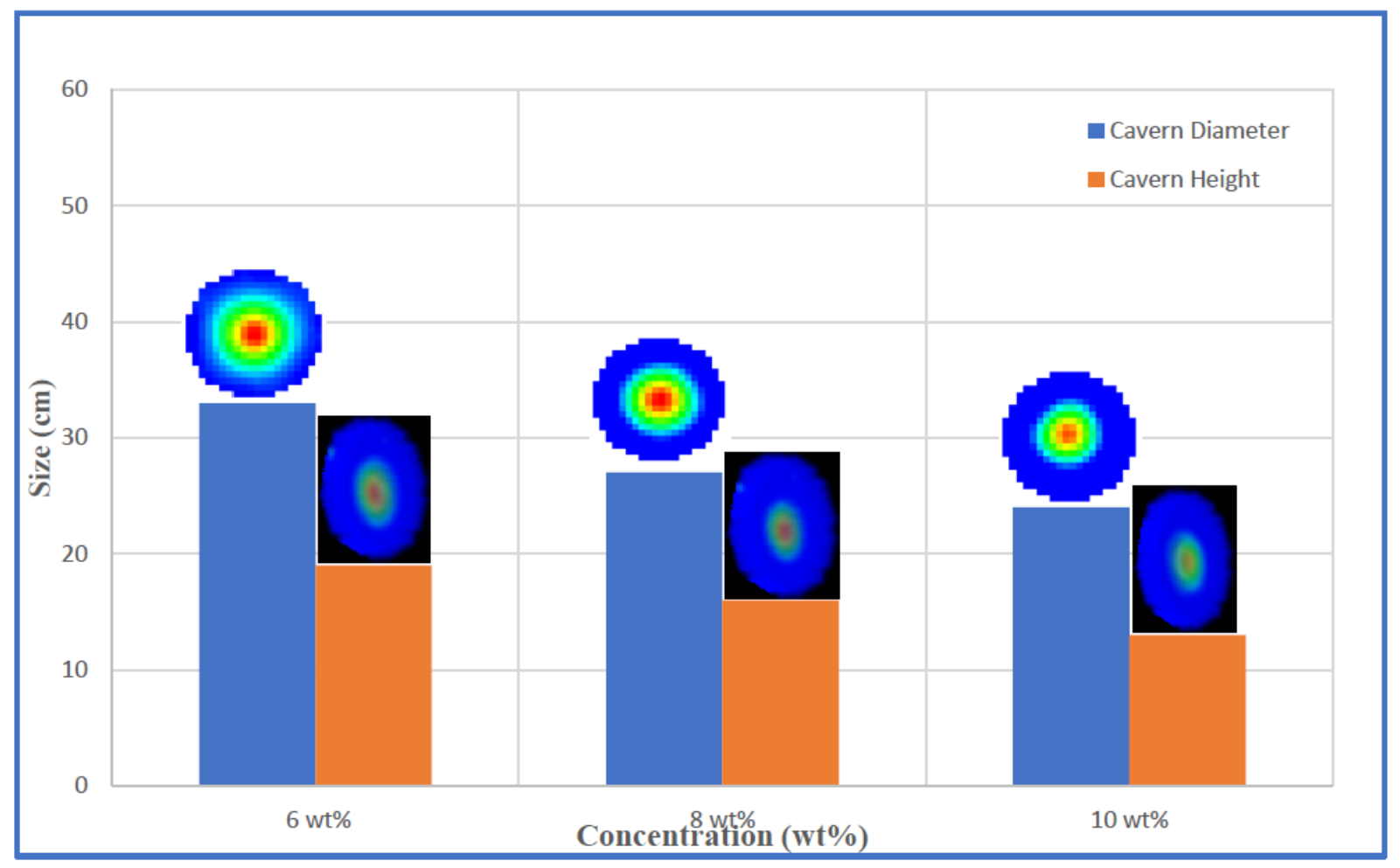

Figure 4.10. Effect of the pretreated wheat straw mass concentration on the diameter (blue) and height (orange) of the cavern formed around the A200 impeller in the agitation of pretreated wheat straw slurries with the fiber size of $\leq 2 \mathrm{~mm}$ at $70 \mathrm{rpm}$.

The cavern diameters of $24 \mathrm{~cm}, 27 \mathrm{~cm}$ and $33 \mathrm{~cm}$ were obtained with the A200 impeller for the slurry concentrations of $10 \mathrm{wt} \%, 8 \mathrm{wt} \%$, and $6 \mathrm{wt} \%$, respectively. The corresponding cavern heights were found to be $13 \mathrm{~cm}, 16 \mathrm{~cm}$, and $19 \mathrm{~cm}$.

Figure 4.11 shows the effect of the slurry concentration on the cavern dimensions when pretreated wheat straw slurries of $\leq 2 \mathrm{~mm}$ fiber size agitated with the A100 impeller at $70 \mathrm{rpm}$. 


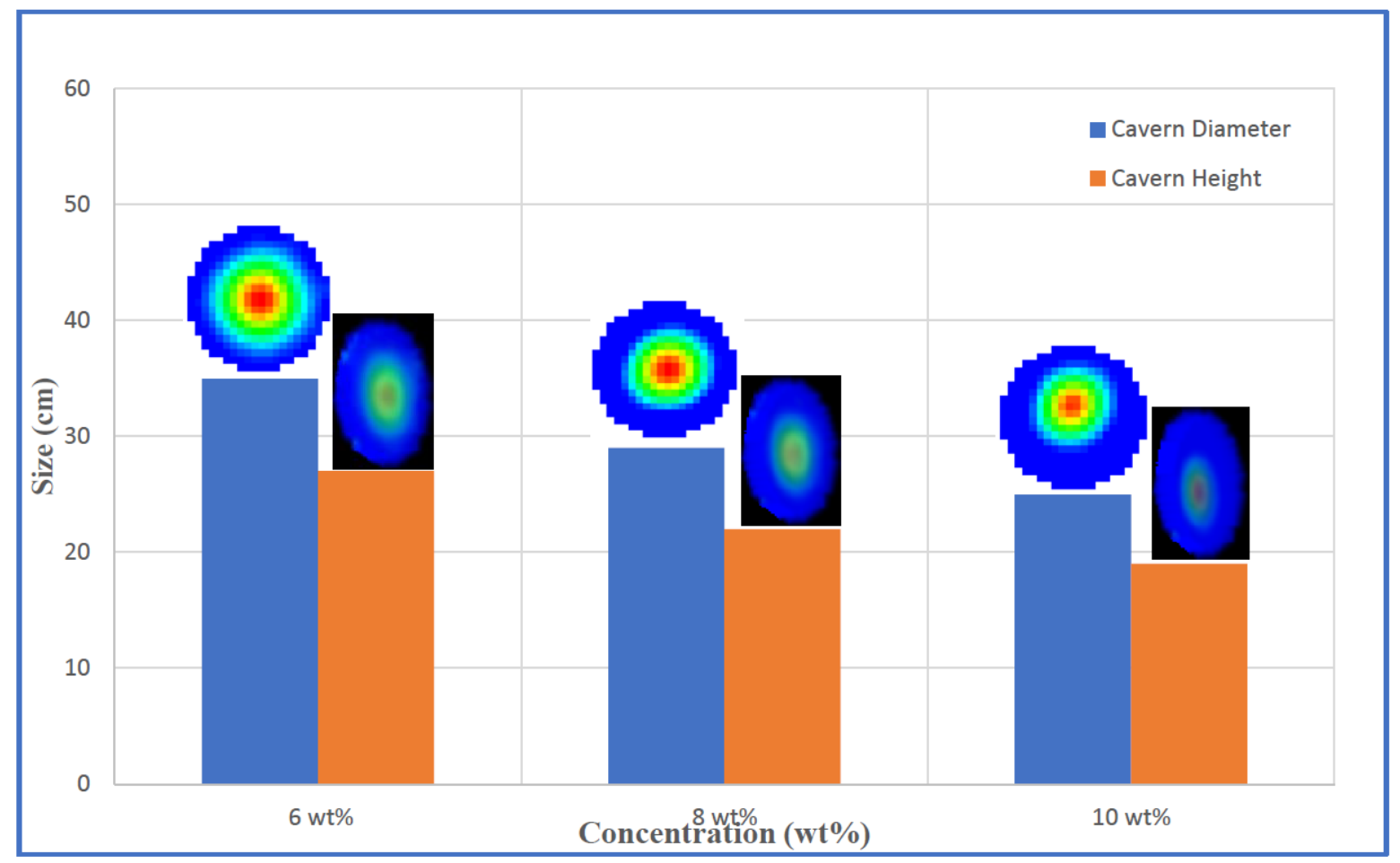

Figure 4.11. Effect of the pretreated wheat straw mass concentration on the diameter (blue) and height (orange) of the cavern formed around the A100 impeller in the agitation of pretreated wheat straw slurries with the fiber size of $\leq 2 \mathrm{~mm}$ at $70 \mathrm{rpm}$.

For the A100 impeller, the cavern diameters of $25 \mathrm{~cm}, 29 \mathrm{~cm}$, and $35 \mathrm{~cm}$ were obtained for the slurry concentrations of $10 \mathrm{wt} \%, 8 \mathrm{wt} \%$, and $6 \mathrm{wt} \%$, respectively. The corresponding cavern heights were found to be $19 \mathrm{~cm}, 22 \mathrm{~cm}$, and $27 \mathrm{~cm}$.

As a result, there is an inverse relationship between $D c$ (or $H c$ ) and PWS concentration. A reduction in the slurry concentration resulted in an increase in $D c$ (or $H c$ ) at a fixed impeller speed. In fact, the yield stress of these slurries decreases with a decrease in the fiber concentration. This leads to the formation of the larger caverns in the mixing of slurries with the lower fiber concentrations. This finding is in agreement with those reported in the literature. For instance, Movafagh et al. (2016) and Pakzad et al. (2008) reported that the cavern diameter increases with a reduction in the yield stress of the agitated fluids. The presence of the yield stress leads to the formation of stagnant regions outside the cavern (blue zone) in which the shear stress falls below 
the slurry yield stress.

\subsubsection{Effect of Impeller Speed on the Cavern Diameter of PWS}

Figure 4.12 depicts the effect of the impeller speed, when it was varied from $50 \mathrm{rpm}$ to $90 \mathrm{rpm}$, on the diameter and height of the cavern for $8 \mathrm{wt} \%$ pretreated wheat straw slurry (with fiber sizes of $\leq 6 \mathrm{~mm}$ ) agitated by the A100 impeller. These tomograms clearly show that the diameter of the cavern increased from $21 \mathrm{~cm}$ to $31 \mathrm{~cm}$ when the impeller speed increased from 50 to $90 \mathrm{rpm}$. The height of the cavern also increased from 15 to $25 \mathrm{~cm}$ when the impeller speed increased from 50 to $90 \mathrm{rpm}$.

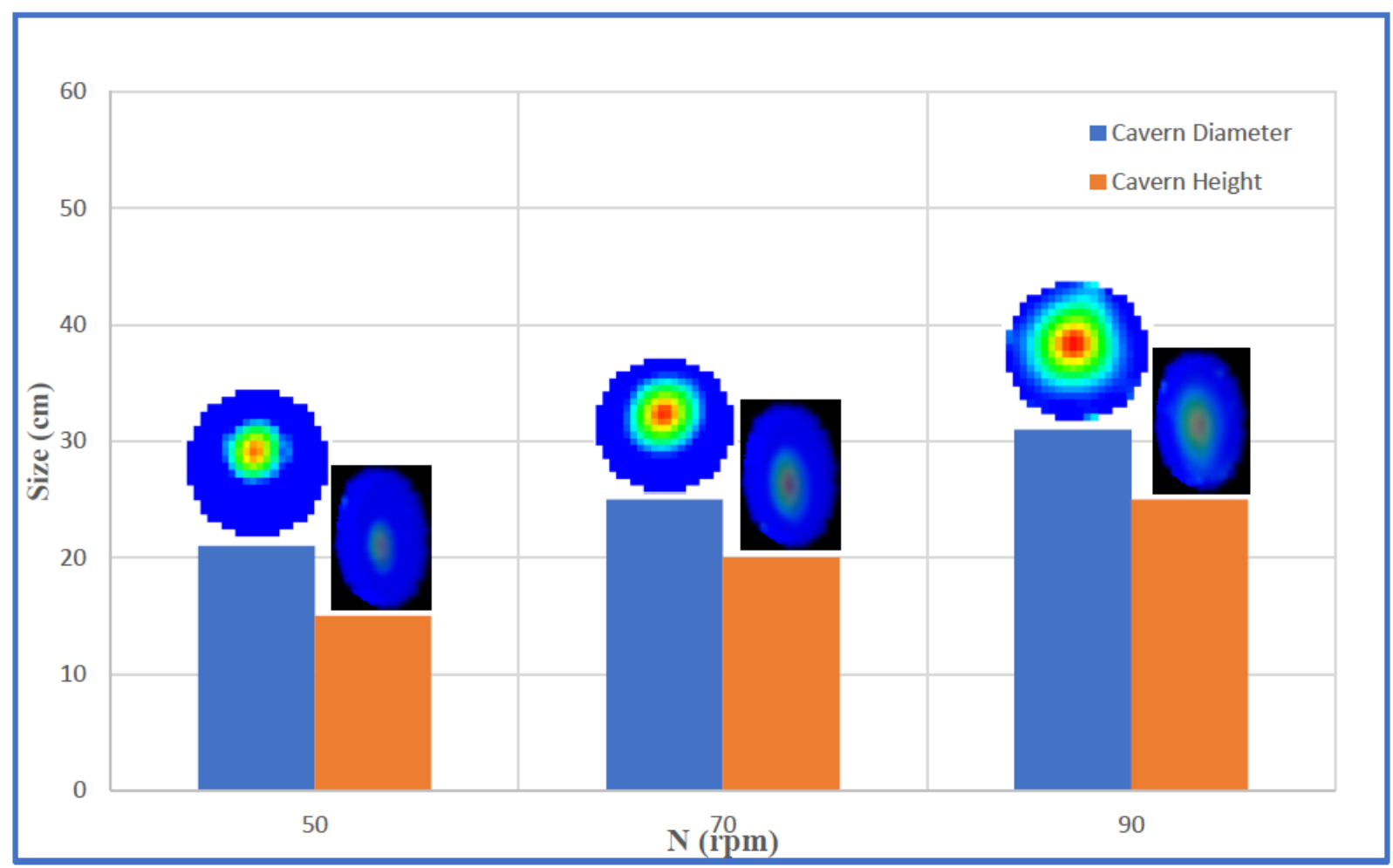

Figure 4.12. Effect of the impeller speed on the diameter (blue)and (b) height (orange) of the cavern formed around the A100 impeller in the agitation of $8 \mathrm{wt} \%$ pretreated wheat straw slurry with the fiber size of $\leq 6 \mathrm{~mm}$. 
Similar results were observed for the A315 and A200 impellers at the same condition as illustrated in Figures 4.13 and 4.14.

Figure 4.13 depicts the effect of the impeller speed, when it was varied from $50 \mathrm{rpm}$ to $90 \mathrm{rpm}$, on the diameter and height of the cavern for $8 \mathrm{wt} \%$ pretreated wheat straw slurry (with fiber sizes of $\leq 6 \mathrm{~mm}$ ) agitated by the A315 impeller.

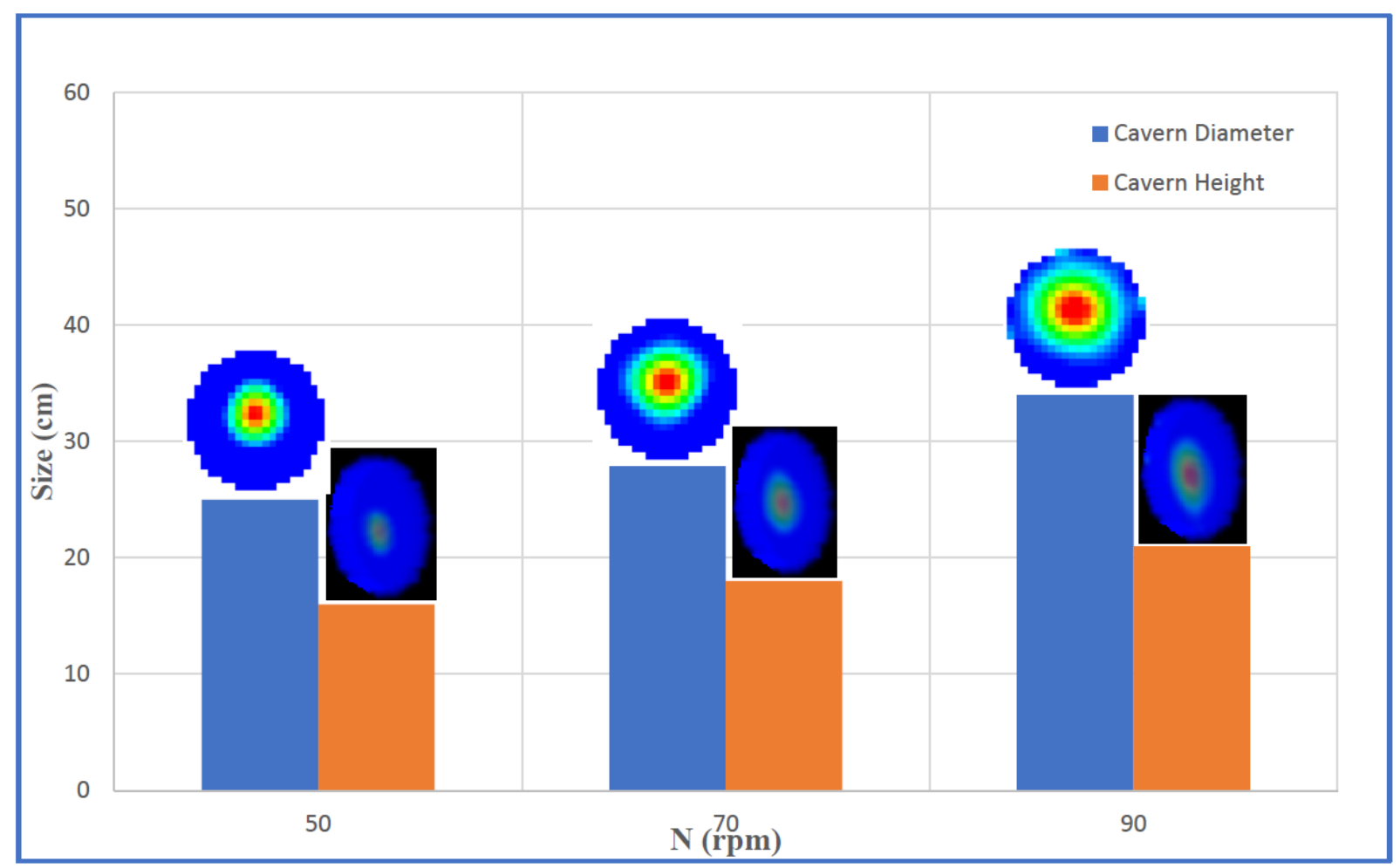

Figure 4.13. Effect of the impeller speed on the diameter (blue)and (b) height (orange) of the cavern formed around the A315 impeller in the agitation of $8 \mathrm{wt} \%$ pretreated wheat straw slurry with the fiber size of $\leq 6 \mathrm{~mm}$.

The diameter of the cavern formed around the A315 impeller increased from $25 \mathrm{~cm}$ to $34 \mathrm{~cm}$ when the impeller speed increased from 50 to $90 \mathrm{rpm}$ (Figure 4.13). Also, the height of the cavern increased from 16 to $21 \mathrm{~cm}$ when the impeller speed increased from 50 to $90 \mathrm{rpm}$.

Figure 4.14 depicts the effect of the impeller speed, when it was varied from $50 \mathrm{rpm}$ to $90 \mathrm{rpm}$, on 
the diameter and height of the cavern for $8 \mathrm{wt} \%$ pretreated wheat straw slurry (with fiber sizes of $\leq 6 \mathrm{~mm}$ ) agitated by the A200impeller.

For the A200 impeller, the diameter of the cavern increased from $17 \mathrm{~cm}$ to $27 \mathrm{~cm}$ when the impeller speed increased from 50 to $90 \mathrm{rpm}$ (Figure 4.14). Also, the height of the cavern increased from 10 to $16 \mathrm{~cm}$ when the impeller speed increased from 50 to $90 \mathrm{rpm}$.

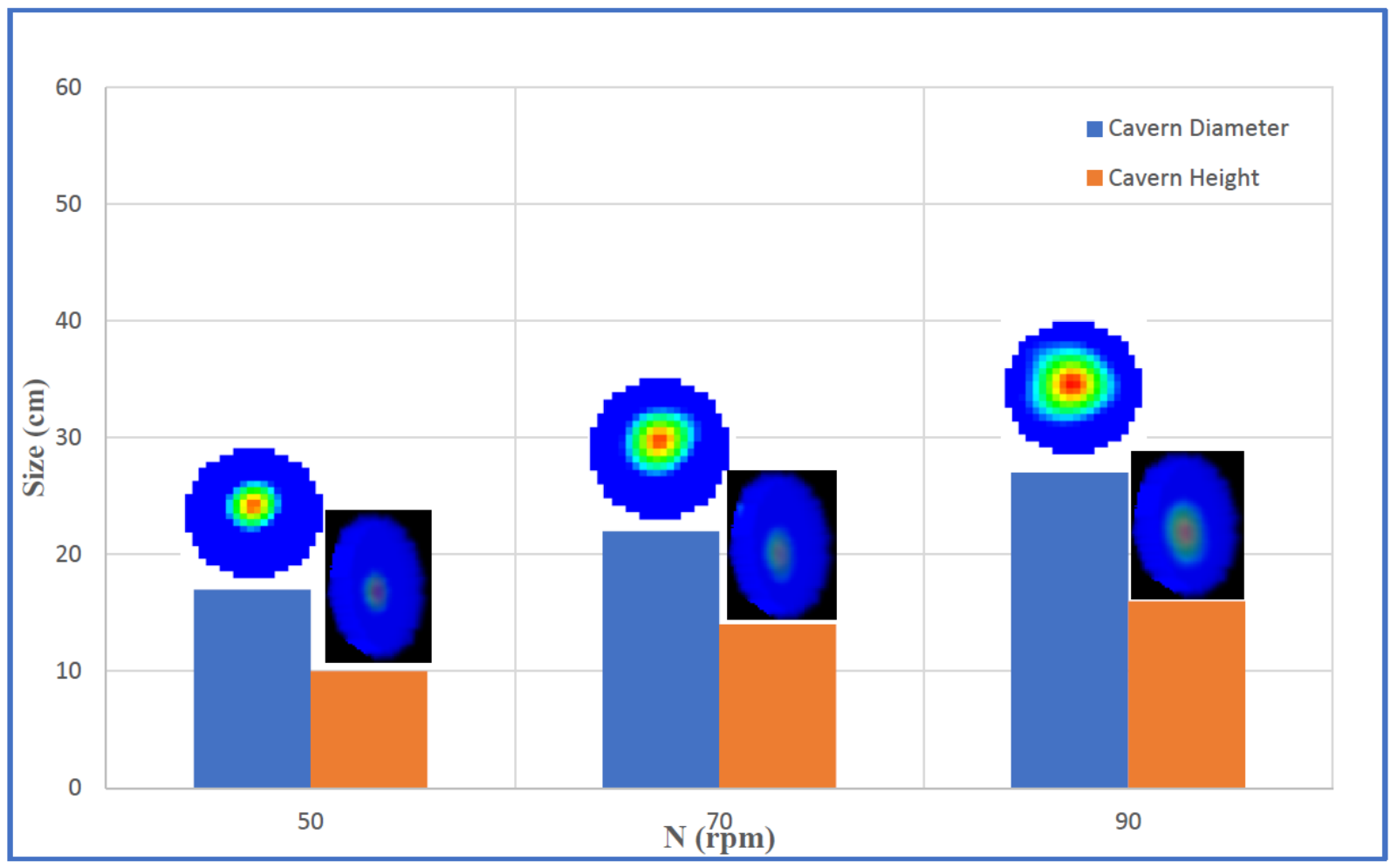

Figure 4.14. Effect of the impeller speed on the diameter (blue)and (b) height (orange) of the cavern formed around the A200 impeller in the agitation of $8 \mathrm{wt} \%$ pretreated wheat straw slurry with the fiber size of $\leq 6 \mathrm{~mm}$.

As can be seen in Figure 4.12, 4.13 and 4.14, the boundary of the cavern moved towards the tank wall and the volume of the stagnant region (dark blue) was reduced when the impeller speed increased. A similar trend was also observed for the other concentrations and rotational speeds. This finding is in agreement with those reported in the literature. For instance, Movafagh et al. (2016) reported that the diameter of the cavern increased when the impeller speed increased for all studied cases. 


\subsubsection{Effect of the Fiber Size on the Cavern Size}

When the fiber size increases, the strength of the fiber network increases since the fiber/fiber interactions enhances, and fibers lose the ability to move freely in the mixing tank. As shown in Figure 4.15, the cavern diameter and height measured for the fiber size of $\leq 6 \mathrm{~mm}$ were smaller than those for the fiber size of $\leq 2 \mathrm{~mm}$ at a fixed rotational speed and concentration due to higher strength of fiber network.

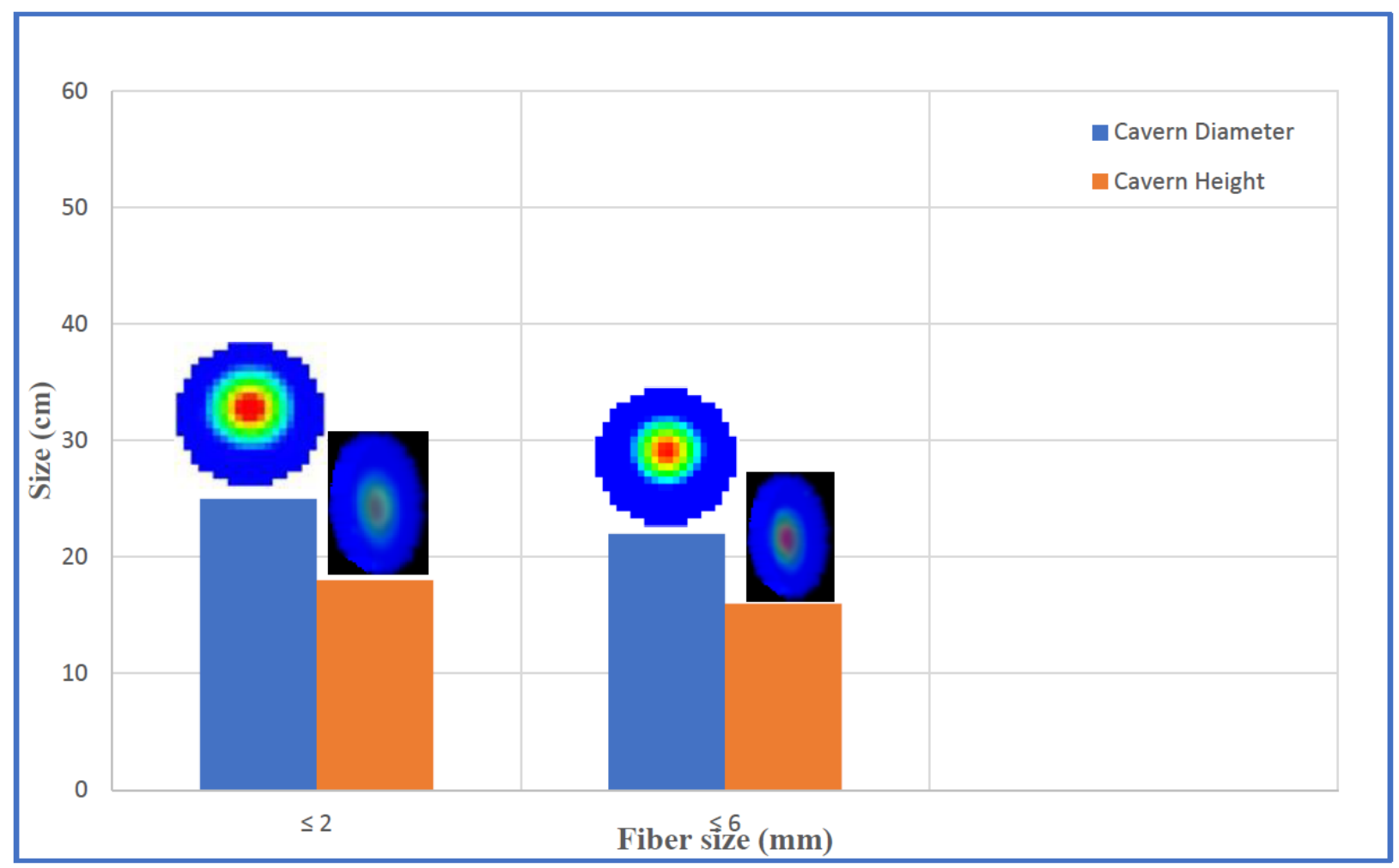

Figure 4.15. Effect of the fiber size on the diameter of the cavern created around the A100 impeller in the mixing of $10 \mathrm{wt} \%$ pretreated wheat straw slurry with fiber sizes of $\leq 2 \mathrm{~mm}$ and $\leq 6 \mathrm{~mm}$ at $60 \mathrm{rpm}$.

The diameter of the cavern decreased from $25 \mathrm{~cm}$ to $22 \mathrm{~cm}$ when the fiber size increased from $\leq$ $2 \mathrm{~mm}$ to $\leq 6 \mathrm{~mm}$. The height of the cavern also decreased from $18 \mathrm{~cm}$ to 16 . Similar results were observed for the A315 and A200 impellers in the mixing of $10 \mathrm{wt} \% \mathrm{PWS}$ at $60 \mathrm{rpm}$ (see Figures 4.16 and 4.17). 
As shown in Figure 4.16, the cavern diameter and height measured for the $10 \mathrm{wt} \% \mathrm{PWS}$ with fiber size of $\leq 6 \mathrm{~mm}$ agitated by A200 at $60 \mathrm{rpm}$ were smaller than those for the fiber size of $\leq 2 \mathrm{~mm}$ at a fixed rotational speed and concentration due to higher strength of fiber network.

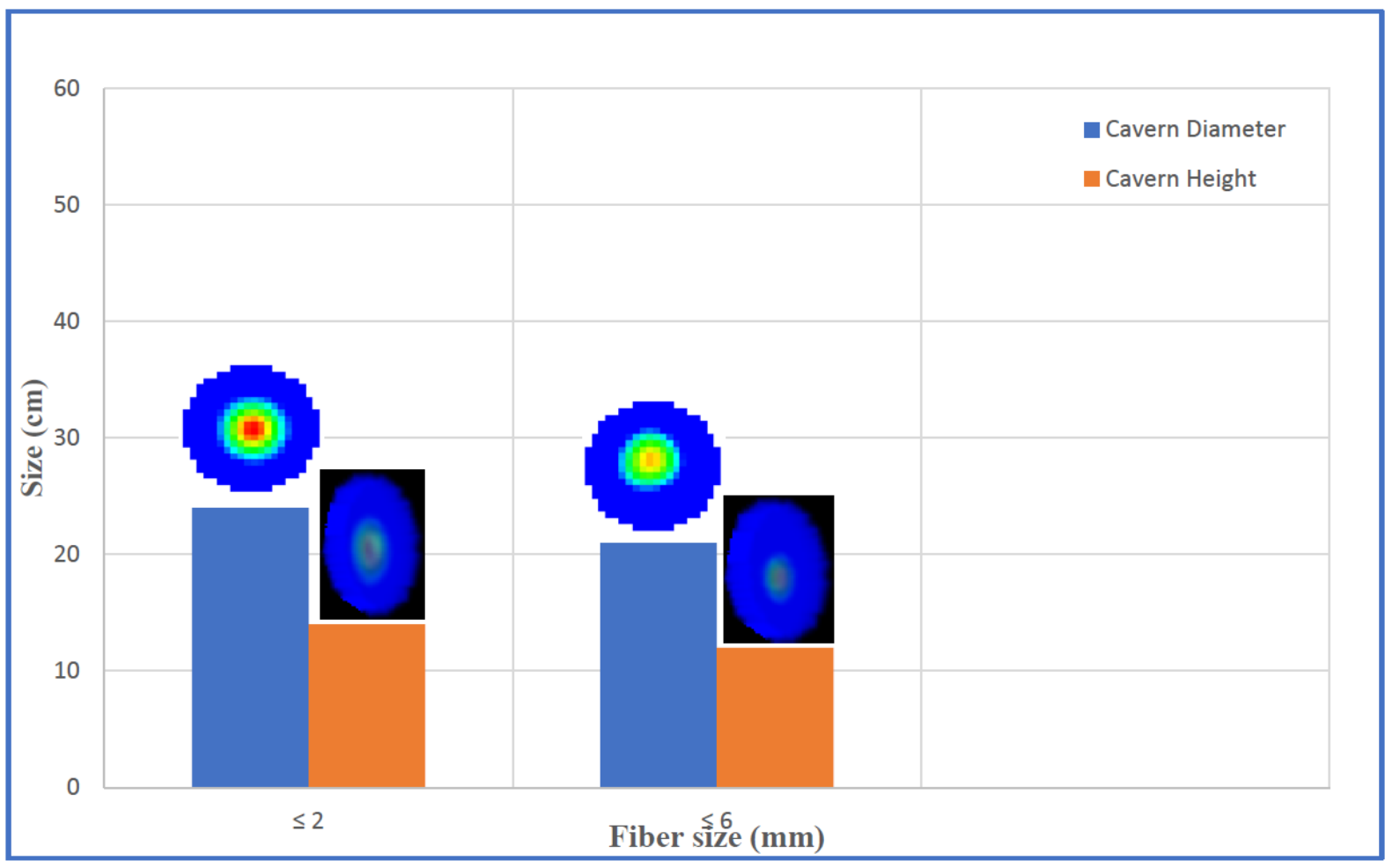

Figure 4.16. Effect of the fiber size on the diameter of the cavern created around the A200 impeller in the mixing of $10 \mathrm{wt} \%$ pretreated wheat straw slurry with fiber sizes of $\leq 2 \mathrm{~mm}$ and $\leq 6 \mathrm{~mm}$ at $60 \mathrm{rpm}$.

The diameter of the cavern decreased from $24 \mathrm{~cm}$ to $21 \mathrm{~cm}$ when the fiber size increased from $\leq$ $2 \mathrm{~mm}$ to $\leq 6 \mathrm{~mm}$. Also, the height of the cavern decreased from $14 \mathrm{~cm}$ to 12 as well.

As shown in Figure 4.17, the cavern diameter and height measured for the $10 \mathrm{wt} \% \mathrm{PWS}$ with fiber size of $\leq 6 \mathrm{~mm}$ agitated by A315 at $60 \mathrm{rpm}$ were smaller than those for the fiber size of $\leq 2 \mathrm{~mm}$ at a fixed rotational speed and concentration. 


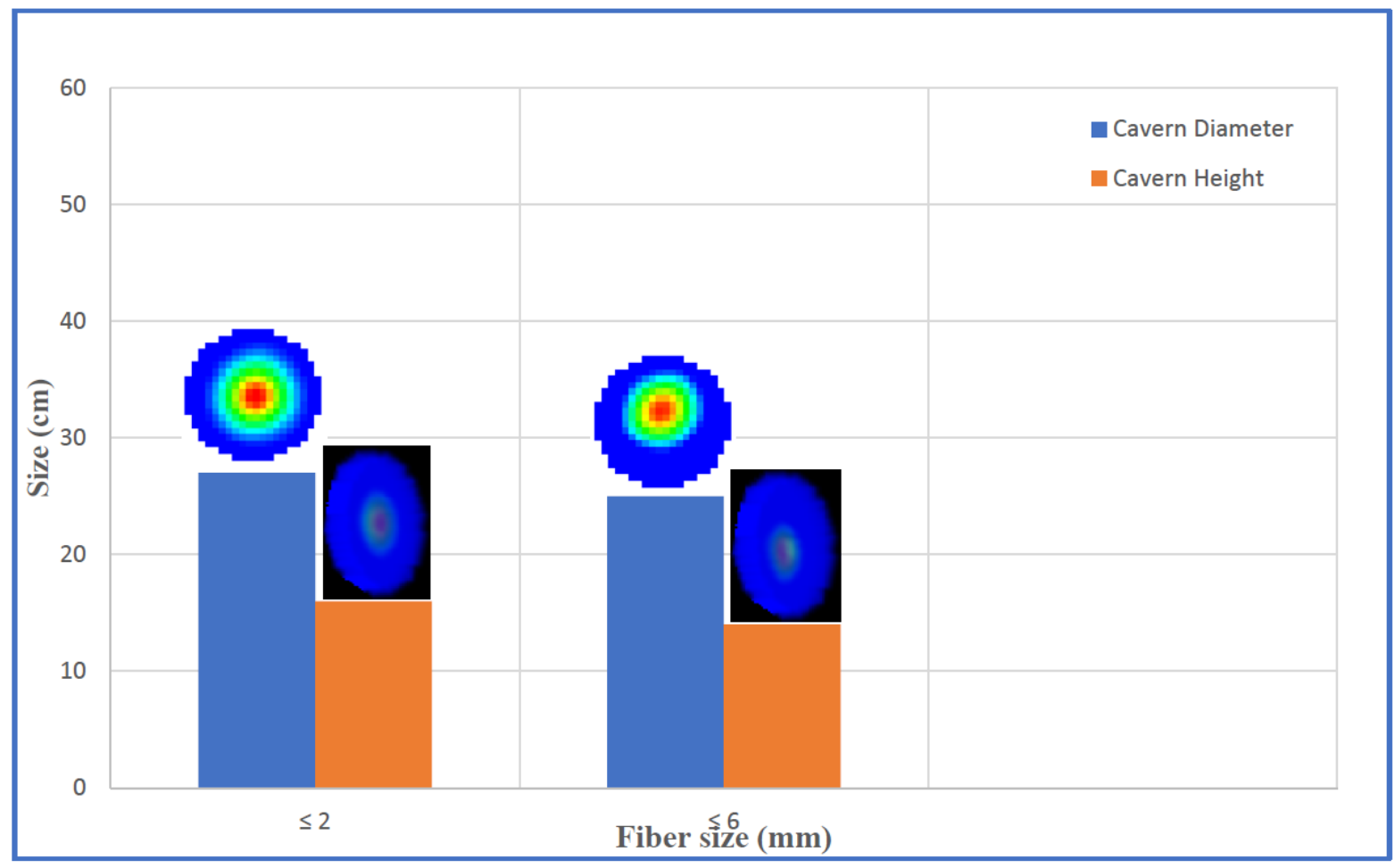

Figure 4.17. Effect of the fiber size on the diameter of the cavern created around the A315 impeller in the mixing of $10 \mathrm{wt} \%$ pretreated wheat straw slurry with fiber sizes of $\leq 2 \mathrm{~mm}$ and $\leq 6 \mathrm{~mm}$ at $60 \mathrm{rpm}$.

For the A315 impeller, the diameter of the cavern decreased from $27 \mathrm{~cm}$ to $25 \mathrm{~cm}$ when the fiber size increased from $\leq 2 \mathrm{~mm}$ to $\leq 6 \mathrm{~mm}$. Also, the height of the cavern decreased from 16 to $14 \mathrm{~cm}$. These results indicate that by increasing the fiber size, fibers can't move easily in the mixing tank. As a result, a smaller cavern is formed for slurries with the greater fibers sizes which have the higher yield stresses.

\subsubsection{Cavern Sizes Measured for PWS and WS Slurries}

Figures 4.18 and 4.19 show the diameters and heights of the cavern at the fixed concentration and impeller speed for pretreated wheat straw and wheat straw slurries with the fiber sizes of $\leq 6$ $\mathrm{mm}$ and $\leq 2 \mathrm{~mm}$, respectively. 


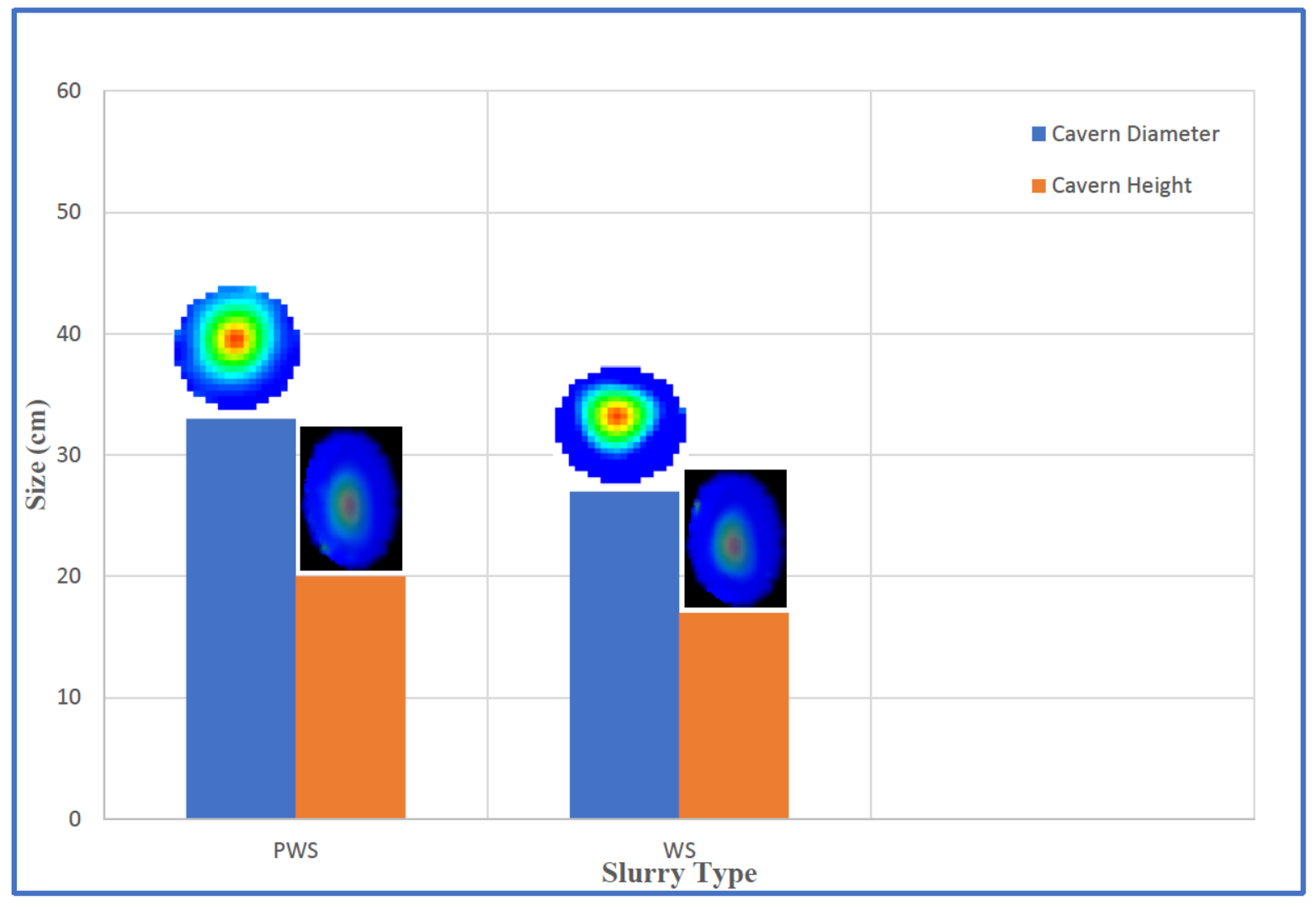

Figure 4.18. Cavern diameter and height formed around the A315 impeller in the agitation of PWS a WS with the fiber sizes of $\leq 6 \mathrm{~mm}$ at $60 \mathrm{rpm}$ with $6 \mathrm{wt} \%$ concentration.

Figure 4.18 demonstrates that the diameter and the height of the cavern formed around the A315 impeller in the mixing of the PWS slurries with the fiber sizes of $\leq 6 \mathrm{~mm}$ were $33 \mathrm{~cm}$ and $20 \mathrm{~cm}$, respectively. However, at the same conditions, the cavern diameter and height for WS slurry were $27 \mathrm{~cm}$ and $17 \mathrm{~cm}$, respectively. These results revealed that the size of cavern for the WS slurry was less than that for the PWS slurry.

Figure 4.19 demonstrates that the diameter and the height of the cavern formed around the A315 impeller in the mixing of the PWS and WS slurries with the fiber sizes of $\leq 2 \mathrm{~mm}$ at $60 \mathrm{rpm}$ with $6 \mathrm{wt} \%$ concentration. 


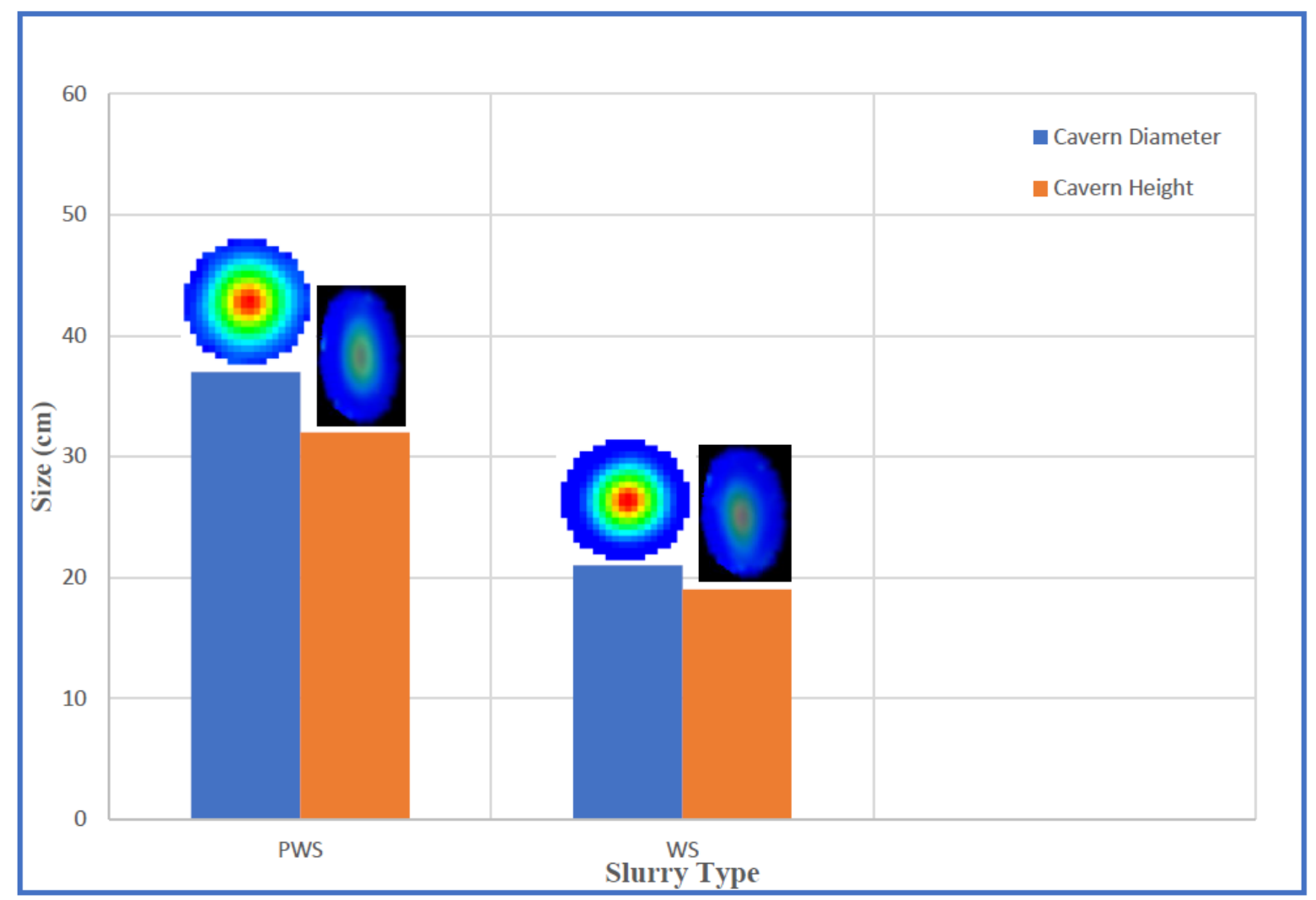

Figure 4.19. Cavern diameter and height formed around the A315 impeller in the agitation of PWS and WS with the fiber sizes of $\leq 2 \mathrm{~mm}$ at $60 \mathrm{rpm}$ with $6 \mathrm{wt} \%$ concentration.

Figure 4.19 shows that the diameter and height of the cavern created around the A315 impeller for the PWS slurry with the fiber sizes of $\leq 2$ were $37 \mathrm{~cm}$ and $21 \mathrm{~cm}$, respectively while the cavern diameter and height for the WS slurry under the same operating conditions were $32 \mathrm{~cm}$ and $19 \mathrm{~cm}$. These results demonstrate that at a fixed rotational speed and concentration, a larger cavern was created for pretreated wheat straw slurries compared to that for the wheat straw slurries for both fiber sizes. As mentioned earlier, due to the pretreatment process, some parts of lignin were removed from the structure of the fibers, which caused fibers to become more fragile and smaller in size. Therefore, by reducing the fiber size through the pretreating process, the strength of the slurry networks decreased due to a decrease in the fiber/fiber interactions within the slurry. As a result, the yield stress of the pretreated slurry decreased and thus the impellers created a larger well- mixed region (cavern) at a fixed speed and concertation compared to that attained for the wheat straw slurries. Similar results were also observed for other concentrations and impeller speeds. 
Figures 4.20, 4.21, and 4.22 depict the diameter and height of the caverns around the A100, A200, and A315 for $6 \mathrm{wt} \%$ PWS and WS slurries with the fiber sizes of $\leq 2 \mathrm{~mm}$.

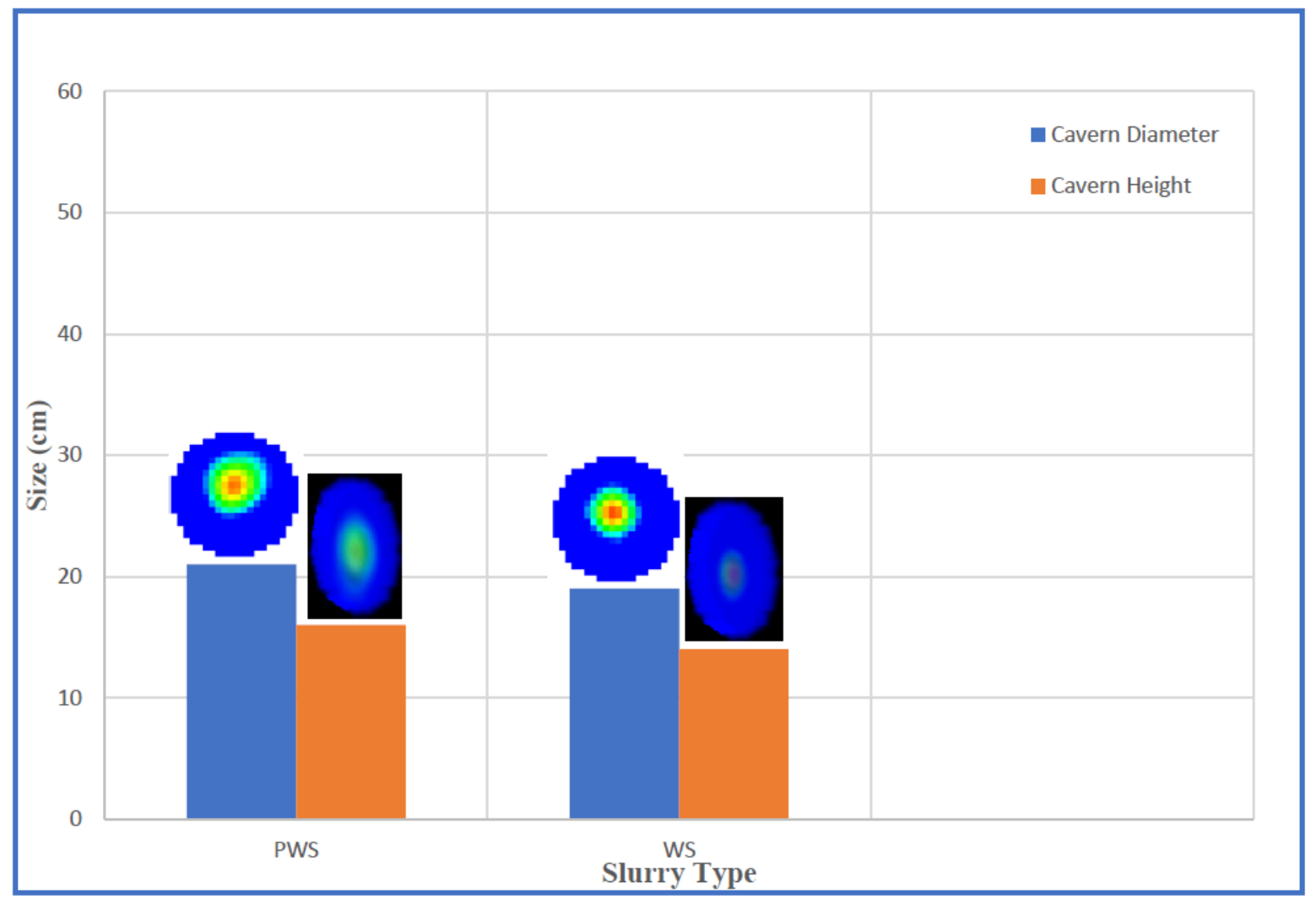

Figure 4.20. Cavern diameter and height formed around the A100 impeller in the agitation of PWS and WS with the fiber sizes of $\leq 2 \mathrm{~mm}$ at $20 \mathrm{rpm}$ with $6 \mathrm{wt} \%$ concentration.

Figure 4.20 shows that the diameter of the cavern formed around the A100 impeller in the case of PWS slurry was $21 \mathrm{~cm}$ and its height was $16 \mathrm{~cm}$. However, at the same conditions the cavern diameter and height were $19 \mathrm{~cm}$ and $14 \mathrm{~cm}$ for the WS slurry.

Figure 4.21 demonstrates that the diameter and the height of the cavern formed around the A200 impeller in the mixing of the PWS and WS slurries with the fiber sizes of $\leq 2 \mathrm{~mm}$ at $20 \mathrm{rpm}$ with $6 \mathrm{wt} \%$ concentration. 


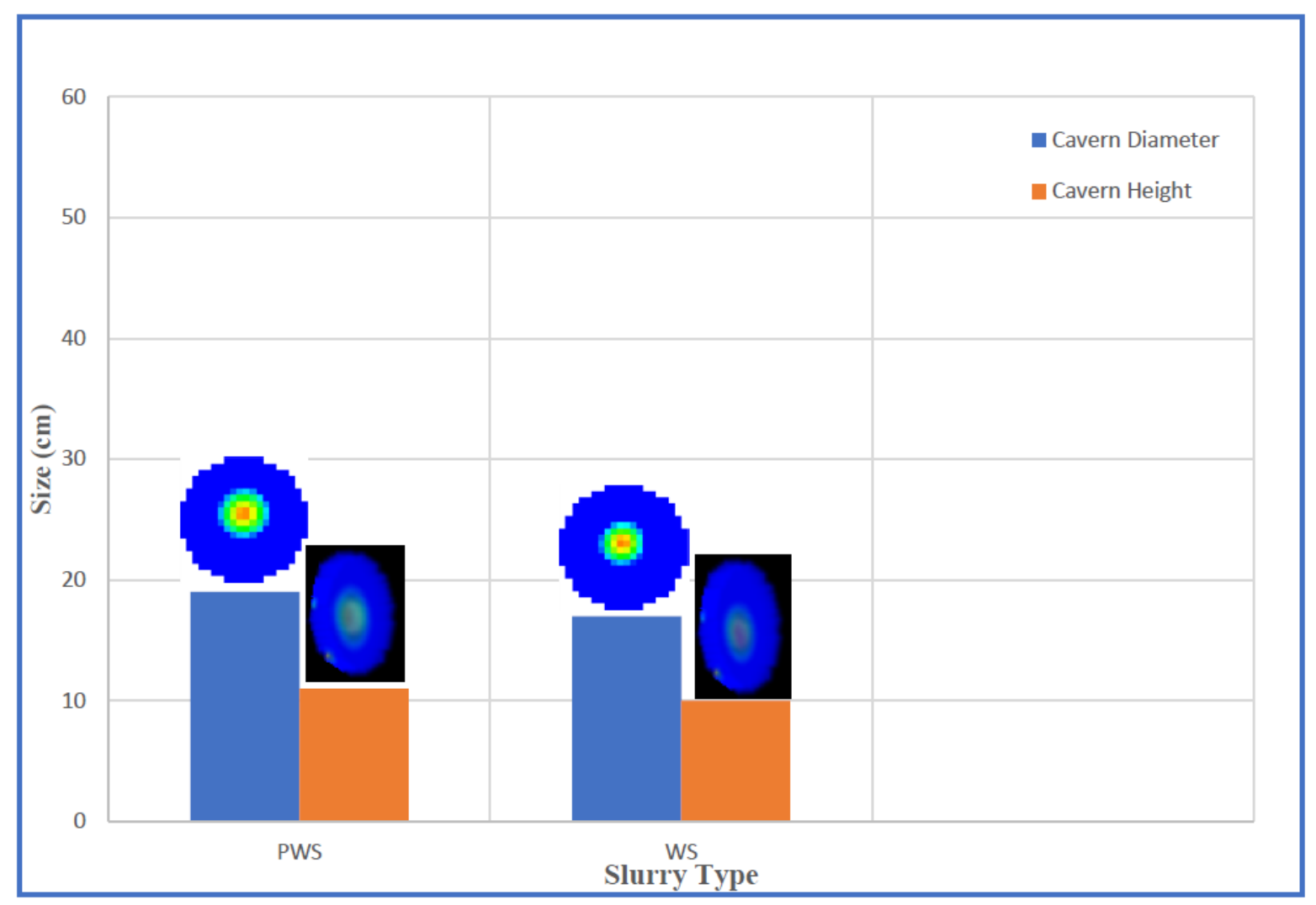

Figure 4.21. Cavern diameter and height formed around the A200 impeller in the agitation of PWS and WS with the fiber sizes of $\leq 2 \mathrm{~mm}$ at $20 \mathrm{rpm}$ with $6 \mathrm{wt} \%$ concentration.

Figure 4.21 shows that the diameter of the cavern formed around the A200 impeller in the case of PWS slurry was $19 \mathrm{~cm}$ and its height was $11 \mathrm{~cm}$. However, at the same conditions the cavern diameter and height were $17 \mathrm{~cm}$ and $10 \mathrm{~cm}$ for the WS slurry.

Figure 4.22 demonstrates that the diameter and the height of the cavern formed around the A315 impeller in the mixing of the PWS and WS slurries with the fiber sizes of $\leq 2 \mathrm{~mm}$ at $20 \mathrm{rpm}$ with $6 \mathrm{wt} \%$ concentration.

Figure 4.22 shows that the diameter of the cavern formed around the A315 impeller in the case of PWS slurry was $23 \mathrm{~cm}$ and its height was $14 \mathrm{~cm}$. However, at the same conditions the cavern diameter and height were $21 \mathrm{~cm}$ and $12 \mathrm{~cm}$ for the WS slurry. 


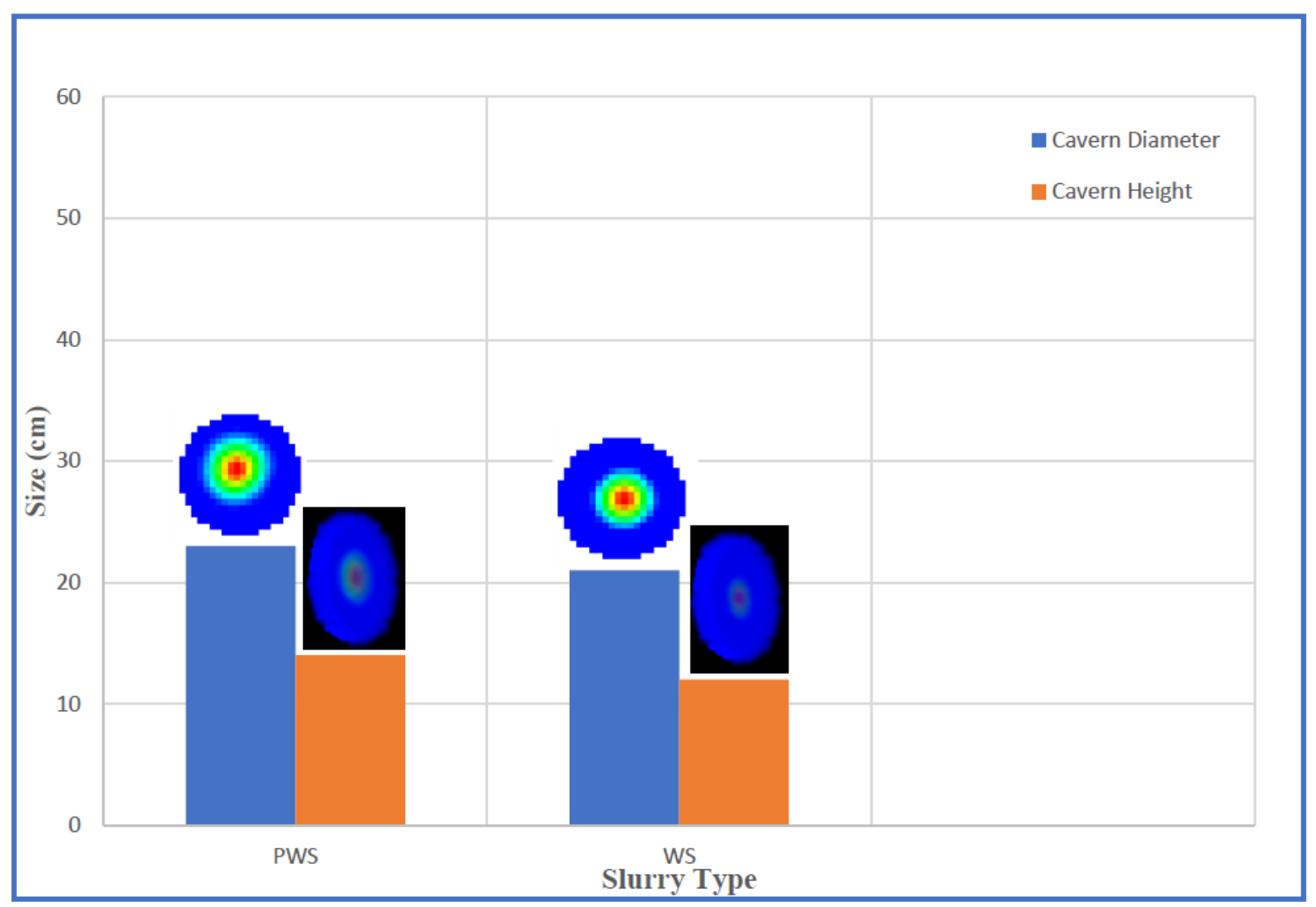

Figure 4.22. Cavern diameter and height formed around the A315 impeller in the agitation of PWS and $W S$ with the fiber sizes of $\leq 2 \mathrm{~mm}$ at $20 \mathrm{rpm}$ with $6 \mathrm{wt} \%$ concentration.

These results revealed that the larger caverns created for PWS slurries compared to those for WS slurries. Due to pretreatment process, some parts of carboxylic acids have been removed from the structure of the fibers, which caused fibers to become more fragile and smaller in size. Therefore, by decreasing the fiber size for pretreated wheat the strength of the slurry networks decreased as well due to a decrease in the number of fiber/fiber interactions. As a result, the yield stress of the slurry decreased, and impellers created a larger well- mixed region (cavern) at a fixed speed and concertation compared to wheat straw.

Furthermore, it was found that the A315 impeller was more effective compared to the A100 and A200 impellers in creating the larger caverns. In the next section the impact of the impeller type on the cavern size is investigated in detail. 


\subsubsection{Impact of impeller type on torque and the cavern size}

Figures 4.23 and Figure 4.24 show the impeller torque for three impellers studied in this study versus the impeller speed for the mixing of pretreated wheat straw slurries with the fiber sizes of $\leq 2 \mathrm{~mm}$ and $\leq 6 \mathrm{~mm}$, respectively.

Figure 4.23 and Figure 4.24 shows that at a fixed impeller speed, concentration and fiber size, the measured torque for the A315 was higher than those for the A100 and A200 impellers. Therefore, due to the higher torque applied by the A315, this impeller was more effective to break the fiber network and create a larger well- mixed region (cavern) at a fixed speed compared to the A200 and A100 impellers.

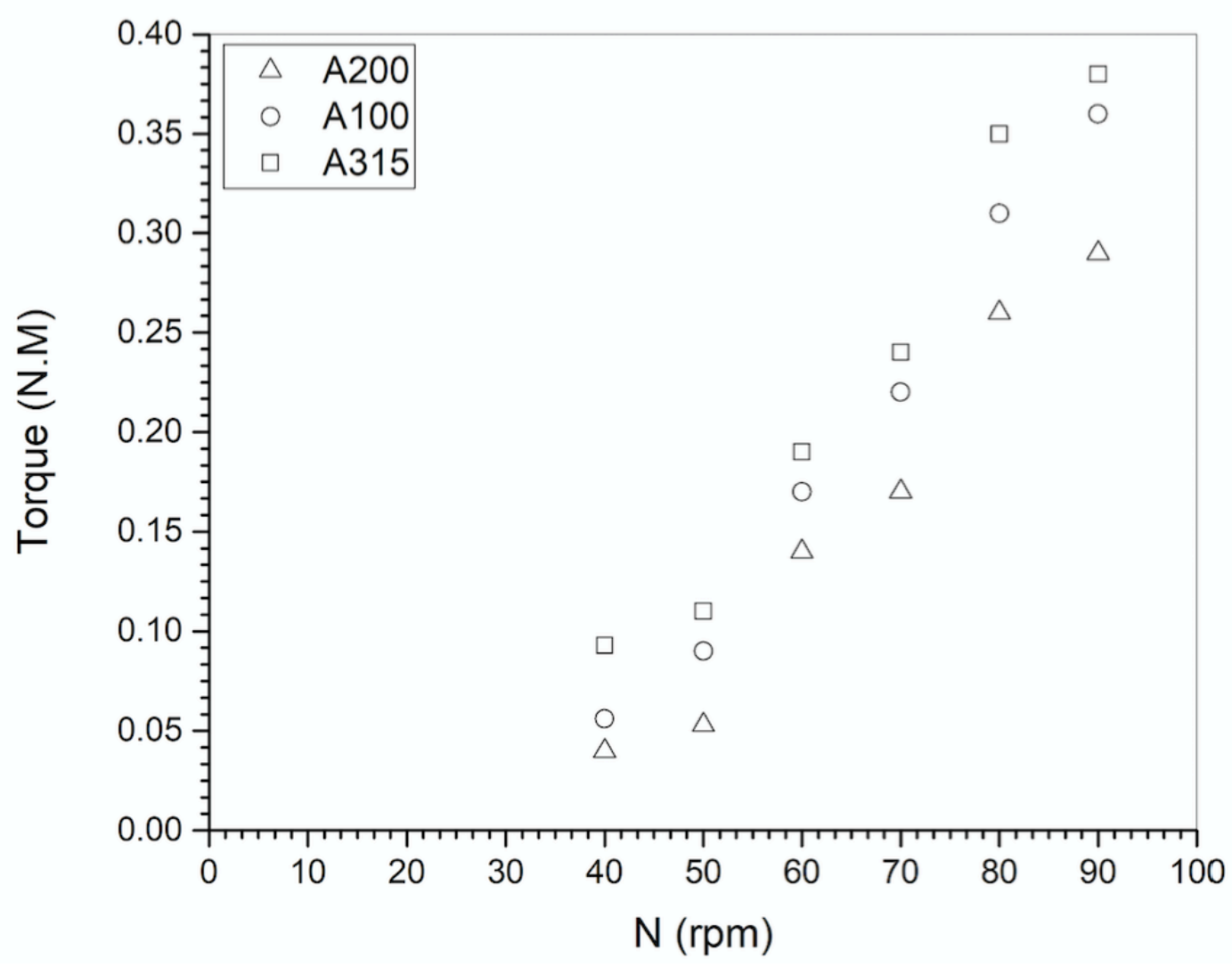

Figure 4.23. Torque versus impeller speed for $8 \mathrm{wt} \%$ pretreated wheat straws $(\leq 2 \mathrm{~mm})$ agitated by A315, A100 and A200 impellers

As shown in Figure 4.23 at $80 \mathrm{rpm}$, the torque recorded for the A315 impeller in the mixing of the pretreated slurry with the fiber sizes $\leq 2 \mathrm{~mm}$ was $0.35 \mathrm{~N}$.m while this value decreased to 0.26 for the A200 impeller. This result shows that impeller A315 is more applicable in mixing process 
since it will generate higher torque.

Figure 4.24 shows the impeller torque for three impellers versus the impeller speed for the mixing of pretreated wheat straw slurries with the fiber sizes of $\leq 6 \mathrm{~mm}$.

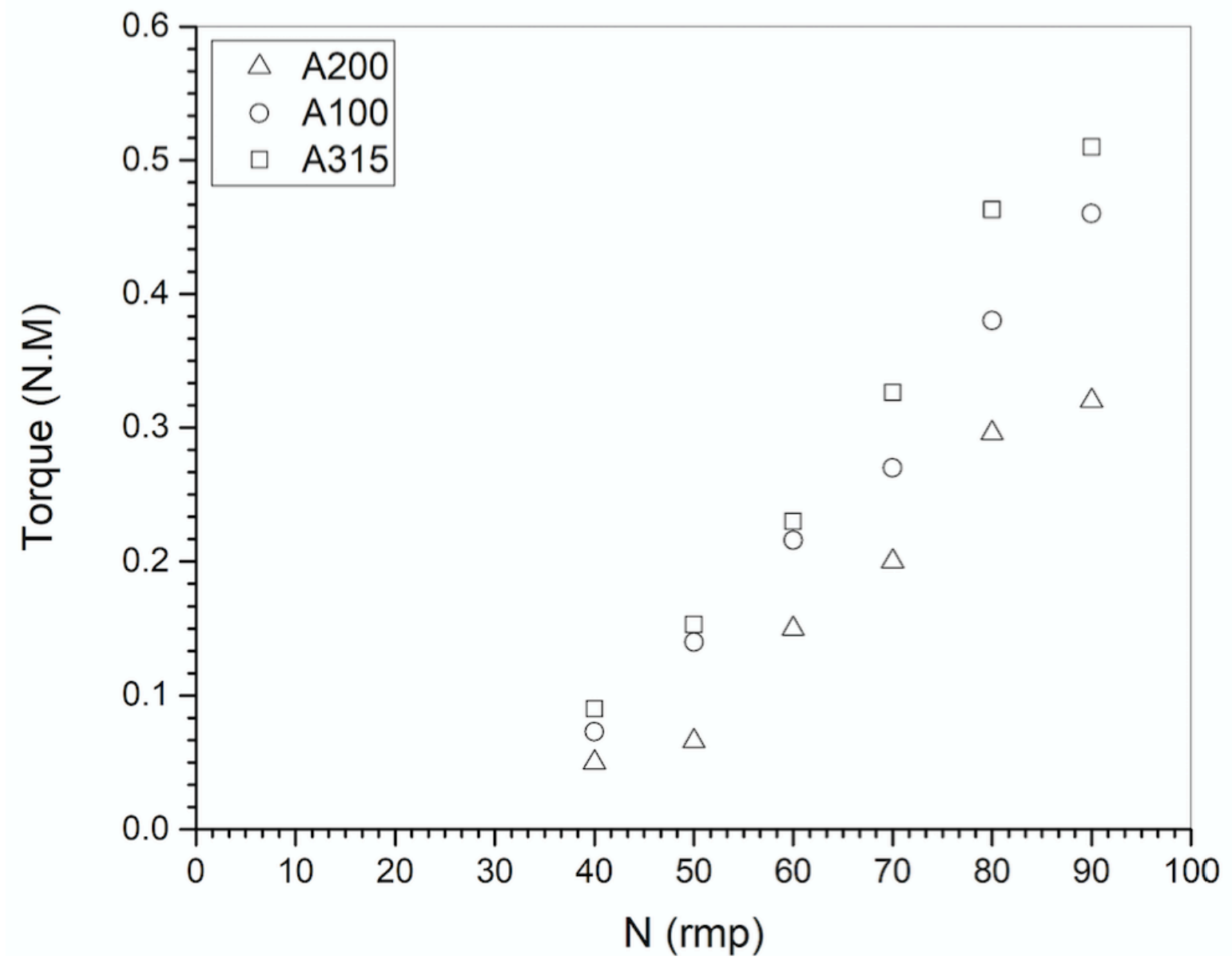

Figure 4.24. Torque versus impeller speed for $8 w t \%$ pretreated wheat straw $(\leq 6 \mathrm{~mm})$ agitated by A315, A100 and A200 impellers

As it shown in Figure 4.24 for $8 \mathrm{wt} \%$ pretreated wheat straw $(\leq 6 \mathrm{~mm})$, at $80 \mathrm{rpm}$, the A315 impeller created 0.46 N.m torque. This value decreased to 0.38 for the A100 impeller and to 0.29 for the A200 impeller.

Figure 4.25 shows tomograms obtained from plane 3 for the A315, A100, and A200 at the rotational speed of $80 \mathrm{rpm}$ and $8 \mathrm{wt} \%$ pretreated wheat straw slurry $(\leq 2 \mathrm{~mm})$. A cavern diameter of $36 \mathrm{~cm}, 31 \mathrm{~cm}$, and $28 \mathrm{~cm}$ was obtained for A315, A100, and A200, respectively. 
The larger cavern diameter created by the A315 impeller and A200 resulted in the smallest cavern.

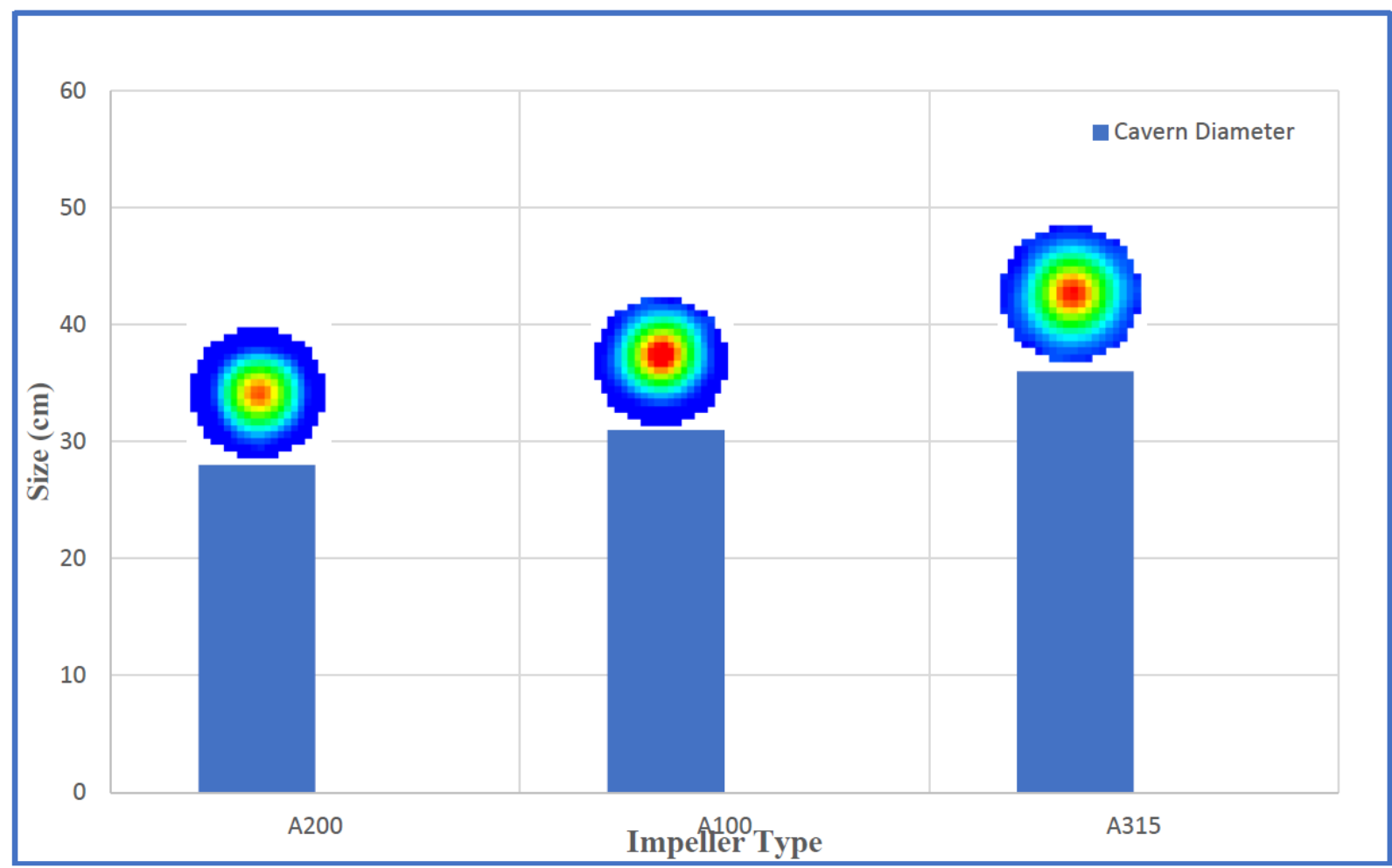

Figure 4.25. Effect of the impeller type on the diameter of the cavern created around the impeller in the mixing of $8 \mathrm{wt} \%$ pretreated wheat straw slurry with fibre size $2 \mathrm{~mm}$ at $80 \mathrm{rpm}$.

When the fiber size of PWS was increased to $\leq 6 \mathrm{~mm}$, a similar trend to that of $\leq 2 \mathrm{~mm}$ was also observed (Figure 4.26) resulting in a larger cavern diameter created by the A315 impeller and A200 resulted in the smallest cavern. 


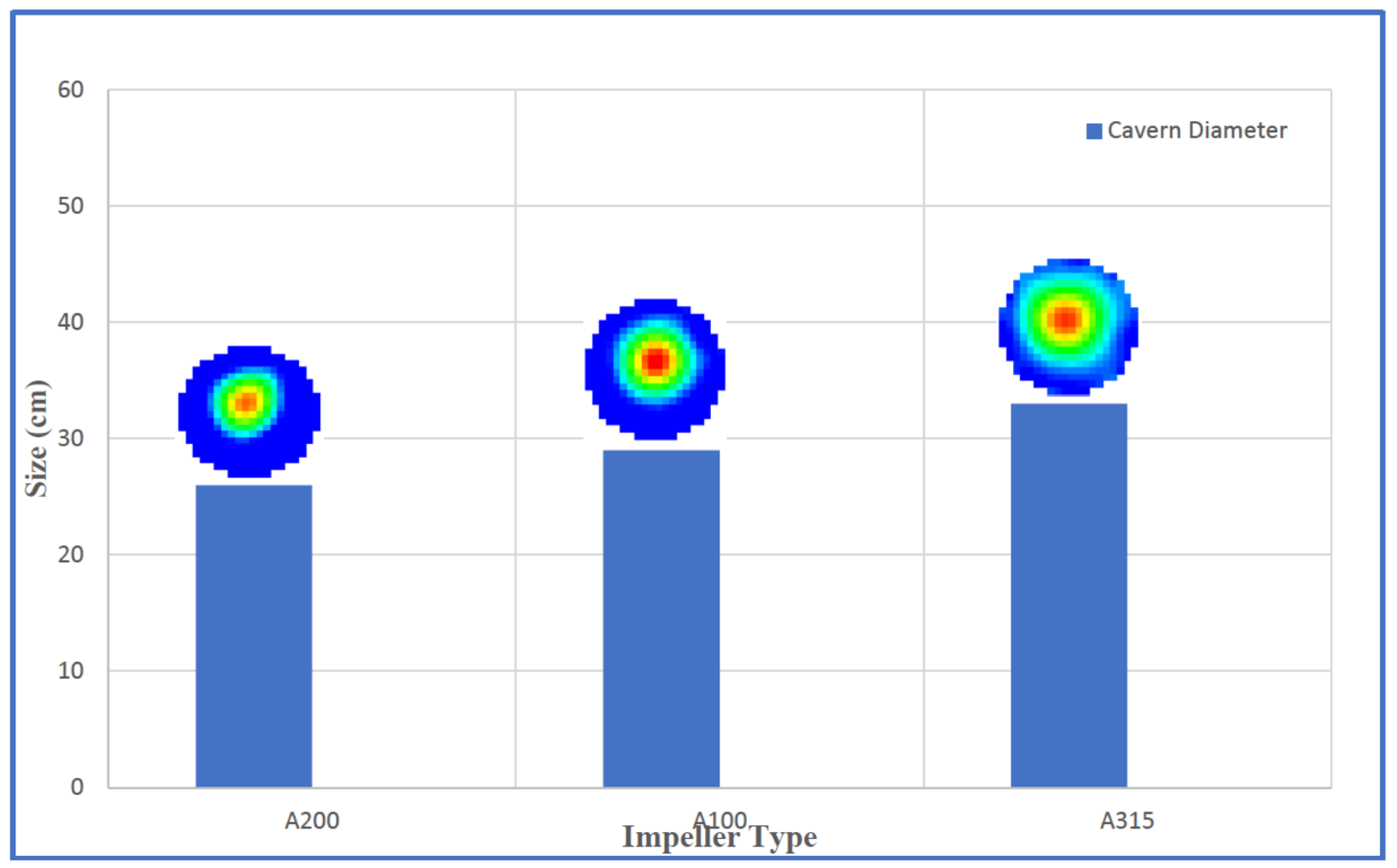

Figure 4.26. Effect of the impeller type on the diameter of the cavern created around the impeller in the mixing of $8 \mathrm{wt} \%$ pretreated wheat straw slurry with fiber size $6 \mathrm{~mm}$ at $80 \mathrm{rpm}$.

\subsection{Dimensionless cavern diameter (Dc/D)}

To estimate the dimensionless cavern diameter $(D c / D)$ as a function of the product of two dimensionless groups of $P_{o}$ and $R e_{y}=\rho N^{2} D^{2} / \tau_{y}$, various models have been recommended in the literature (Solomon et al. 1981; Elson et al.1986 and 1988). As mentioned before, $D c$ is the cavern diameter, $D$ is the impeller diameter, $P_{o}$ is the impeller power number, and $R e_{y}$ is the yield stress Reynolds number. According to Elson's model defined by Equation (3.1), a plot of the dimensionless cavern diameter, $D c / D$, versus $P_{o} R e_{y}$ is a straight line with a slope of 0.33 in log$\log$ scale. This model defines the formation of a cylindrical cavern centered upon the impeller.

Figure $4.27(\mathrm{a}, \mathrm{b}, \mathrm{c})$ depicts the dimensionless cavern diameter $\left(D_{c} / D\right)$ versus the product of $P_{O}$ (power number) and $\rho N^{2} D^{2} / \tau_{y}$ (Reynolds yield stress) for the A200, A315 and A100 for all three concentrations for fiber size $\leq 2 \mathrm{~mm}$ and $\leq 6 \mathrm{~mm}$. According to Equation (3.1), a plot of $D_{c} / D$ 
versus $P_{O} R e_{y}$ should give a straight line with a slope of 0.33 on a log-log scale. Thus, to test the validity of this model for the size of the cavern generated in the mixing of pretreated wheat straw slurries, $D_{c} / D$ values were plotted as a function of $P_{o} R e_{y}$.

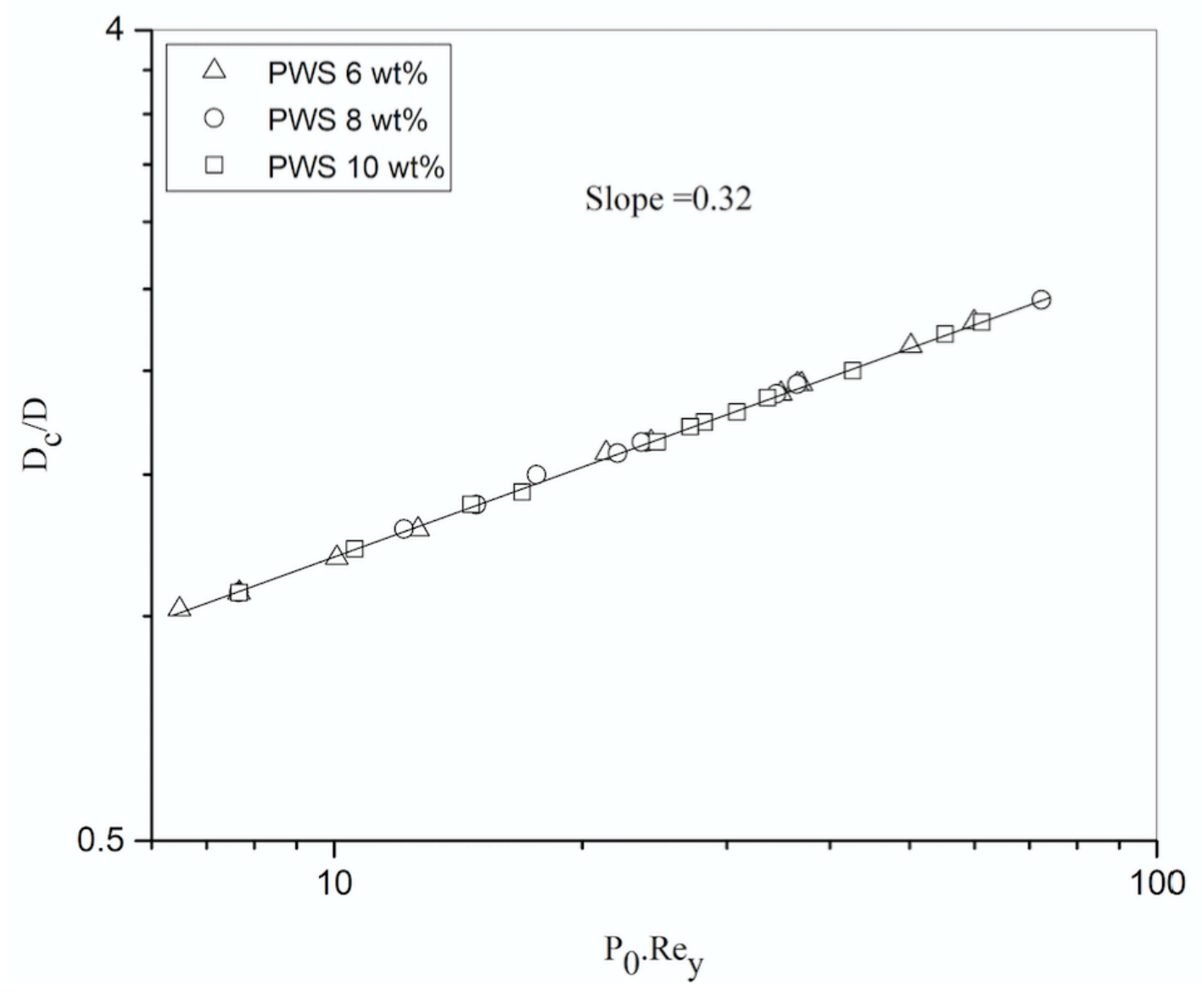

(a) 


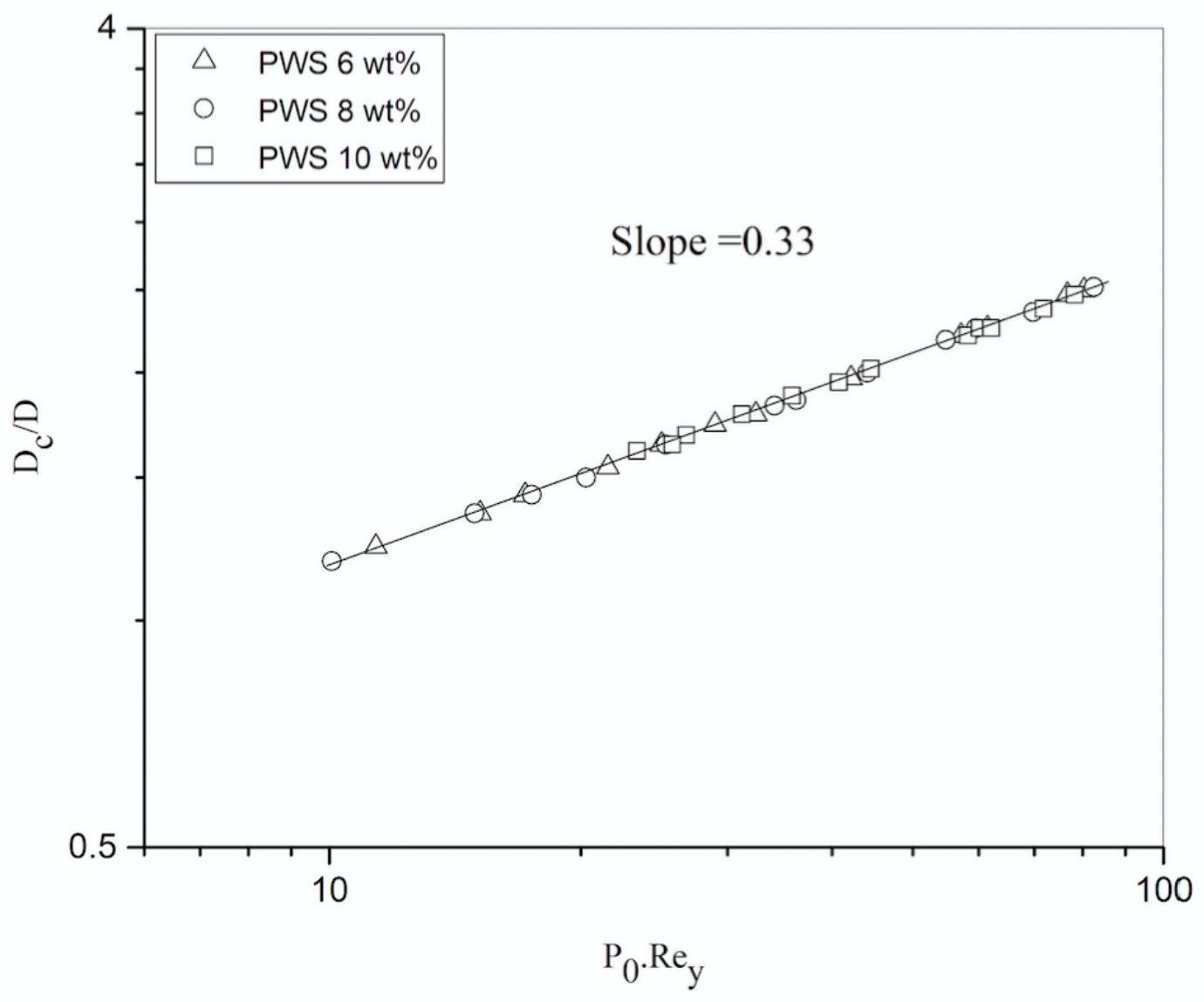

(b) 


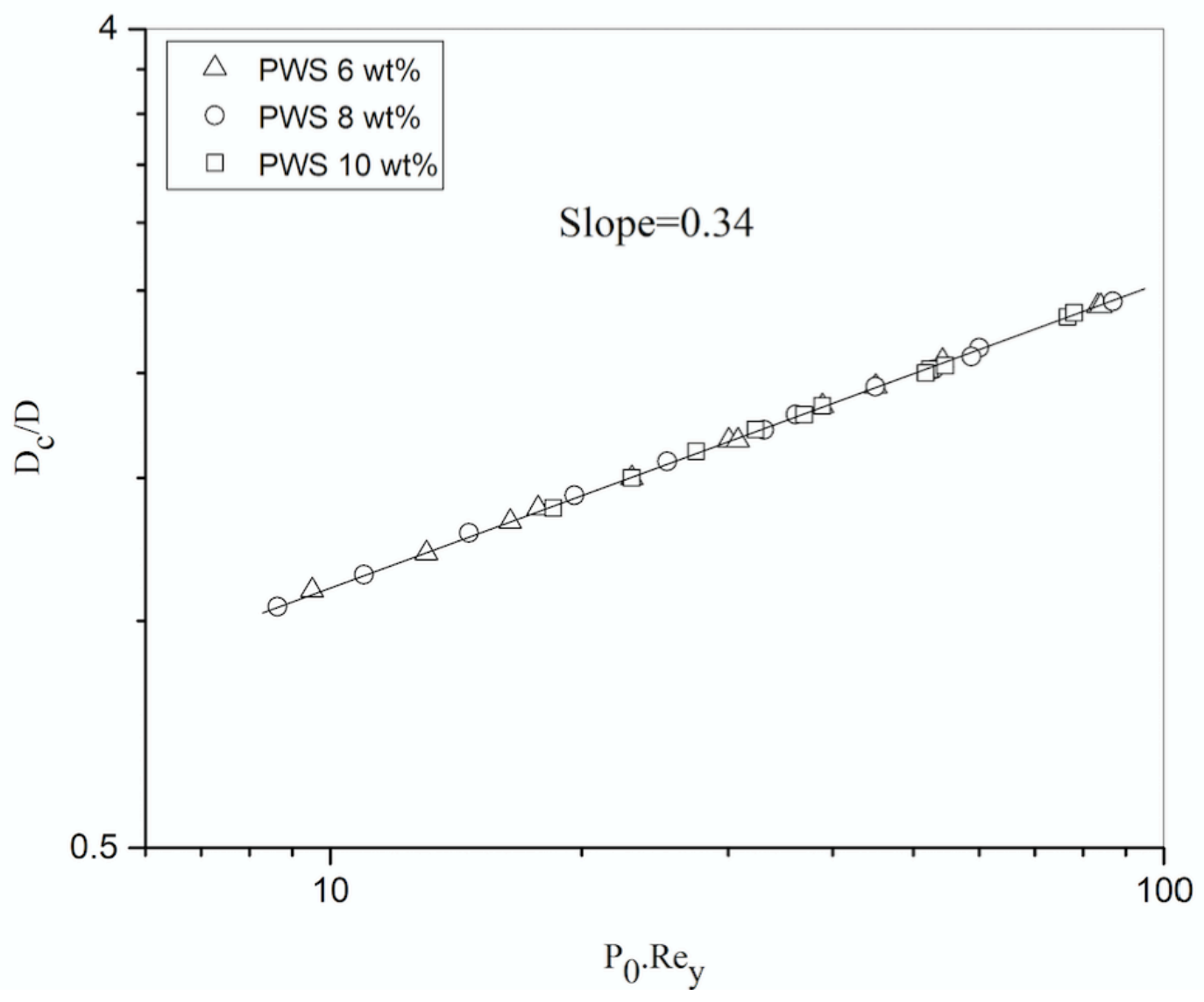

(c)

Figure 4.27. Dimensionless cavern diameter versus dimensionless stress $\left(P_{O} R_{y}\right)$ for 6,8 , and 10 wt\% pretreated wheat straw slurries with fiber size $\leq 2 \mathrm{~mm}$ and $\leq 6 \mathrm{~mm}$ agitated by (a) A200 impeller, (b) A315, and (c) A100 impeller.

The cylindrical model predicts a slope of 0.33 from a log-log plot of $\left(D_{c} / D\right)$ versus $P_{o} R e_{y}$. This model defines the formation of a cylindrical cavern centered upon the impeller. The slopes of the $\left(D_{C} / D\right)$ versus $P_{o} R e_{y}$ for A315, A100, and A200 impellers for fiber size $\leq 2 \mathrm{~mm}$ and $\leq 6 \mathrm{~mm}$ are in a good agreement with that expected from Elson's model (0.33). It should be mentioned that our results demonstrated that Elson's model is valid for the prediction of dimensions of the cavern formed around the impeller in the mixing of wheat straw and pretreated wheat straw slurries. Thus, the cavern dimensions and the impeller power measured in this study were employed to estimate 
the slurry yield stress as a function of the fibre size and concentration via Elson's model.

\subsection{Cavern Height to Diameter Ratio $\left(H_{c} / D_{c}\right)$}

Figures 4.28 (a), (b), and (c) show the cavern dimensionless height $\left(H_{c} / D_{c}\right)$ versus the impeller speed for the mixing of 6,8 , and $10 \mathrm{wt} \%$ pretreated wheat straw slurries with the fiber sizes $\leq 2$ $\mathrm{mm}$ and $\leq 6 \mathrm{~mm}$ for the A200, A315, and A100 impellers. The ratio of cavern height to cavern diameter $\left(H_{c} / D_{C}\right)$ remained nearly constant versus the impeller speed, for each specific type of impellers before the cavern touched the wall. By increasing the impeller speed, both height and diameter of cavern increased while their ratio $\left(H_{c} / D_{c}\right)$ remained approximately constant.

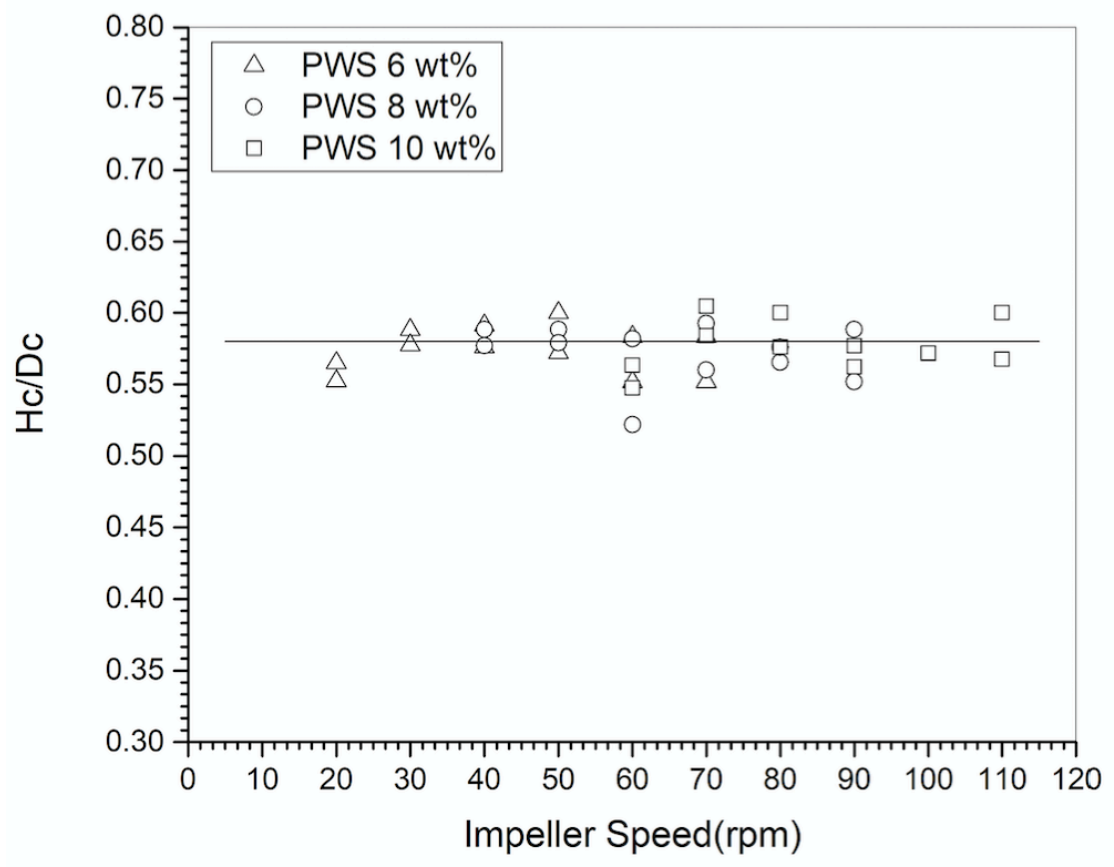

(a) 


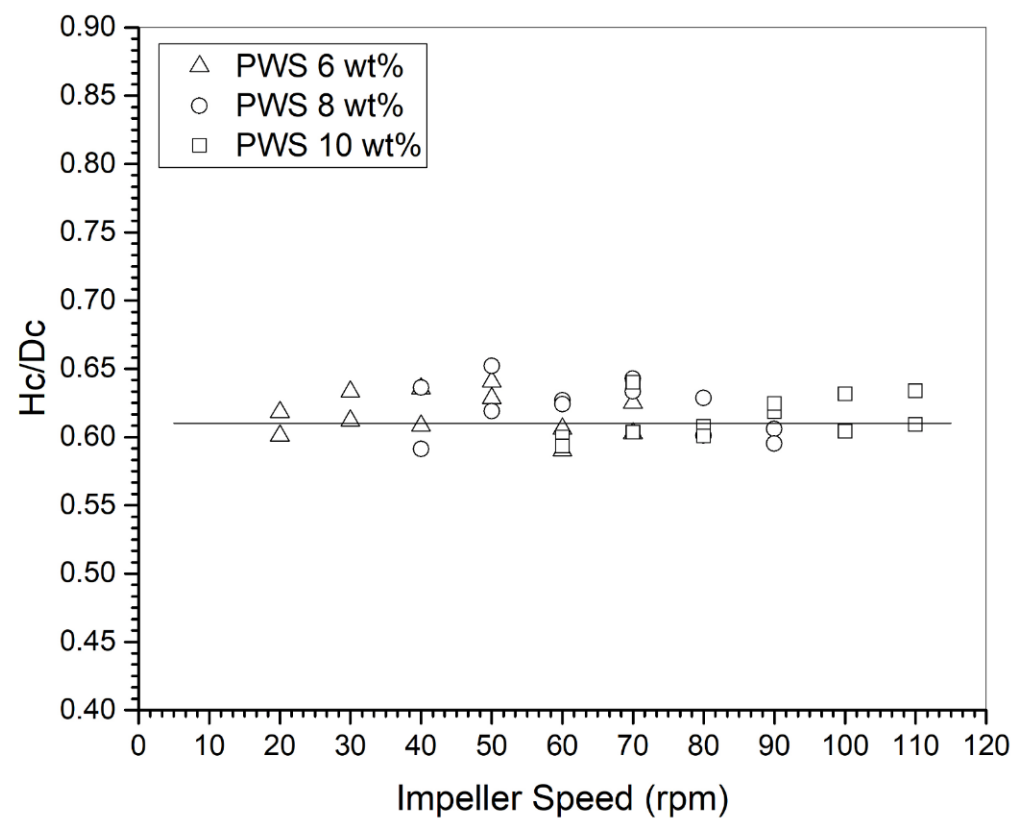

(b)

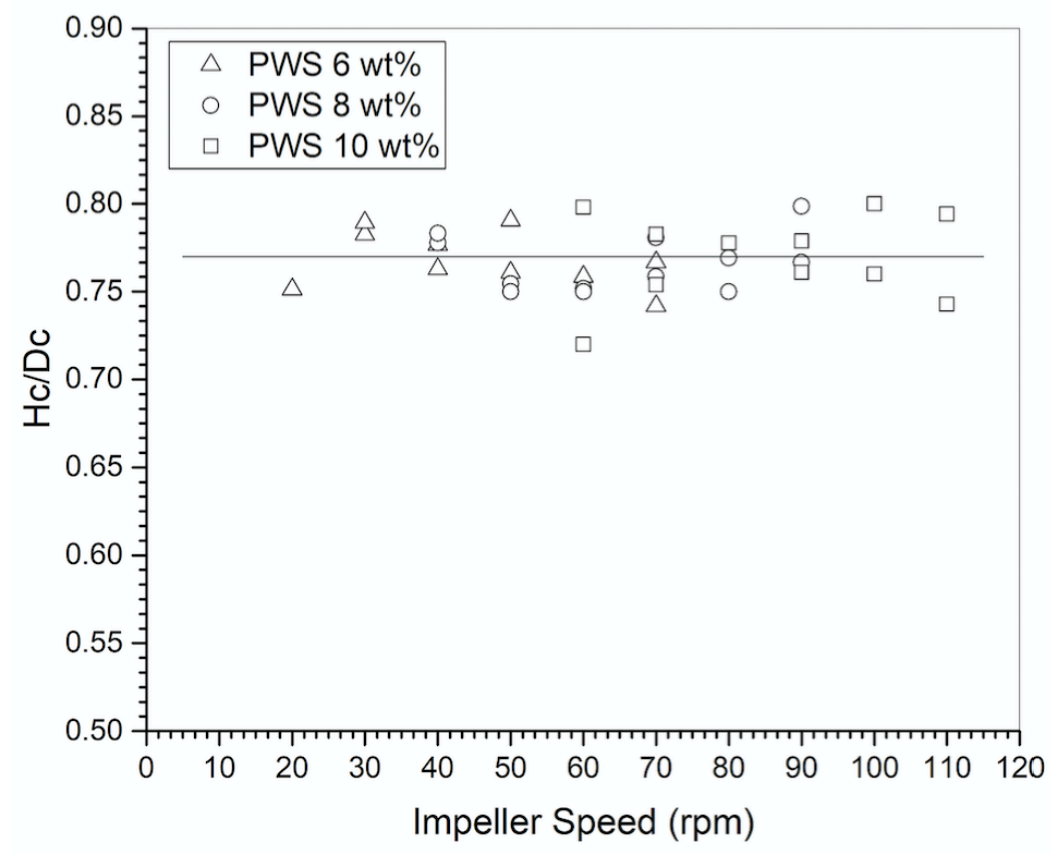

(c)

Figure 4.28. $H_{c} / D_{c}$ versus the impeller speed at 6,8 and $10 w t \%$ pretreated wheat straw slurries $(\leq 2$ mm and $\leq 6 \mathrm{~mm}$ ) agitated by (a) A200 impeller with error bar $<0.04$ at 95\% confidence , (b) A315 
impeller with error bar $<0.02$ at 95\% confidence, and (c) A100 impelle with error bar $<0.04$ at $95 \%$ confidence.

The ratio $\left(H_{C} / D_{c}\right)$ remained relatively constant once the range of impeller speed varied from 20 to $110 \mathrm{rpm}$, at a value of 058,0.61, and 0.77, respectively for the A200, A315 and A100 impeller. These values are in good agreement with those reported by Movafaght et al. (2016) and saeed et al. (2008), who found $H_{C} / D_{C}=0.55-0.57$ for the A200, by Galindo et al. (1992), who found $0.58 \pm 0.05$ for the A315, and by Movafaght et al. (2016) and Amanullah et al. (1998), who found $0.75 \pm 0.05$ for $\mathrm{A} 100$.

\subsection{Yield Stress of Pretreated Wheat Straw Slurries and Wheat Straw Slurries Using Tomography Data}

The yield stress of pretreated wheat straw slurries and wheat straw slurries for concentrations of 6, 8, $10 \mathrm{wt} \%$ and two fiber sizes were estimated using the cylindrical model of Elson (Equation 3.1). As mentioned in the previous section, the diameter and height of the cavern were determined through ERT. These dimensions as well as the impeller speed and the power number were substituted into Elson's model to obtain the slurry yield stress.

Figure 4.29 depicts the variation of calculated yield stress for $6 \mathrm{wt} \%$ PWS slurry with the fiber sizes of $\leq 2 \mathrm{~mm}$ for the A315 impeller when the impeller speed varied from $20 \mathrm{rpm}$ to $70 \mathrm{rpm}$. 


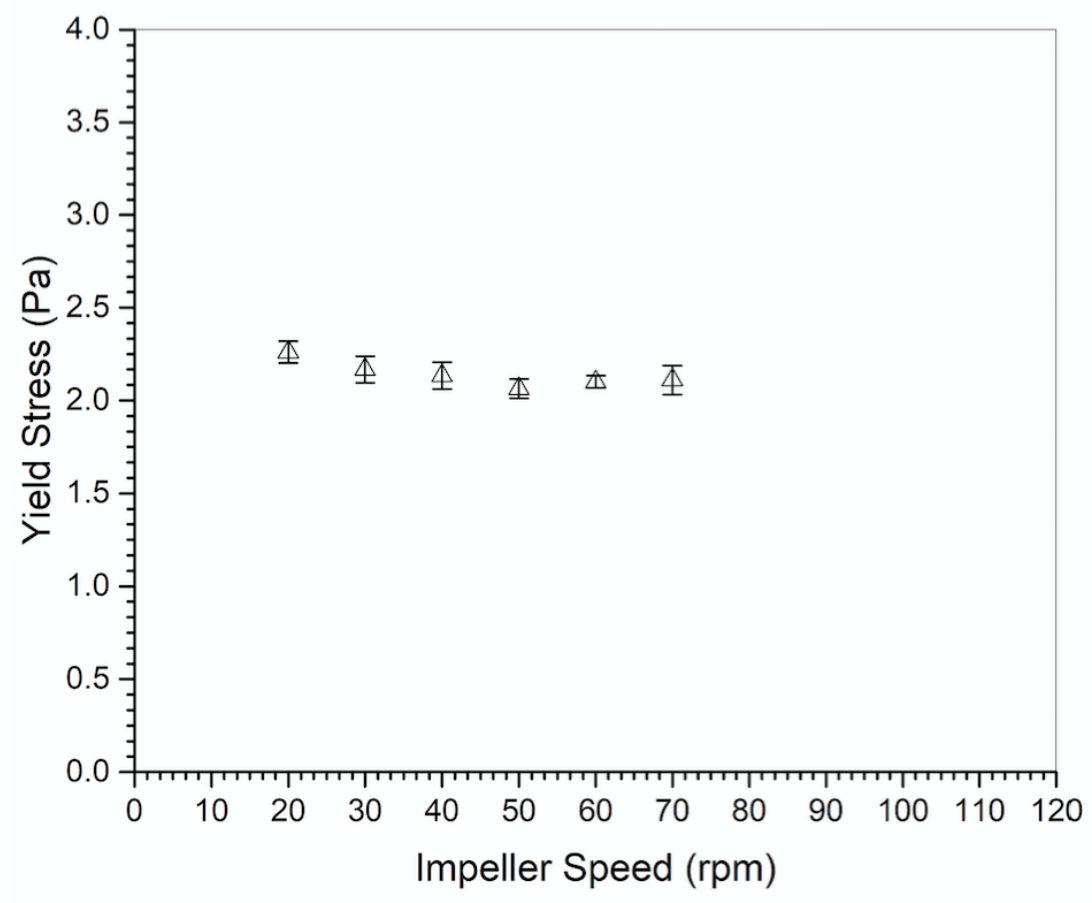

Figure 4.29. Yield stress versus rpm for $6 w t \%$ PWS for fiber size $\leq 2 \mathrm{~mm}$.

These results demonstrate that the yield stress measured via this approach is not a function of the impeller speed.

Tables 4.2 and 4.3 shows the yield stresses of PWS and WS slurries obtained via the experiments with three impellers (A200, A315 and A100) at different concentrations (6, 8, and $10 \mathrm{wt} \%)$ for the slurries with the fiber sizes of $\leq 2 \mathrm{~mm}$ and $\leq 6 \mathrm{~mm}$, respectively. 
Table 4.2. Average yield stress of the pretreated wheat straw and wheat straw slurries for fiber size of $x \leq$ $2 \mathrm{~mm}$ calculated from Elson's model using experimental data for $H_{c}$ and $D_{c}$.

\begin{tabular}{|c|c|c|c|}
\hline $\begin{array}{c}\text { Impeller } \\
\text { type }\end{array}$ & $\begin{array}{c}\text { Fiber Mass } \\
\text { Concentration }\end{array}$ & $\begin{array}{c}\text { Yield Stress (Pa) } \\
\text { of PWS Slurry }\end{array}$ & $\begin{array}{c}\text { Yield Stress (Pa) of WS } \\
\text { Slurry }\end{array}$ \\
\hline \multirow{2}{*}{$\mathrm{A} 200$} & $6 \mathrm{wt} \%$ & $1.99 \pm 0.04$ & $4.33 \pm 0.08$ \\
\cline { 2 - 4 } & $8 \mathrm{wt} \%$ & $5.43 \pm 0.23$ & $11.29 \pm 0.07$ \\
\cline { 2 - 4 } & $10 \mathrm{wt} \%$ & $8.60 \pm 0.07$ & $14.79 \pm 0.04$ \\
\hline \multirow{2}{*}{$\mathrm{A} 315$} & $6 \mathrm{wt} \%$ & $2.12 \pm 0.06$ & $4.60 \pm 0.07$ \\
\cline { 2 - 4 } & $8 \mathrm{wt} \%$ & $5.70 \pm 0.2$ & $11.68 \pm 0.06$ \\
\cline { 2 - 4 } & $10 \mathrm{wt} \%$ & $8.80 \pm 0.12$ & $15.07 \pm 0.06$ \\
\hline \multirow{2}{*}{$\mathrm{A} 100$} & $6 \mathrm{wt} \%$ & $1.9 \pm 0.06$ & $4.18 \pm 0.04$ \\
\cline { 2 - 4 } & $8 \mathrm{wt} \%$ & $5.18 \pm 0.06$ & $11.20 \pm 0.13$ \\
\cline { 2 - 4 } & $10 \mathrm{wt} \%$ & $8.13 \pm 0.1$ & $14.37 \pm 0.12$ \\
\hline
\end{tabular}

Table 4. 3. Yield stress of the pretreated wheat straw and wheat straw slurries for the fiber size of $\leq 6 \mathrm{~mm}$ calculated from Elson's model using experimental data for $H_{c}$ and $D_{c}$.

\begin{tabular}{|c|c|c|c|}
\hline $\begin{array}{c}\text { Impeller } \\
\text { type }\end{array}$ & $\begin{array}{c}\text { Fiber Mass } \\
\text { Concentration }\end{array}$ & $\begin{array}{c}\text { Yield Stress(Pa) } \\
\text { of PWS Slurry }\end{array}$ & Yield Stress(Pa) of WS Slurry \\
\hline \multirow{3}{*}{$\mathrm{A} 200$} & $6 \mathrm{wt} \%$ & $4.27 \pm 0.07$ & $7.12 \pm 0.1$ \\
\cline { 2 - 4 } & $8 \mathrm{wt} \%$ & $9.26 \pm 0.08$ & $14.66 \pm 0.1$ \\
\cline { 2 - 4 } & $10 \mathrm{wt} \%$ & $13.97 \pm 0.05$ & $20.45 \pm 0.08$ \\
\hline \multirow{3}{*}{$\mathrm{A} 315$} & $6 \mathrm{wt} \%$ & $4.35 \pm 0.09$ & $7.08 \pm 0.08$ \\
\cline { 2 - 4 } & $8 \mathrm{wt} \%$ & $9.5 \pm 0.2$ & $14.51 \pm 0.06$ \\
\cline { 2 - 4 } & $10 \mathrm{wt} \%$ & $13.74 \pm 0.11$ & $20.76 \pm 0.09$ \\
\hline \multirow{3}{*}{$\mathrm{A} 100$} & $6 \mathrm{wt} \%$ & $4.17 \pm 0.07$ & $7.14 \pm 0.06$ \\
\cline { 2 - 4 } & $8 \mathrm{wt} \%$ & $9.14 \pm 0.10$ & $14.42 \pm 0.18$ \\
\cline { 2 - 4 } & $10 \mathrm{wt} \%$ & $13.8 \pm 0.15$ & $20.33 \pm 0.16$ \\
\hline
\end{tabular}

These data show that the yield stress values obtained through the experiments conducted with the different impeller types were almost the same. Thus, the approach introduced in this study can be utilized with any type of the impeller to measure the yield stress of the PWS and WS slurries.

These results also demonstrate that the yield stress of the slurry increases with an increase in the fiber mass concentration. In fact, the number of fiber/fiber interactions increases with the fiber 
concentration and resulting in a stronger fiber network and thus a higher yield stress. Furthermore, from Tables 4.2 and 4.3 it can be seen that the yield stress increased with an increase in the fiber sizes. A stronger fiber network was achieved for the slurries with the larger fiber sizes due to a greater fiber-fiber interaction.

This result is in agreement with those reported in the literature. Movafagh et al. (2016) reported that the yield stress of wheat straw increased with particle size and fiber concentration. Viamajala et al. (2009) observed that acid hydrolyzed corn stover slurries behaved as yield stress fluids, at various concentrations, and that with increasing particle size, the yield stress increased. Pimenova and Hanley (2004) measured the apparent rheological properties of pretreated corn stover suspensions of 5, 10, 20, and $30 \mathrm{wt} \%$ and reported that the yield stress of the suspensions increased as the fiber size and concentration increased. Ehrhardt et al. (2010) measured the rheological properties of acid hydrolyzed corn stover slurries. They reported that these materials are behaved as yield stress fluids and the yield stresses increase with increasing solids concentration of acid hydrolyzed corn stover. Samaniuk et al. (2011) reported that the yield stress of concentrated lignocellulosic biomass (corn stover) increased with particle length.

The data from these two tables also shows that the yield stress values measured for the PWS slurries were less than those for the WS slurries at the same concentration and fiber sizes. This result is in agreement with those reported in the literature. For instance, Viamajala et al. (2009) measured the rheology of acid hydrolyzed corn at concentrations between 10.0-40.0 wt $\%$ and particle size of $(0.17 \mathrm{~mm}$ and $0.84 \mathrm{~mm})$. These slurries behaved like yield stress fluids. They explained that dilute acid pretreatment leads to lower viscosity and yield stresses at equivalent solids concentrations compared to untreated samples, as does smaller particle size. 


\section{Chapter 5 Conclusions and Recommendations}

\subsection{Conclusions}

Electrical resistance tomography (ERT) was utilized to measure the dimensions of cavern formed around the A200, A315, and A100 impellers in the mixing of pretreated wheat straw and wheat straw slurries. The tomography images showed that the diameter and height of the cavern decreased when the concentration increased for three impellers employed in this study. Furthermore, at different slurry concentrations, the diameter and height of the cavern increased when the impeller speed increased. The cavern diameter and height measured for the slurries with the fiber sizes of $\leq 6 \mathrm{~mm}$ were smaller than those for the fiber sizes of $\leq 2 \mathrm{~mm}$ at a fixed rotational speed and concentration due to the higher fiber network strength. Also, the larger cavern diameter created by the A315 impeller and the A200 impeller resulted in the smallest cavern. In fact, the A315 impeller was more effective to break the fiber network and create a larger well- mixed region (cavern) at a fixed speed compared to the A200 and A100 impellers.

In this study, for the first time, the yield stress of the pretreated wheat straw slurry was estimated from the cavern size measured by ERT for three concentrations of pretreated wheat straw slurry $(6,8$, and $10 \mathrm{wt} \%)$ and two sizes of fiber $(\leq 2 \mathrm{~mm}$ and $\leq 6 \mathrm{~mm})$. The average yield stresses of pretreated wheat straw slurries with the fiber sizes of $\leq 2 \mathrm{~mm}$ at 6,8 , and $10 \mathrm{wt} \%$ were $2.00 \mathrm{~Pa}$, 5.43 Pa, and 8.51 Pa, respectively, and were 4.26 Pa, 9.3 Pa, and 13.84 Pa, for the slurries with the fiber sizes of $\leq 6 \mathrm{~mm}$. As expected, these values were independent of the impeller type. As the slurry concentration and fiber size increased, the yield stress of the slurry also increased due to a stronger fibrous network structure. In addition, the yield stress values measured for the pretreated wheat straw slurries were less than those for the wheat straw slurries at the same concentration and fiber sizes. In fact, some parts of carboxylic acids were removed from the structure of the fibers after the acid pretreatment, which caused fibers to become more fragile and smaller in size. This resulted in the reduction of the pretreated slurry network strength and the number of fiber/fiber interactions, and thus a lower yield stress. 


\subsection{Recommendations}

The results from experimental work in this study drew attention to areas for future considerations, as follows:

- Increasing the duration of the dilute acid pretreatment to see whether it has any influence on the measured yield stress or not.

- Using computational fluid dynamics (CFD) to study the mixing of pretreated wheat straw slurries.

- Assessing the impact of the different pretreatment methods such as alkaline pretreatment and ozonolysis on the yield stress of the pretreated wheat straw slurry.

- Studying the performance of more advanced mixers such as coaxial mixers in the agitation of pretreated wheat straw slurries.

- Using tomography technique to obtain the yield stresses of other pretreated agricultural wastes such as rice straw. 


\section{Nomenclature}

$\begin{array}{ll}C m & \text { Mass concentration } \\ C v & \text { Volume concentration } \\ D & \text { Impeller diameter }(\mathrm{m}) \\ D c & \text { Cavern diameter }(\mathrm{m}) \\ F a & \text { Axial Force }(\mathrm{N} \mathrm{m}) \\ g & \text { Gravitational acceleration, }\left(\mathrm{m} / \mathrm{s}^{2}\right) \\ H & \text { Fluid height in the vessel }(\mathrm{m}) \\ H c & \text { Cavern height (m) } \\ K & \text { Flow Consistency index }\left(\mathrm{Pa} . \mathrm{s}^{\mathrm{n}}\right) \\ \mathrm{ks} & \text { Metzner-Otto constant }(-) \\ M & \text { Torque }(\mathrm{N} . \mathrm{m}) \\ n & \text { Power-law index }(-) \\ N & \text { Impeller rotational speed }\left(\mathrm{s}^{-1}\right) \\ N f & \text { Axial force number } \\ n e & \text { Number of electrodes }(-) \\ P & \text { Power (W) } \\ P o & \text { Power number }(-) \\ P l-P 4 & \text { Plane number }(-) \\ T & \text { Tank diameter (m) } \\ Z & \text { Height of the liquid in the tank (m) } \\ & \end{array}$

\section{Greek Letters}

$\begin{array}{ll}\mu_{a p p} & \text { Apparent viscosity }(\mathrm{Pa} . \mathrm{s}) \\ \rho & \text { Fluid density }\left(\mathrm{kg} . \mathrm{m}^{-3}\right) \\ \tau & \text { Shear stress }(\mathrm{Pa}) \\ \tau y & \text { Fluid yield stress }(\mathrm{Pa}) \\ \mu & \text { Newtonian viscosity }(\mathrm{Pa} . \mathrm{s}) \\ \dot{\gamma} & \text { Shear rate }\left(\mathrm{s}^{-1}\right)\end{array}$


$\mu_{0} \quad$ Fluid viscosity at high shear rate (Pa.s)

\section{Abbreviations}

2D Two-dimensions

AFEX Ammonia fiber expansion

DAS Data acquisition system

DP Degree of polymerization

ERT Electrical resistance tomography

PWS Pretreated wheat straw

WS Wheat straw 


\section{Appendix A}

\section{Sample Yield Stress Calculation for 8 wt\% Pretreated Wheat Straw Slurry}

Cavern dimensions measured using ERT. For each impeller speed, the experiment was repeated 3 time. Table A.1 and A.2 show the average of cavern diameter and height for each speed.

Table A.1. Cavern diameter average calculated for 8 wt\% pretreated wheat straw slurry $(\leq \mathbf{2} \mathbf{m m})$ agitated by $A 315$ impeller at 40 to $90 \mathrm{rpm}$.

\begin{tabular}{|c|c|c|c|c|}
\hline $\begin{array}{c}\text { Impeller } \\
\text { Speed } \\
(\mathrm{rpm})\end{array}$ & $\begin{array}{c}\text { Cavern } \\
\text { Diameter }(\mathrm{m}) \\
\text { Run1 }\end{array}$ & $\begin{array}{c}\text { Cavern } \\
\text { Diameter }(\mathrm{m}) \\
\text { Run2 }\end{array}$ & $\begin{array}{c}\text { Cavern } \\
\text { Diameter }(\mathrm{m}) \\
\text { Run3 }\end{array}$ & $\begin{array}{c}\text { Cavern } \\
\text { Diameter }(\mathrm{m}) \\
\text { Average }\end{array}$ \\
\hline 40 & 0.21 & 0.23 & 0.22 & 0.220 \\
\hline 50 & 0.22 & 0.23 & 0.24 & 0.230 \\
\hline 60 & 0.27 & 0.28 & 0.28 & 0.276 \\
\hline 70 & 0.29 & 0.30 & 0.31 & 0.300 \\
\hline 80 & 0.34 & 0.35 & 0.36 & 0.350 \\
\hline 90 & 0.36 & 0.37 & 0.38 & 0.37 \\
\hline
\end{tabular}

Table A.2. Cavern height average calculated for $8 w t \%$ pretreated wheat straw slurry $(\leq \mathbf{2 m m})$ agitated by $A 315$ impeller at 40 to $90 \mathrm{rpm}$.

\begin{tabular}{|c|c|c|c|c|}
\hline $\begin{array}{c}\text { Impeller } \\
\text { Speed } \\
(\mathrm{rpm})\end{array}$ & $\begin{array}{c}\text { Cavern } \\
\text { Height }(\mathrm{m}) \\
\text { Run1 }\end{array}$ & $\begin{array}{c}\text { Cavern } \\
\text { Height }(\mathrm{m}) \\
\text { Run2 }\end{array}$ & $\begin{array}{c}\text { Cavern } \\
\text { Height }(\mathrm{m}) \\
\text { Run3 }\end{array}$ & $\begin{array}{c}\text { Cavern } \\
\text { Height }(\mathrm{m}) \\
\text { Average }\end{array}$ \\
\hline 40 & 0.13 & 0.15 & 0.14 & 0.140 \\
\hline 50 & 0.14 & 0.15 & 0.16 & 0.150 \\
\hline 60 & 0.17 & 0.18 & 0.17 & 0.173 \\
\hline 70 & 0.18 & 0.19 & 0.20 & 0.190 \\
\hline 80 & 0.20 & 0.21 & 0.22 & 0.210 \\
\hline 90 & 0.21 & 0.22 & 0.22 & 0.216 \\
\hline
\end{tabular}

Yield stress values are shown in Table A.3., were calculated according to the steps presented after Table A.3. 
Table A.3. Yield stress of 8 wt\% pretreated wheat straw slurries for fiber size $(\leq \mathbf{2 m m})$, agitated by A315 impeller at 40 to $90 \mathrm{rpm}$.

\begin{tabular}{|c|c|c|c|c|c|c|c|c|c|c|}
\hline $\begin{array}{c}N \\
(\mathrm{rpm})\end{array}$ & $\begin{array}{c}N \\
(\mathrm{rps})\end{array}$ & $\begin{array}{c}M \\
(\mathrm{~N} . \mathrm{M})\end{array}$ & $\begin{array}{c}P \\
(\mathrm{~J} / \mathrm{s})\end{array}$ & $\begin{array}{c}D \\
(\mathrm{~m})\end{array}$ & $\begin{array}{c}\rho \\
\left(\mathrm{kg} / \mathrm{m}^{3}\right)\end{array}$ & $\begin{array}{c}P_{0} \\
(-)\end{array}$ & $\begin{array}{c}D_{c} \\
(\mathrm{~m})\end{array}$ & $\begin{array}{c}H_{c} \\
(\mathrm{~m})\end{array}$ & $\begin{array}{c}\tau_{y} \\
(\mathrm{~Pa})\end{array}$ & $\begin{array}{c}\tau_{y, \text { ave }} \\
(\mathrm{Pa})\end{array}$ \\
\hline 40 & 0.667 & 0.093 & 0.390 & 0.18 & 1000 & 6.958 & 0.220 & 0.140 & 5.734 & \\
\cline { 1 - 8 } 50 & 0.883 & 0.110 & 0.576 & 0.18 & 1000 & 5.267 & 0.230 & 0.150 & 5.840 & \multirow{2}{*}{$5.699 \pm 0.2$} \\
\hline 60 & 1.000 & 0.190 & 1.194 & 0.18 & 1000 & 6.318 & 0.276 & 0.173 & 5.992 & \\
\cline { 1 - 8 } & 1.167 & 0.240 & 1.759 & 0.18 & 1000 & 5.863 & 0.300 & 0.190 & 5.854 & \\
\hline 80 & 1.333 & 0.350 & 2.932 & 0.18 & 1000 & 6.546 & 0.350 & 0.210 & 5.568 & \\
\hline 90 & 1.5000 & 0.380 & 3.581 & 0.18 & 1000 & 5.616 & 0.370 & 0.216 & 5.208 & \\
\hline
\end{tabular}

\section{Step by step calculation for $\mathrm{N}=60 \mathrm{rpm}$ :}

1. Value of " $N$ " (impeller speed) was measured using a tachometer, the value was read in revolutions per minute (rpm) and then converted to revolutions per second (rps).

For $N=60 \mathrm{rpm}, N=60 / 60=1 \mathrm{rps}$

2. Value of " $M$ " (impeller torque) was measured using a torque meter in N.m. At $N=60 \mathrm{rpm}, \mathrm{M}$ was measured as 0.19 N.m

3. Value of (impeller power) was calculated using equation $P=2 \pi N M$

$$
P=2 \times \pi \times 1 \times 0.19=1.194 \mathrm{~J} / \mathrm{S}
$$

4. Value of " $D$ " (impeller diameter) for A 315 was $D=0.18 \mathrm{~m}$

5. The density of the slurry was assumed constant at $\rho=1000 \frac{\mathrm{kg}}{\mathrm{m}^{3}}$

6. $P_{0}$ (power number) was calculated using equation $P_{0}=\frac{P}{\rho N^{3} D^{5}}$

$$
P_{0}=\frac{1.194}{1000 \times 1^{3} \times 0.18^{5}}=6.318
$$

7. Value of yield stress was calculated by re-arranging equation

$$
\begin{aligned}
& \left(\frac{D_{c}}{D}\right)^{3}=\left[\frac{1}{\left(\frac{H_{C}}{D_{C}}+\frac{1}{3}\right) \pi^{2}}\right]\left(\frac{N^{2} D^{2} \rho}{\tau_{Y}}\right) P_{0} \\
& \tau_{y}=\left(\frac{D}{D_{c}}\right)^{3}\left(\frac{N^{2} D^{2} P_{0} \rho}{\left(\frac{H_{C}}{D_{c}}+\frac{1}{3}\right) \pi^{2}}\right)=\left(\frac{0.18}{0.276}\right)^{3}\left(\frac{1^{2} \times 0.18^{2} \times 6.318 \times 1000}{\left(\frac{0.173}{0.276}+\frac{1}{3}\right) \pi^{2}}\right)=5.992 \mathrm{~Pa}
\end{aligned}
$$


8. Standard deviation for the yield stress is calculated using $\sigma=\sqrt{\frac{\sum_{i=1}^{N}\left(\tau_{y, i}-\overline{\tau_{y}}\right)^{2}}{K}}$ Where $K$ is the number of measurements, $\tau_{y, i}$ is the yield stress measurement for sample $i$ and $\tau_{y}$ is the mean value of the yield stress measurements. So,

$$
\begin{gathered}
\sigma=\sqrt{\frac{1}{6}\left[(5.734-5.699)^{2}+(5.840-5.699)^{2}+(5.992-5.699)^{2}+(5.854-5.699)^{2}+(5.568-5.699)^{2}+(5.208-5.669)^{2}\right]} \\
\sigma=0.2449 \mathrm{~Pa}
\end{gathered}
$$

The margin of error at 95 percent confidence level, was calculating using $\mp 1.96 \frac{\sigma}{\sqrt{k}}$

$$
\mp 1.96 \frac{0.2449}{\sqrt{6}}=0.196 \mathrm{~Pa}
$$




\section{References}

Abdullah M.Z., "Electrical impedance tomography for imaging conducting mixtures in hydrocyclone separators." PhD Dissertation, University of Manchester, (1993).

Adams L.W., and Barigou M.," CFD analysis of caverns and pseudo- caverns developed during mixing of non-Newtonian fluids", Chemical Engineering Research and Design 85(5):598-604 (2007).

Alvira P., Tomás-Pejó E., Ballesteros M., and Negro M.J.," Pretreatment technologies for an efficient bioethanol production process based on enzymatic hydrolysis: A review." Bioresource Technology 101:4851-4861(2010).

Amanullah A., Hjorth S.A., and Nienow A.W., "A new mathematical model to predict cavern diameters in highly shear thinning, power law liquids using axial flow impellers." Chemical Engineering Science 53(3):455-469 (1998).

Babaei R., Monakdarpour B., and Ein-Mozaffari F.'The use of electrical resistance tomography for the characterization of gas holdup inside a bubble column bioreactor containing activated sludge." Chemical Engineering Journal 268:260-269 2015).

Balat M., "Production of bioethanol from lignocellulosic materials via the biochemical pathway: A review." Energy Conversion and Management 52:858-875(2011).

Barber C.D., Brown B.H., and Freeston I.L., "Imaging spatial distributions of resistivity using applied potential tomography." Electronics Letters, 19:933-935 (1983).

Bashir R., "Yield stress of concentrated wheat straw suspensions." M.A.Sc Thesis, Ryerson University, 2008.

Bennington C.P.J., Kerekes R.J., and Grace J.R., "The yield stress of suspensions" Canadian Journal of Chemical Engineering 68(10):748-757 (1990).

Bhole M.R., and Bennington C.P.J., "Performance of four axial flow impellers for agitation of pulp suspensions in a laboratory-scale cylindrical stock chest." Industrial Engineering Chemical Research 49: 4444-4451(2010). 
Volynets B., Ein-Mozaffari F., and DahmanY.," Biomass Processing into Ethanol: Pretreatment, Enzymatic Hydrolysis, Fermentation, Rheology, and Mixing. "Green Process Synthesis 6:1-6 (2017).

Buranov A.U., and Mazza G., "Lignin in straw of herbaceous crops." Industrial Crop Production 28:237-259 (2008).

Cara C., Ruiz E., Oliva J.M., Sáez F., and Castro E.," Conversion of olive tree biomass into fermentable sugars by dilute acid pretreatment and enzymatic saccharification." Bioresource Technology 99:1869-1876 (2008).

Carletti C., Montante G., Blasio C.D., and Paglianti N.," Liquid mixing dynamics in slurry stirred tanks based on electrical resistance tomography" Chemical Engineering Science 152:478487(2016).

Chhabra R.P., and Rchardson J.f.," Non-Newtonian Flow in the Process Industries" $1^{\text {st }}$ ed. Butterworth Heinemman (1999).

Chhabra R.P., and Richardson J.F., "Non-Newtonian flow and applied rheology." 2 nd ed. Engineering Application. Amsterdam: Butterworth-Heinemann, (2008).

Chiti F., Bakalis S., Bujalski W., Barigou M., Eaglesham A., and Nienow A.W., "Using positron emission particle tracking (PEPT) to study the turbulent flow in a baffled vessel agitated by a Rushton turbine: Improving data treatment and validation." Chemical Engineering Research and Design 89:1960-1974 (2011).

Dickin F., and Wang M., "Electrical resistance tomography for process applications." Measurement Science and Technology 7(3):247-260 (1996).

Dehkhoda A., "Concentrating lignocellulosic hydrolysate by evaporation and its fermentation by repeated fedbatch using flocculating Saccharomyces cerevisiae. “, M.A.Sc thesis, Industrial Biotechnology Boras University, Sweden; (2008).

Dong T., Knoshaug E., Davis R., Laurens L., Wychen S., Pienkos P., and Nagle N., “Combined 
algal processing: A novel integrated biorefinery process to produce algal biofuels and bioproducts." Algal Research 27:43-54 (2017).

Ehrhardt M. R., Monz T. O., Root T. W., Connelly R. K., Scott C. T. and Klingenberg D. J.” Rheology of Dilute Acid Hydrolyzed Corn Stover at High Solids Concentration "Applied Biochemistry Biotechnology 160:1102-1115 (2010).

Ein-Mozaffari F., Bennington C., Dumont G., and Buckingham D.” Measuring flow velocity in pulp suspension mixing using ultrasonic doppler velocimetry." Institute of Chemical Engineering 85(A5):591-597 (2007).

Elson T.P., and Cheesman D.J., "X-Ray studies of cavern sizes and mixing performance with fluids possessing a yield stress." Chemical Engineering Science 41(10): 2555-2562 (1986).

Galbe M., and Zacchi, G., "Pretreatment of lignocellulosic materials for efficient bioethanol production. "Advances in Biochemical. Engineering/Biotechnology 108: 41-65 (2007).

Gabelle C., Augier F., Carvalho A., Rousset R., and Morchain J., "Effect of tank size on kLa and mixing time in aerated stirred reactors with Non-Newtonian fluids." The Canadian Journal of Chemical Engineering 89(5): 1139-1153 (2011).

Gaur R., Soam S., Sharma S., Gupta R., Bansal V., Kumar R., and Tuli D.,” Bench scale dilute acid pretreatment optimization for producing fermentable sugars from cotton stalk and physicochemical characterization.” Industrial Crops and Products 83:104-112 (2016).

Georgieva TI, Mikkelsen MJ, and Ahring BK., "Ethanol production from wet exploded wheat straw hydrolysate by thermophillic anaerobic bacterium Thermoanaerobacter BG1L1 in a continuous immobilized reactor." Applied Biochemistry and Biotechnology 145:99-110 (2008).

García-Cubero M.T., Gonzalez-Benito G., Indacoechea I., Coca M., and Bolado S., "Effect of ozonolysis pretreatment on enzymatic digestibility of wheat and rye straw. "Bioresource Technology 100:1608-13 (2009).

Hahn-Hagerdal, B., Karhumaa K., Fonseca C., Spencer-Martins I., and Gorwa- Grauslund M.F., "Towards industrial pentose fermenting yeast strains." Applied Microbial Biotechnology 74:937- 
953 (2007).

Hahn-Hagerdal B., Galbe M., Gorwa-Grauslund M.F., Liden G., and Zacchi G., "Bioethanol - The fuel for tomorrow from the residues of today." Trend in Biotechnology 24(12): 541-556 (2006).

Harrison S.T.L, Stevenson R., Cilliers J.J," Assessing solids concentration homogeneity in Rushton-agitated slurry reactors using electrical resistance tomography (ERT)." Chemical Engineering and Science 71:392-399 (2012).

Hashemi N., Ein-Mozaffari F., Upreti S., and Hwang K.," Analysis of mixing in an aerated reactor equipped with the coaxial mixer through electrical resistance tomography and response surface method." Chemical Engineering Research and Design 109:734-752 (2016).

He Y., Zhang L., Zhang J., and Bao J., "Helically agitated mixing in dry dilute acid pre- treatment enhances the bioconversion of corn stover into ethanol." Biotechnology and Biofuels 7:1-7 (2014).

Hirata Y., and Aoshima Y., "Formation and growth of cavern in yield stress fluids." Transactions of the Institution of Chemical Engineers 74(A):438-444 (1996).

Holden P. J., Wang M., Mann R., Dickin F.J., and Edwards R.B., "Imaging Stirred-Vessel Macromixing Using Electrical Resistance Tomography." American Institute of Chemical Engineering Journal 44:780-790 (1998).

Hosseini S., Patel D., Ein-Mozaffari F., and Mehrvar M.," Study of solid-liquid mixing in agitated tanks through electrical resistance tomography." Chemical Engineering Science 65:1374-1384 (2010).

Hou W., An R., Zhang J., and Bao J.," On-site measurement and modeling of rheological property of corn stover hydrolysate at high solids content.” Biochemical Engineering Journal 107: 61-65(b) (2016).

Hou W., Zhang L., Zhang J., and Bao J.," Rheology evolution and CFD modeling of lignocellulose biomass during extremely high solids content pretreatment." Biochemical Engineering Journal 105:412-419(a) (2016).

Hsu T., Guo G., Chen, and Hwang W." Effect of dilute acid pretreatment of rice straw on structural properties and enzymatic hydrolysis." Bioresource Technology 101: 4907-4913 (2010). 
Hua P., Woo E.J., Webster J.G., and Tompkins W.J., "Using compound electrodes in electrical impedance tomography." IEEE Transactions on Biomedical Engineering 40: 29-34 (1993).

Hui L., Bennington C., and Dumont G.," Cavern formation in pulp suspensions using side-entering axial-flow impellers." Chemical Engineering Science 64:509-519 (2009).

Ihejirika I., and Ein-Mozaffari F.," Using CFD and Ultrasonic Velocimetry to Study the Mixing of Pseudoplastic Fluids with a Helical Ribbon Impeller." Chemical Engineering Technology30(5): 606-614 (2007).

Kaminoyama, M., Taguchi S., Misumi R., and Nishi K., "Monitoring stability of reaction and dispersion states in a suspension polymerization reactor using electrical resistance tomography measurements." Chemical Engineering Science 60: 5513-5518 (2005).

Karimi K, Emtiazi G, and Taherzadeh MJ. "Ethanol production from dilute-acid pretreated rice straw by simultaneous saccharification and fermentation with Mucor indicus, Rhizopus oryzae, and Saccharomyces cerevisiae." Enzyme and Microbiol Technology 40:138-44 (2006).

Kazemzadeh A., Ein-Mozaffari F., Lohi A., and Pkzad L.," Investigation of hydrodynamic performances of coaxial mixers in agitation of yield-pseudoplasitc fluids: Single and double central impellers in combination with the anchor" Chemical Engineering Journal 29: 417-430 (2016).

Kazemzadeh A., Ein-Mozaffari F., Lohi A., and Pakzad L.," A new perspective in the evaluation of the mixing of biopolymer solutions with different coaxial mixers comprising of two dispersing impellers and a wall scraping anchor "Chemical Engineering Research and Design 114:202-219 (2016).

Kerekes R.J., Soszynski R.M., and Tam Doo P.A.," The flocculation of pulp fibres. In: Papermaking Raw Materials. Transactions of the VIII ${ }^{\text {th }}$ Fundamental Research Symposium, V. Puton, ed.," Mechanical Engineering Publication Limited, London, 3: 265-310 (1985).

Kim S., Lee S., Jang E., Han S., Park C., and Kim S." Sugar recovery from rice straw by dilute acid pretreatment." Journal of Industrial and Engineering Chemistry 18:183-187 (2012). 
Kim S., Nkaya A.N, and Dyakowski T., "Measurement of mixing of two miscible liquids in a stirred vessel with electrical resistance tomography." International Communication in Heat and Mass Transfer 33: 1088-1095 (2006).

Lavenson D.M., Tozzi E.J., McCarthy M.J., and Powell R.L., "Yield stress of pretreated corn stover suspensions using magnetic resonance imaging." Biotechnology and Bioengineering 108(10):2312-2319 (2011).

Pakzad L., Ein-Mozaffari F., and Chan P.," Measuring Mixing Time in the Agitation of NonNewtonian Fluids through Electrical Resistance Tomography." Chemical Engineering Technology 12:1838-1845 (2008).

Lu X.B., Zhang Y.M., Yang, J., and Liang, Y., "Enzymatic hydrolysis of corn stover after pretreatment with dilute sulfuric acid." Chemical Engineering and Technology 30(7): 938-944 (2007).

Madhavi M., Sardeshpande V., Kumar G., Aditya T., Ranade V.,"Mixing studies in unbaffled stirred tank reactor using electrical resistance tomography." Flow Measurement and Instrumentation 47:110-121(2016).

Magnus W., Benny P., Eva T., and Gunnar L., "Rheological characterization of dilute acid pretreated softwood." Biotechnolog and Bioengineering. 108:1031-1041(2011).

Mann R., M.Dickin T., Wang, R.A., Dyakowski R.B., Williams S., and Edwards A.E., "Application of electrical resistance tomography to interrogate mixing processes at plant scale." Chemical Engineering Science 52: 2087-2097 (1997).

Mavros P., "Flow Visualization in Stirred Vessels: A Review of Experimental Techniques.” Trans Institution of Chemical Engineers 79(A):113-127 (2001).

McCabe W.L., Smith J.C., and Harriott P.," Unit Operations of Chemical Engineering ( $7^{\text {th }}$ edition).” New York: McGraw-Hil, (2005).

Meher LC., Sagar DV., and Naik SN., "Technical aspects of biodiesel production by transesterification - a review.” Renewable Sustainable Energy Rev 10: 248-68 (2006). 
Metzner A.B., and Otto R.E., “Agitation of non-Newtonian fluids.” American Institute of Chemical Engineerin Journal 3(1): 3-10 (1957).

Morrison F. Understanding Rheology: Oxford university press, (2001).

Movafagh H., Turcotte G., and F. Ein-Mozaffari., "Ussing tomography images to study the mixing of wheat straw slurries.". Taylor and Francis Group, Biofules 7(4):365-375 (2016).

Pakzad, L. "Using Electrical Resisitance Tomography (ERT) and Computational Fluid Dynamics (CFD) to Study the Mixing of Pseudoplastic Fluids with a Scaba 6SRGT Impeller." M.A.Sc Thesis, Ryerson University, (2007).

Pakzad, L., Ein-Mozaffari F., and Chan P.,"Using electrical resistance tomography and computational fluid dynamics modeling to study the formation of cavern in the mixing of pseudoplastic fluids possessing yield stress." Chemical Engineering Science 63: 2508-2522 (2008).

Pakzad L.," Using electrical resistance tomography (ERT) and computional fluid dynamics to study the mixing of pseudoplastic fluids with a Scaba 6RGT impeller." M.A.Sc Thesis, Ryerson University, (2007).

Palmqvist B., Wiman M., and Lidén G," Effect of mixing on enzymatic hydrolysis of steampretreaed spruce: a quantitative analysis of conversion and power consumption" Biotechnology for Biofuels 2:4-10 (2011).

Pan X., Xie D., Gilkes N., Gregg D.J., and Saddler J.N.," Strategies to enhance the enzymatic hydrolysis of pretreated softwood with high residual lignin content." Applied Biochemistry and Biotechnology 121 (124):1069-1079 (2005).

Parkash M. and Ein-Mozaffari F.," Using computational fluid dynamics to analyze the performance of the Maxblend impeller in solid-liquid mixing operations "International Journal of Multiphase Flow 91:194-207 (2017).

Patel D., Ein-Mozaffari F., and Mehrvar M.," Tomography images to analyze the deformation of the cavern in the continuous-flow mixing of non-Newtonian fluids. "American Institute of 
Chemical Engineers 60(1):315-331(2014).

Patel S.J., Onkarappa R., and Gurumurty S.B., "Pretreatment studies of wheat straw and rice." The Internet Journal of Microbiology 7(1): 63-65 (2009).

Paul E.L., Atiemo-Obeng V.A., and Kresta S.M., Hand book of industrial mixing: science and practice. Hoboken: John Wiley and Sons, (2004).

Paulson K., Breckon W., and Pidcock M.,"Electrode modeling in electrical impedance tomography." Journal of Applied Mathematics 52 (4):1012-1022 (1992).

Pimenova N.V., and Hanley A.R.," Effect of corn stover concentration on rheological characteristics." Applied Biochemistry Biotechnology 113:347-360 (2004).

Pinherio P.A.T., Loh W.W., and Dickin F.J., "Optimal sized electrodes for electrical resistance tomography." Electronic Letters 34(1): 69-70 (1998).

Pooja N.S., and Padmaja G.," Enhancing the enzymatic Saccharification of agricultural and processing residues of Cassava through pretreatment techniques “, Waste biomass Valor 6: 303315 (2015).

Prakash M., and Ein-Mozaffari F., "Using tomograms to assess the local solid concentrations in a slurry reactor equipped with a Maxblend impeller" Powder Technology 301:701-712 (2016).

Gigue're R., Fradette L., Mignon D., and Tanguy P.A.," Characterization of slurry flow regime transitions by ERT." Chemical Engineering Research and Design 86: 989-996 (2008).

Dasari R., and Berson R.E., "The effect of particle size on hydrolysis reaction rates and rheological properties in cellulosic slurries." Applied Biochemistry and Biotechnology 137-140(1-12): 289299 (2007).

Ranjan A., and Moholkar V.,"Comparative study of various pretreatment techniques for rice straw saccharification for the production of alcoholic biofuels." Fuel 112: 567-571 (2013).

Ridzuan Aw., Rahim R. A., Rahiman M. H., Yunus F. R., Goh C. L.,” Electrical resistance tomography: A review of the application of conducting vessel walls." Powder Technology 
254:256-264 (2014).

Rosgaard, L., Pedersen S., and Meyer A.S., "Comparison of different pretreatment strategies for enzymatic hydrolysis of wheat and barley straw." Applied Biochemistry Biotechnology 143: 284296 (2007).

Saha B.C., Iten L.B., Cotta M.A., and Wu YV., "Dilute acid pretreatment, enzymatic saccharification and fermentation of wheat straw to ethanol." Process Biochemistry 40:3693-3700 (2005).

Saha B.C., Iten L.B., Cotta M.A., and Wu Y.V., "Dilute acid pretreatment, enzymatic saccharification and fermentation of wheat straw to ethanol." Process Biochemistry 40: 3693-3700 (2005).

Saini J., Saini R., and Tewari L.," Lignocellulosic agriculture wastes as biomass feedstocks for second-generation bioethanol production: concepts and recent developments." 3 Biotech 5(4):337-353 (2015).

Samaniuk J., Scott T., Root T., and Klingenberg D.," Rheological modification of corn stover biomass at high solids concentrations." Journal of Rheology 56: 649-665 (2012).

Sarkar N., Ghosh S., Bannerjee S, and Aikat K.," Bioethanol production from agricultural wastes: An overview." Renewable Energy 37:19-27 (2012).

Schmidt AS. and Thomsen AB.," Advances in Biofeedstocks and Biofuels, Volume 1: Biofeedstocks and their Processing.", Bioresource Technology 64: 139-151 (1998).

Sharifi M., and Young B., "Electrical Resistance Tomography (ERT) applications to chemical engineering." Chemical Engineering Research and Design 91:1625-1645 (2013).

Shekiro J., Kuhn E., Nagle N., Tucker M., Elander R., and Schell D.," Characterization of pilotscale dilute acid pretreatment performance using deacetylated corn stover." Biotechnology for Biofuels 5: 7-23(2014).

Sher F., Sajid Z., TokayB., Khzouz M., and Sadiq H.,’ Study of gas-liquid mixing in stirred vessel using electrical resistance tomography" Asia-Pacific Journal of Chemical Engineering 11: 855- 
865 (2016).

Skelland A.H.P.,’Non-Newtonian flow and heat transfer.” New York: Wiley, (1967).

Solomon, J., Elson T.P., and Nienow A.W., "Cavern sizes in agitated fluids with a yield stress." Chemical Engineering Communication 11: 143-164 (1981).

STEFFE, J.F” Rheological Methods in Food Process Engineering”, 2nd Ed., Freeman Press, East Lansing, MI (1996).

Stickel J.J., Knutsen J.S., Liberatore M.W., Luu W., Bousfield D.W., Klingenberg D.J., Scott C.T., Root T.W., Ehrhardt M.R., and Monz T.0." Rheology measurements of a biomass slurry: an interlaboratory study." Rheologica Acta 48: 1005-1015 (2009).

Taherzadeh MJ, Karimi K. Acid-based hydrolysis processes for ethanol from lignocellulosic materials: a review. BioResources 2:472-99 (2007).

Taherzadeh MJ, Karimi K. Enzyme-based hydrolysis processes for ethanol from lignocellulosic materials: a review. Bioresources 2(4):707-38 (2007).

Taherzadeh MJ., and Karimi K.” Pretreatment of lignocellulosic wastes to improve ethanol and biogas production: a review." International Journal of Molecular Sciences 9:1621-51(2008).

Talebnia F., Karakashev D., and Angelidaki I., "Production of bioethanol from wheat straw: An overview on pretreatment, hydrolysis and fermentation" Bioresource Technology 101:4744-4753 (2010).

Tan C., Dong F., Hua S., Qi G., "Gas-liquid two-phase flow measurement with dual-plane ERT system in vertical pipes.”, AIP Conference Proceeding 914:734-739 (2007).

Tomas-Pejo E., Olive J.M., and Ballesteros M., "Realistic approach for full-scale bioethanol production from lignocellulose: a review." Journal of Scientific and Industrial Research 67:874884 (2008).

Viamajala S., McMillan J.D, Schell D.J., and Elander R.T, "Rheology of corn stover slurries at high solids concentrations-effects of saccharification and particle size." Bioresource Technology 
100: 925-934 (2009).

Viergever M.A., and Todd-Pokropek A.E., "Mathematics and Computer Science in Medical Imaging." Berlin: Springer, (1988).

Volynets B., and Dahman Y., “Assesment of pretreatments and enzaymatic hydrolysis of wheat straw as a sugar source for bioprocess industry." International Journal of Energy and Enviromet 2: 427-446 (2011).

Wiman M., Palmqvist B., Tornberg E., and Lide' n G.," Rheological Characterization of Dilute Acid Pretreated Softwood.” Biotechnology and Bioengineering108:1031-1041(2011).

Wichterle K., and Wein O., "Agitation of concentrated suspensions." CHISA 75, (1975).

Williams R.A., and Beck M.S.," Process Tomography: Principles, Techniques and Applications. Waltham: Butterworth-Heinemann, (1995).

Wu B.X.," CFD simulation of mixing for high-solids anaerobic digestion." Biotechnology and Bioengineering109: 2116-2126 (2012).

Xiao Q., Yang N., Zhu J., and Guo L.," Modeling of Cavern Formation in Yield Stress Fluids in Stirred Tanks." American Institute of Chemical Engineers 60(8):3057-3070 (2014).

Yenjaichon W., Pageau G., Bhole M., Bennington C.P.J., Grace J.R.,” Assessment of mixing quality for an industrial pulp mixer using electrical resistance tomography." The Candian Journal of Chemical Engineering 89(5):996-1004 (2011).

Zhang L., Zhang J., Li C., and Jie Bao J.," Rheological characterization and CFD modeling of corn stover-water mixing system at high solids loading for dilute acid pretreatment." Biochemical Engineering Journal 90:324-332 (2014).

Zhao Z.F., Mehrvar M., Ein-Mozaffari F.," Mixing time in an agitated multi-lamp cylindrical photoreactor using electrical resistance tomoghraphy." Journal of Chemical Technology and Biotechnology 83: 1676-1688 (2008). 